\title{
A PROPOSED HEAT TRANSFER MODEL FOR THE GAS-LIQUID HEAT TRANSFER EFFECTS OBSERVED IN THE STANFORD RESEARCH \\ INSTITUTE SCALED TESTS
}

by

Michael Corradini

Ain A. Sonin

Neil Todreas

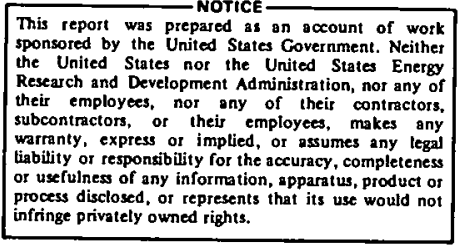

December 1976

Department of Nuclear Engineering

Massachusetts Institute of Technology

77 Massachusetts Avenue

Cambridge, Massachusetts 02139

Approved

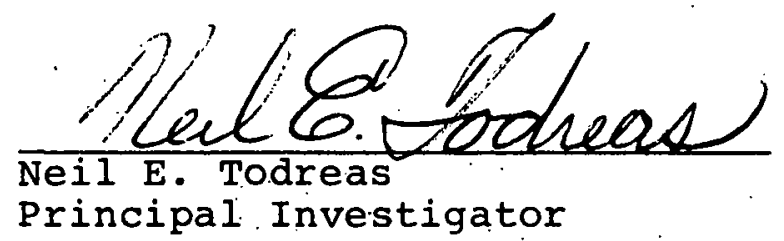




\section{DISCLAIMER}

This report was prepared as an account of work sponsored by an agency of the United States Government. Neither the United States Government nor any agency Thereof, nor any of their employees, makes any warranty, express or implied, or assumes any legal liability or responsibility for the accuracy, completeness, or usefulness of any information, apparatus, product, or process disclosed, or represents that its use would not infringe privately owned rights. Reference herein to any specific commercial product, process, or service by trade name, trademark, manufacturer, or otherwise does not necessarily constitute or imply its endorsement, recommendation, or favoring by the United States Government or any agency thereof. The views and opinions of authors expressed herein do not necessarily state or reflect those of the United States Government or any agency thereof. 


\section{DISCLAIMER}

Portions of this document may be illegible in electronic image products. Images are produced from the best available original document. 
Reports and Papers Published under MIT Fuel-Coolant Interaction Project.

(This project was funded until. June 30,1975 by. ANL and reports issued as 31-109-38-2831-XX; starting July 1 , 1975 reports were issued as $\mathrm{COO}-278.1-\mathrm{XX}$ )

Progress Reports (Available from National Technical Information Service, U.S. Department of Commerce, Springfield, Va. 22151)

W:F. Lenz, G. Shiralker and N. Todreas, Fuel Coolant Thermal Interaction Project UC 79P, C00-2781-1, Nov. 1975.

W.F. Lenz, G. Shiralker and N. Todreas, Fuel Coolant Thermal Interaction Project UC 79P, COO-2781-2, Feb. 1976.

G. Shiralker, W.F. Lenz and M. Corradini, Fuel Coolant Thermai Interaction Project UC 79P, COO-2781-3, April. 1976.

G. Shiralker, W.F. Lenz and M. Corradini, Fuel Coolant Thermal Interaction Project UC 79P, COO-2781-5, Oct. 1976.

G. Shiralker, W:F. Lenz and M. Corradin1, Fuel Coolant Thermal Interaction Project UC 79P, COO-2781-10, Dec.. 1976. 
Reports Issued under this Contract

Topical Reports (Available from National Technical Information Service, U.S. Department of Commerce, Springfield, Va. 22151)

Mujid S. Kazimi, "Theoretical Studies on Some Aspects of Molten Fuel-Coolant Thermal Interaction," 31-109-38-2831-1TR, MITNE-155, May 1973.

Charles $\Xi$. Watson, "Transient Heat Transfer Induced Pressure Fluctuations in the Fuel-Coolant Interaction," 31-109-38-28312TR, MITNE-156, August 1973.

Trond A.. Bjornard, "An Experimental Investigation of Acoustic Cavitation as a Fragmentation Mechanism of Molten Tin Droplets in Water,". 31-109-38-2831-3TR, MITNE-163, May 1974.

Glen Bjorkquist, "An Experimental Investigation of the Fragmentation of Molten' Metals in. Water," 31-109-38-2831-4TR, June 1975.

Roland 3. Knapp, "Thermal Stress Initiated Fracture as a Fragmentation Mechanism in the $\mathrm{UO}_{2}$-Sodium Fuel-Coolant Interaction," 31-109-33-2831-5TR, May 1975.

Michael Corradini, "Prediction of Minimum $\mathrm{UO}_{2}$ Particle Size Based on Thermal Stress Initiated Fracture Model," COO-2781-4TR, August 1976.

M. Kazimi, C. Watson, D. Lanning, W. Rohsenow; N. Todreas, "Acoustic Cavitation as a Mechanism of Fragmentation of Hot Molten Droplets in Cool Liquids," COO-2781-6TR, November 1976.

Gautam S. Shiralkar, "An Investigation of the Fragmentation of Molten Metals Dropped Into Cold Water," COO-2781-7TR, November 1976 .

William $F$. Lenz, Jr. "Mixing Requirements for the Limiting Fuel-Coolant Interactions in Liquid Metal Fast Breeder

Reactors;" COO-2781-8TR, November 1.976

M. Corradini, A.A. Sonin, N. Todreas, "A Proposed Heat Transfer Model for the Gas-Liquid Heat Transfer Ef'fects Observed in the Stanford Research Institute Scaled Tests," COO-2781-9TR, December 1976 .

M. Corradini, W.M. Rohisenow, N.E. Todreas, "Application of Spontaneols Nucleation Theory to Tin-H2O Interactions, "COO.. 2781-11TR; January 1977. 


\section{Reports Issued under this Contract}

Papers and Summaries

M.S. Kazimi, N.E. Todreas, D.D. Lanning and H.M. Rohsenow, "A Criterion for Free-Contact Fragmentation of Hot Molten llaterials in Coolants," Transactions of the American Nuclear Society, Vol. 5, No. 2, p. 835, November 1972.

M.S. Kazimi, N.E. Todreas, W.M. Rohsenow and D.D. Lanning, "A Theoretical Study of the Dynamic Growth of a Vapor Film Around a Hot Sphere in a Coolant," Fifth International Heat Transfer Conference, Tokyo, 1974.

T.A. Bjornard, W.M. Rohsenow and N.E. Todreas; "The Pressure Behavior Accompanying the Fragmentation of Tin in Water," Transactions of the American Nuclear Society, Vol. 19, pp. 247248,1974 .

R. Knapp and N. Todreas, "Thermal Stress Initiated Fracture as a Fragmentation Mechanism in the $\mathrm{UO}_{2}$-Sodium Fuel-Coolant Interaction," Nuclear Engineering and Design 35, pp. 69-85, 1975. 
"This report was prepared as an account of Governmentsponscred work. Neither the United States, or the Energy Research and Development Administration nor any person acting on behalf of the Commission.

A. Makes any warranty or representation, expressed or implied, with respect to the accuracy, completeness or usefulness of the information contained in this report, or that the use of any information, apparatus, method, or process disclosed in this report may not infringe privately owned rights; or.

B. Assumes any liabilities with respect to the use of, or for damages resulting from the use of, any information, apparatus, method, or process disclosed in this report.

As used in the above, 'person acting on behalf of the Commission' includes any employee or contractor of the Administration or employee of such contractor, to the extent that such employee or contractor prepares, disseminates, or provides access to, any information pursuant to his employment or contract vith the Administration or his employment with such contractor." 
TABLE OF CONTENTS

1. Introduction .............. . . 1

2. Background of SRI Tests .......... 2

3. Proposed Heat Transfer Model . . . . . . . 13

4. Comparison to SRI Test Results . . . . . . 21

4.1 Functional Dependence of Acceleration . . 22

4.2 Integral Comparison of SRI Data to Model : 23

5. Conclusion . . . . . . . . . . . . 40

Figures and Tables................

Appendix A SRI Test Results ............ 44

Appendix B Brief Review of Taylor Instabilities... 53

Appendix C

C.1 Calculation of Heat Transfer to Liquid . .

C.2 Functional Dependence of Acceleration ...

C.3 Integral Comparison of the Data to Heat Transfer Model ..........

Appendix $D$. Estimation of the Cooling Time for a Gas 


\section{ACKNOWLEDGEMENTS}

It is with sincere gratitude that I express my appreciation to Prof. Neil Todreas and Prof. Ain Sonin for their suggestions and wealth of experimental experience which helped in the development of the model.

Discussion with and assistance from Dr. Dominic Cagliostro and my peers Kerry Basehore, Fred Lenz and Tom Rodack were also most helpful.

Finally, loving thanks to my wife Debi who helped me immensely by her support through this summer's work.

Sponsorship of this work was provided through the auspieces of the Energy Research and Development Administration. 


\section{LIST OF FIGURES}

Figure 2:1 Pressure-Volume Characteristics for

$150 \mathrm{MW}-\mathrm{sec}$ SOCOOL Results.......

Figure 2.2 . View of FFTF Reactor Vessel . . . . . . . 10

Figure 2.3 Rigid Piston-Cylinder Apparatus . . . . . . 11

Figure 2.4: Gas Work vs. Water Depth Relationship . . : 12

Figure 3.1 Physical Picture of Progression of Initial Disturbance : . . . . . . . 19

Figure 3.2 Model of Interface Condition . . . . . . 20

Figure 4.I Heat Transfer Rate as a Function of Acceleration of the Gas-Liquid

Interface .............

Figure 4.2 Gas Work Energy as a Function Volume

Ratio for Test AVG2 . . . . . . . . . 31

Figure 4.3 Comparison of Total Heat Transfer as

a. Function of the Volume Ratio for

Model and Experimental Results. . . . . 32

Figure 4.4 Reproducibility Comparison for

Pressure vs. Time Results for

1/30 Scale Tests . . . . . . . . .

Figure 4.5 Comparison of Total Heat Transfer as a Function of the Volume Ratio

for Model and Experimental Results : . . .

Figure 4.6 Pressure-Volume Relationship for

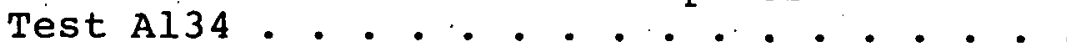

Figure 4.7 Comparison of Gas Work Energy as a

Function of the Volume Ratio for.

Test AVG2 and BlO2 ........... 36

Figure 4.8 Comparison of Total Heat Transfer as

a Function of the Volume Ratio for

Model and Experimental Results. . . . . 
Figure A.l Flexible Scale Model Apparatus . . . . . . 46

Figure A.2: Gas Work-Volume Ratio Relationship: Mylar Sheet on Water Surface . : . . . .

Figure A.3: Gas Work-Volume Ratio Relationship: Effect of Internals . . . . . . . . . .

Figure A. 4 Comparison of Pressure-Volume Relationships to SOCOOL Results . . . . .

Figure B.l Taylor Instability Model for Interface between Two Fluids

Figure B.2 Effect of Surface Tension on Taylor Instability Criterion : . . . . . . . . . •

Figure C.1 Comparison of Internal Energy Change for Three $1 / 30$ Scale Tests . . . . . .

Figure C.2 Comparison of Heat Transfer to Liquid for Three $1 / 30$ Scale Tests to Determine Functional Dependence on Acceleration...

Figure C.3. Graph of Displacement vs. Time for Determination of $Q_{I}$ Dependence on Acceleration . . . . . . . . . . . . . .

Figure C.4 Graph of Displacement vs. Time for Integral Comparison of the Model and Experiment . . . . . . . . . . . .

Figure C.5 Time Smoothing of Pressure Pulses

for $1 / 30$ Scale Tests . . . . . . . .

Figure C. 6 Time Smoothing of Pressure Pulse for $1 / 10$ Scale Test $\mathrm{Bl02}$. . . . . . .

Figure C.7 Pressure-Volume Relationship for Test AVG2 . . . . • . . . . . . . .

Figure C. 8 Gas Work vs. the Volume Ratio for Test Al22 • • • . . . . . . . . . •

Figure C.9. Gas Work vs. the Volume Ratio for Test Al34. . . . . . . . . . . . . .

Figure C.10 Pressure-Volume Relationship for Test Bl02 


\section{LIST OF TABLES}

Table 4.1 Results of Functional Dependence of Heat Transfer Rate on Acceleration .......

Table 4.2 Determination of Constant by Experimental Data . . . . . . . . . . : . . . 39

Table A.1 1/30 Scale Experiments $\quad 50$

Table A.2 1/10 Scale Experiments . . . . . . . . 51

Table A.3. Comparison of $1 / 10$ and $1 / 30$ Scale Gas Work Energy Results.

Table B.l Critical Wavelength for a Taylor Instability in water and Sodium... . . .

Table C.1 Functional Dependence of a Heat Transfer Rate on Acceleraticin . . . . . . . 79

Table C. 2 Summary of Integral Comparison-Test AVG2 . . . . . . . . . . . . . 80

Table C. 3 Summary of Integral Comparison--

Table C.4 Summary of Integral Comparison-Test B102 . . . . . . . . . . . . . .

Table C.5 Summary of Integral Comparison-Test A122 . . . . . . . . . . : . .

Table D.1 Estimation of Cooling Time for Gas Bubble . . . . . . . . . . . . . . . 
NOMENCLATURE

a. acceleration of gas-1iquid interface in pistoncylinder tests

$A_{p}$ area of piston surface in SRI tests

co overall constant for heat transfer model

cp specific heat at constant pressure

c. specific heat at constant volume

D piston diameter

g acceleration of gravity

$g_{1}$ arbitrary acceleration at an interface

i increment to designate the value of parameter

$\mathrm{K}_{1}, \mathrm{~K}_{2}, \mathrm{~K}_{3}, \mathrm{~K}_{4}$ specified constant in model

L characteristic wavelength of disturbance at gasliquid interface

$m$ parameter determined by experiment to find $q \propto a^{m}$

$n$ number of moles of gas in rigid piston-cylinder

$\mathrm{n}_{0}$ initial number of moles of gas before detonation

$\mathrm{p}$ pressure of gas in piston cylinder

$p_{0}$ reference pressure at 1 atmosphere

$q$ : heat transfer rate of gas to liquid

$Q_{W} \quad$ total heat transfer to wall

$Q_{\mathrm{L}}$. total heat transfer to liquid

Q total heat transfer

R radius of curved interface 


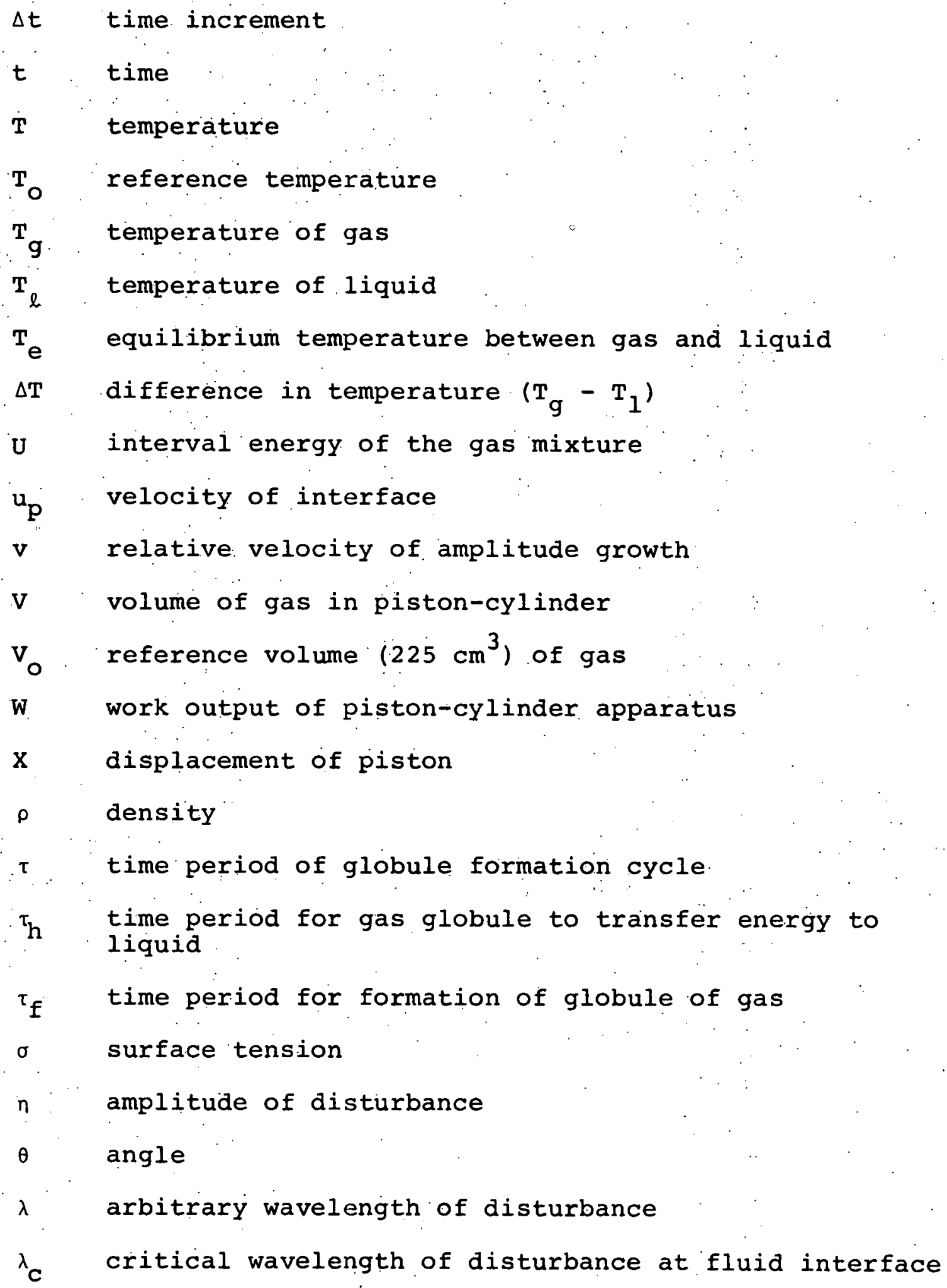




\section{ABSTRACT}

In 1971-72, the Stanford Research Institute conducted a series of scaled experiments which simulated a sodium-vapor expansion. in a hypothetical core disruptive accident (HCDA) for the Fast Fiux Test Facility. A non-condensible explosive source was used to model the pressure-volume expansion characteristics of sodium vapor as predicted by computer code calculations. Rigid piston-cylinder experiments $(1 / 10$ and $1 / 30$ scale) were undertaken to determine these expansion characteristics. The results showed that the pressur-volume characteristics depend significantly on the presence of water in the cylinder reducing the work output by about $50 \%$ when a sufficient water depth was present.

This study proposes that the mechanism of heat transfer between the water and high temperature gas was due to area enhancement by Taylor instabilities at the gas-liquid interface. A simple heat transfer model is proposed which describes this energy transport process and agrees well with the experimental data from both scaled experiments. The consequences of this analysis suggest that an estimate of the heat transfer to the cold slug during a full-scale HCDA due to sodium vapor expansion and the accompanying reduction in mechanical work energy warrants further investigation. The implication of this analysis is that for either sodium or fuel vapor expansion in an HCDA, there is an inherent heat transfer mechanism which significantly reduces the work output of the expanding bubble. 
In the design of any engineering system, possible accident situations must be considered and their probable consequences evaluated and designed for.' Specifically in the Liquid Metal Fast Breeder Reactor (LMFBR) Program the Energy and Research Development Administration (ERDA) has devoted considerable research effort to fast reactor safety for the LMFBR (specifically the Fast Flux Test Facility FFTF and [Clinch] River Breeder Reactor CRBR) . Within this scope of safety considerations is the analysis of Hypothetical Core Disruptive Accidents (HCDA). These extremely low probability accidents represent the upper conservative bound on possible mechanistic events which can occur in an LMFBR. To get a detailed description of these accident analyses references 1 and 2 are suggested. A mechanistic cause of the HCDA is if the reactor experiences a transient power excursion due to a loss of coolant flow (LOF) or overpower transient (TOP) with a failure to insert the control rods to shutdown the reactor.

In the loss of flow transient the working fluid is the fuel vapor. Due to the flow reduction the coolant heats up at a much faster rate than the fuel. This eventually leads to boiling of the sodium and voiding of the core. Subsequently the fuel pins fail due to a lack of cooling and also the overpower transient imposed by the sodium voiding. 
The fuel pins release the fuel in a high pressure two-phase mixture which acts as the working fluid for the accident. In contrast the working fluid is sodium for the transient overpower accident. The initial overpower ramp causes a fuel pin heat up faster than the coolant and failure, with the fuel being expelled into the coolant subchannels. This fuel-coolant interaction (FCI) results in the vaporization of sodium as the working fluid for the accident. In either case the result of this improbable disruption of the core is a two-phase mixture at a high temperature and pressure expanding into the sodium above the core. The expansion of this mixture mainly converts the energy into kinetic energy of the sodium slug above the core (with some energy going into radial strain of the core barrel and vessel). The resultant impact on the reactor vessel head could cause mechanical damage of the reactor vessel, a break in the vessel containment integrity, and release of some of the radioactive inventory. Although improbable, this subject of fast reactor safety must be investigated.

In 1971-72, the Stanford Research Institute conducted a series of scaled experiments which simulated the sodium vapor bubble expansion as would be experienced in a TOP for the FFTF. A non-condensible explosive source was used to model the pressure-volume expansion characteristics of sodium in scaled rigid piston-cylinder tests (1D effects in $1 / 10$ and $1 / 30$ scale). The source was developed to produce the same scaled pressure vs. volume curve as was predicted 
by the computer code socool [3] for the full-scale TOP. The computer code is based on the model of an adiabatic and isentropic expansion of the two-phase mixture. The reason for this is that the expansion time to the point of slug impact on the head in full scale is so short ( $~ 30 \mathrm{msec}$ ) that the heat transfer was assumed to be negligible. Based upon the results of the SRI tests, Holten [4] demonstrated that the heat transfer effects were not negligible at all in the scale model experiments. In fact the original SRI results iliustrated that the gas work derived from the experiment was reduced by $50 \%$ when the piston-cylinder arrangement contained a small level of water (greater than 3") .

It is the purpose of this study to propose a mechanism of heat transfer from the hot expanding gas to the liquid water. This model is based upon the idea of Epstein [5] (first proposed by Cagliostro [7]) that the mechanism for this large amount of heat transfer is area enhancement at the gas-liquid interface due to Taylor instabilities at the moving interface. After the model is described, it is compared to the SRI experimental results to illustrate the key independent variables and to determine the proportionality constant. Secondly it is compared to the experimental results in an integral energy balance to demonstrate its overall modeling of the experimental results. Finally the effects of experimental reproducibility, pressure source 
magnitude and scaling are examined to see how the model might help in predicting in the partitioning of energy in the full-scale hypothetical accident.

The results indicate that the simple model is successful in explaining the small-scale SRI results. Secondly and probably more important it gives a clear view of how the energy might be proportioned in the full-scale hypothetical TOP. 
Scale-model test experiments were performed at Stanford Research Institute to model the dynamic structural loading of the reactor vessel due to the hypothetical pressure source from an HCDA. Working in cooperation with Argonne National Laboratory's structural mechanics group, the stanford tests simulated the expansion of sodium vapor from a fuel coolant interaction due to a TOP. The reference full-scale data used to develop the expansion characteristics of the experiment was the output of the computer code socool [6]. The code's output are the $p-v$ and $p-t$ curves for an isentropic expansion of sodium vapor (see Fig. 2.1). The 150. Mw-sec $\mathrm{p}-\mathrm{v}$ curve represents the design upper-bound on energy available to do destructive work on the reactor vessel for the Fast Flux Test Facility. This amount of energy refers to the isentropic expansion on the initial core volume $\left(V_{0}\right)$ at a specific temperature and pressure to a reference pressure of one atmosphere.

The scaling of the experiments were made on the basis of the dynamic structural loading. of the reactor vessel. The results of the SRI analysis indicate that the pressure should stay constant with a change of scale. Thus for the work energy ( $p d v)$, the scaling factor with $p$ constant is $\mathrm{dv}$ or $\mathrm{L}^{3}$. Two different sizes of rigid piston-cylinder tests were used in the experiments ( $1 / 10$ and $1 / 30$ scale). Given the full scale diameter of the core as $228 \mathrm{~cm}$, these models then have diameters of $228 / 10$ and $228 / 30$ respectively. 
Similarly the explosive charge masses are reduced from full scale by $(1 / 10)^{3}$ and $(1 / 30)^{3}$ respectively: The experimental effect of the scaling laws on the time for gas expansion to $\mathrm{V} / \mathrm{V}_{\mathrm{o}}=3.14$ is that it is reduced by the length scale $(1 / 10)$ and $(1 / 30)$ respectively. Finally the shape of the SRI experimental $p-v$ and $p-t$ curves were matched to the analytical SOCOOL resülts up to a volume expansion ratio of $\mathrm{V} / \mathrm{V}_{\mathrm{o}}=3.14$. The reason for this is that in the FFTF design if the vapor bubble expands beyond this point, the sodium slug above it will impact the reactor head and impart its kinetic energy to the vessel structure in the form of strain energy. The use of the rigid piston-cylinder arrangement allows the measurement of the energy imparted to the vessel in terms of the slug kinetic energy due to the expansion of the high pressure gas mixture up to the point of impact. Thus the effects of the expansion can be measured in a one-dimensional framework of piston displacement and be related to available energy that could go into straining the reactor vessel.

The rigid piston-cylinder apparatus is shown in Fig. 2.3. The non-condensible source explodes in the canister and mixes with the air volume. The total mixture of hot gas then expands, pushing the piston downward. The pressure within the reaction chamber is measured in three locations to detect any differences. The piston movement (X) is recorded as a function of time ( $t$ ) by the light ladder arrangement at the end of the piston body. 
The non-condensible sources developed for the simulation of sodium vapor was a mixture of PETN $\left(65 \% \mathrm{C}_{5} \mathrm{H}_{8} \mathrm{O}_{12} \mathrm{~N}_{4}\right)$ and glass spheres called microballons (358). The explosion occurs within a louvered canister to dampen the initial shock wave and give a p-t curve similar to that predicted by socool. For a more detailed account of the tests, references 7 and 8 are helpful.

In some experiments SRI inserted water in the piston cylinder apparatus to simulate the sodium slug. At room temperature, water has comparable thermophysical properties to sodium at the reactor operating temperatures. When water was inserted, the magnitude of gas expansion work decreased by a half (see Fig. 2.4). Further results of the tests are given in Appendix A. The only conclusion that could be drawn from this was that a large amount of heat transfer occurs at the interface between the gas mixture and the liquid water. As Fig. 2.4 illustrates, there appears to be a saturation depth above which the decrease in gas work does not increase. The expansion times of these experiments are of the order of milliseconds (time is scaled by the inverse of the linear scale factor $1 / 30$ scale $\sim 1.5 \mathrm{msec}$ expansion time). One way that a large amount of energy can be transferred to the water is if the area for heat transfer is greatly enhanced in this short span of time. Cagliostro [7] suggested that Taylor instabilities at the interface could be the mechanism of this area enhancement. 
One misconception about this data is that the amount of heat transferred to the water is just the difference between the gas expansion work without water and that with water. This is not the case at all. To see why, recall the first law of thermodynamics for the closed system of the expanding gas :

$$
\Delta \mathrm{U}=\Delta \mathrm{Q}-\Delta \mathrm{W}
$$

where $\Delta U$ is the decrease in internal energy of the gas,

$\Delta Q$ is the heat transferred to cold structure and to the water,

$\Delta W$ is the work output of the expanding gas on the piston.

There is a partition of energy of the gas between the heat transferred out and work done on the piston. It will be illustrated that the amount of heat transfer during the expansion accounts for the significant majority of internal energy change in the gas mixture. Therefore the contribution due to heat transfer to the water is not just the difference in the water/no water tests because in either case the system is not adiabatic and there is heat transfer to the cylinder walls (see Appendix C).

In the next section the basic model for heat transfer between the gas mixture and the liquid is presented. The operative mechanism at the interface to give heat transfer is assumed to be Taylor instability. The results though must be considered in the context of the partitioning of the energy between work output and heat loss. 


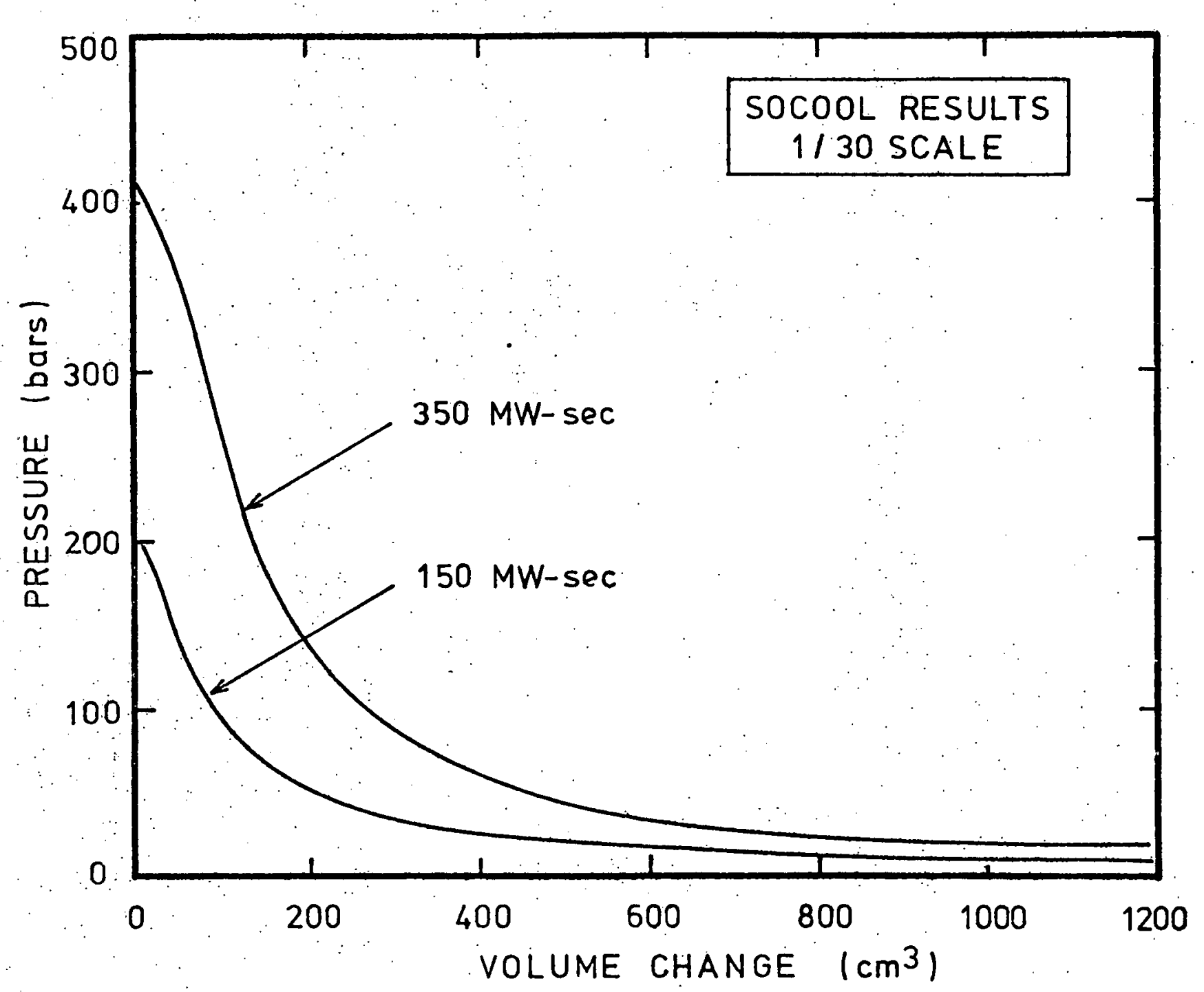

Figure 2.1 Pressure-Volume Characteristics for $150 \mathrm{MW}-\mathrm{sec}$ socool results 


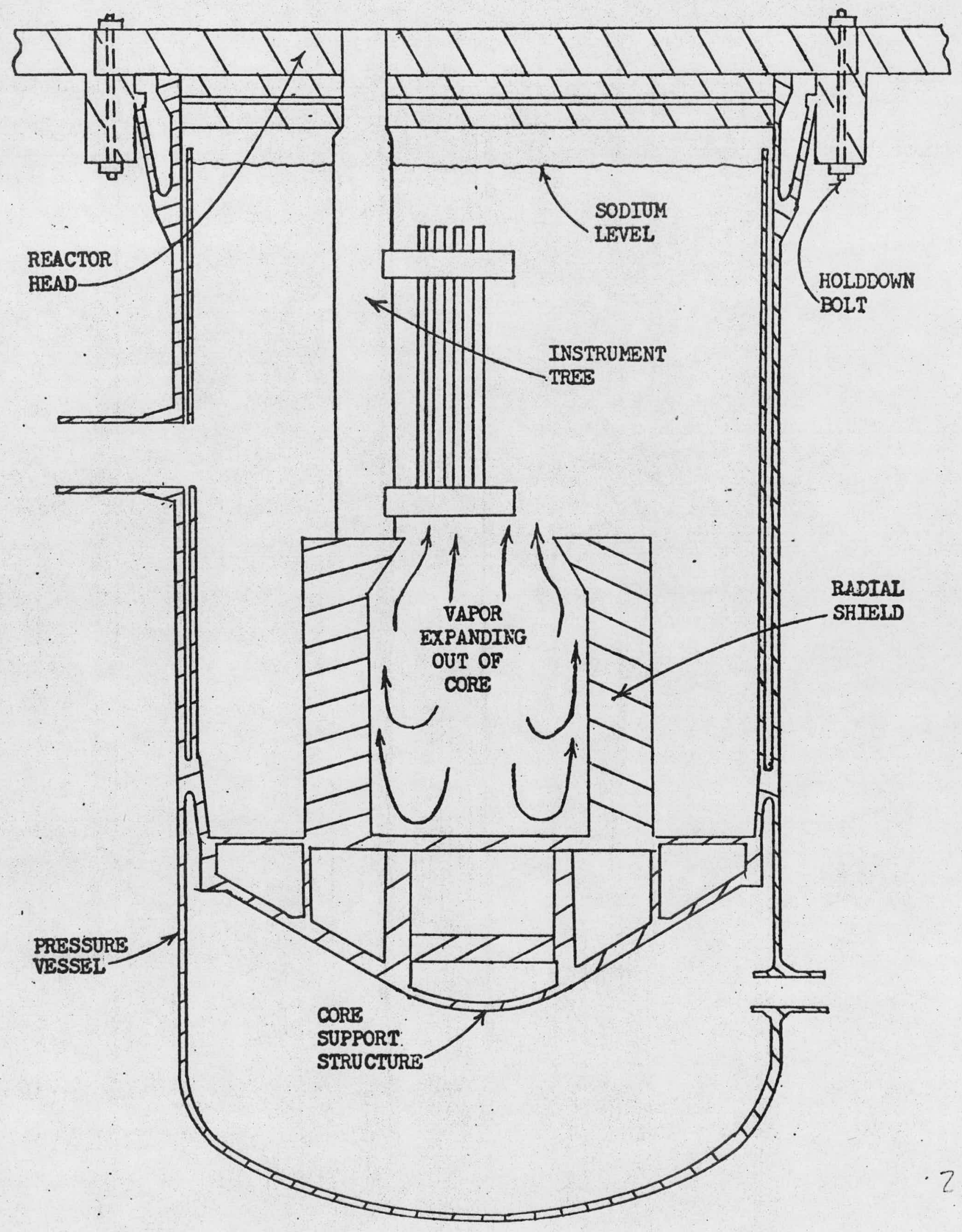

Figure 2.2 View of FFTF Reactor Vessel 


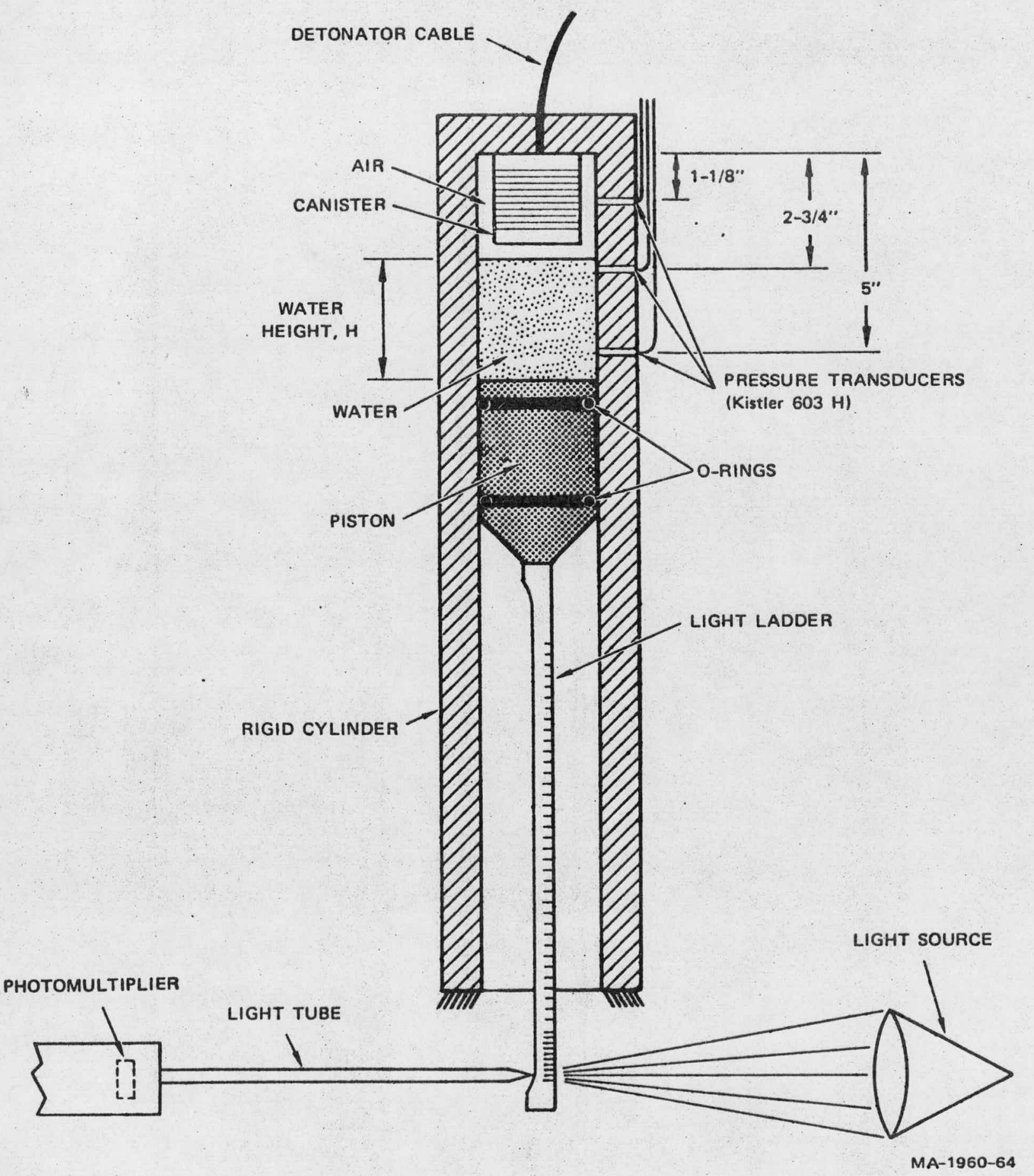

Figure 2.3. RIGID CYLINDER-PISTON APPARATUS 


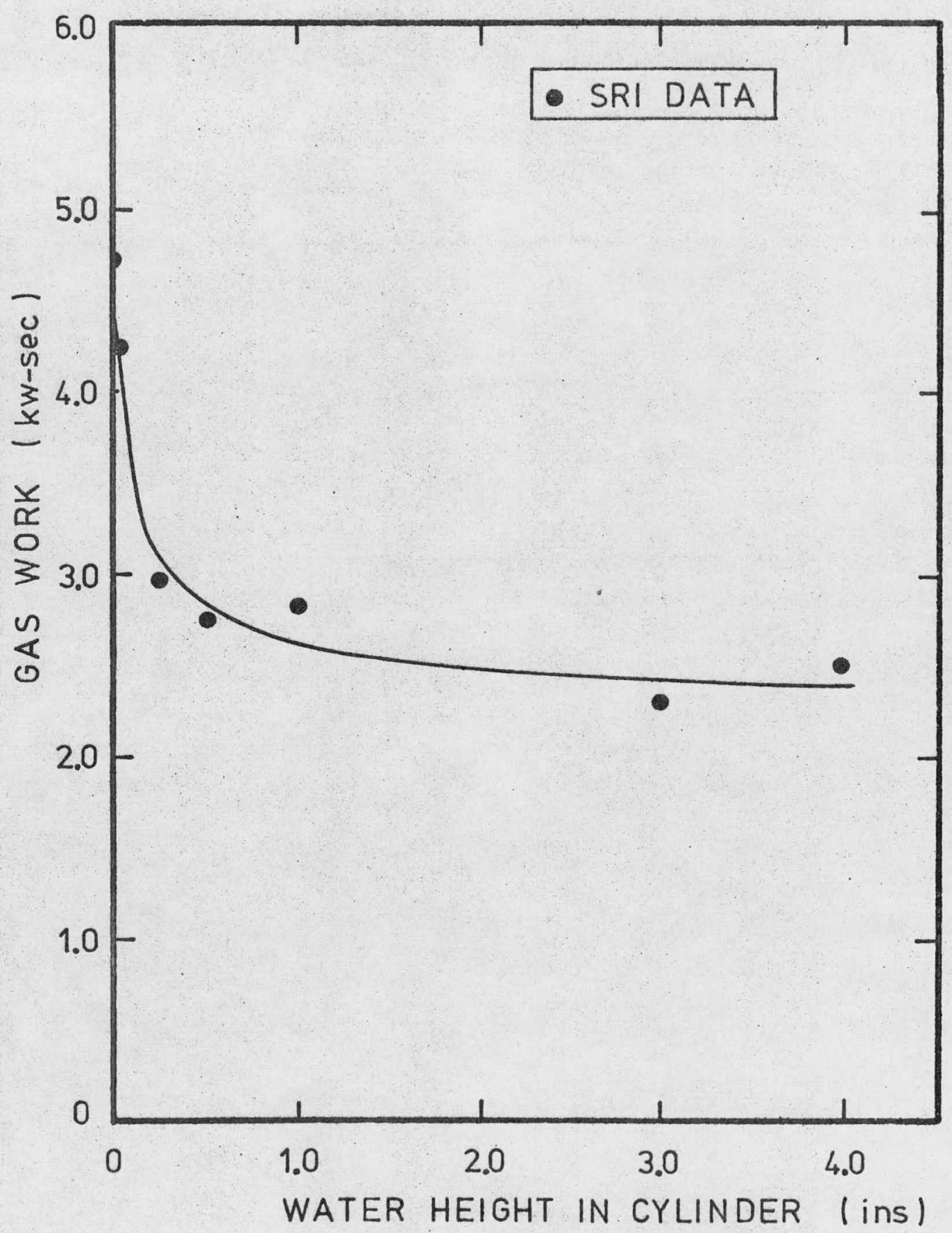

Figure 2.4 Gas Work vs. Water Depth Relationship 
The stanford test results indicate that there is heat transfer from the hot gas mixture to the cooler liquid. Since the expansion time is so short the area available for heat transfer must increase very rapidly to allow such a noticeable increase in the heat loss from the expanding gas. To facilitate an understanding of the mechanism causing this area enhancement, a physical picture of the phenomena is first presented.

Before the detonation of the explosive the liquid-gas interface is flat and undisturbed. Immediately after the detonation the gas acquires a high temperature $\left(\sim 3000^{\circ} \mathrm{K}\right)$ and pressure ( $\sim 200$ bars) and starts to expand against the water interface and move the piston. The acceleration of the gas-liquid interface is from the less dense gas to the more dense liquid. As the piston moves downward a thin film of liquid remains on the walls of the cylinder. Along the initially. smooth gas-liquid interface the turbulent flow caused by the detonation has created distortions. The amplitude and wavelength of these disturbances vary to a large extent, but there probably is a representative amplitude and wavelength ( $L$ ) which characterizes the size and type of pressure source used (see Fig. 3.1): As time progresses the liquid-gas front moves downward decreasing the pressure and temperature of the gas mixture. At the interface, because the acceleration of the front is from the less dense fluid to the more dense, Taylor instabilities [9] can exist. 
If the characteristic wavelength $(L)$ is greater than a critical wavelength $\left(\lambda_{C}\right)$ this disturbance will grow with time [10]: (refer to Appendix B for details on Taylor Instabilities). The rate of growth of the amplitude was experimentally identified by Lewis [11] to be divided into two major stages. For a situation where the initial amplitude $\left(\eta_{0}\right)$ of the disturbance $(L)$ is small $\left(\eta_{0} \ll L\right)$ then the amplitude grows with a relative velocity to the interface given as (see Appendix B),

$$
\frac{d n}{d t} \simeq{\frac{n_{0}}{L}}^{2 \pi}(a t)
$$

This relationship holds until $n \simeq 4 \mathrm{~L}$. Then the second stage of growth occurs with the relative velocity being

$$
\frac{d n}{d t} \simeq \sqrt{a L}
$$

Because of the nature of the SRI experiments where the initial pressure wave is larger, it seems probable that the initial amplitude of the disturbance ( $n_{0}$ ) is equal to or greater than its characteristic wavelength (L). This would suggest that the second stage of growth predominates the interaction and it should be used to characterize the relative velocity of the gas-liquid interface. Physically this can be visualized by the movement of the gas-liquid interface sweeping out a regional liquid (Fig. 3.1). After a span of time small globules (length $\sim L$ ) of gas trapped in the liquid (liquid globules entrained in the gas) appear 
near the interface. This essentially equal volume configuration is the resultant area anhancement which aids heat transfer from the gas to the liquid.

During the whole process energy is being transferred across the gas-liquid interface. The model views this energy exchange in an equilibrium viewpoint. Consider the movement of the gas-liquid interface over a span of time where the amplitude of the initial disturbance (wavelength $=\mathrm{L}$ ) has grown and globules have formed (see Fig. 3.2). The rate at which heat is transferred from the hot gas to the liquid can be characterized by the equation

$$
\dot{q}=\rho_{g} C_{\rho_{g}}\left(T_{g}-T_{\ell}\right) \frac{d V}{d t}
$$

where $\rho_{g} C_{\rho g} \Delta T$ is the amount of energy per unit volume that the gas globules transfer in coming into equilibrium with the surrounding liquid. The term (dV/dt) represents the rate of generation of the droplet volume. This rate of generation is proportional to the projected surface area of the piston $\left(A_{p}\right)$ and the velocity with which the interface amplitude grows and creates this equal volume mixture of globules. The interface moves with a velocity $u_{p}$ (Fig. 3.2) caused by the expansion of the hot gas against the piston. But the amplitude growth of the disturbance (L). grows with a velocity $u_{p}+K_{2} \sqrt{a I}$. So the relative velocity of the amplitude and the rate at which these globules are formed is $\mathrm{V} \sim \sqrt{\mathrm{aL}}$. Thus the rate of 
generation of droplet volume is

$$
\frac{\mathrm{dV}}{\mathrm{dt}}=\mathrm{K}_{2} \mathrm{~A}_{\mathrm{p}} \sqrt{\mathrm{aL}}
$$

If equations (3.3) and (3.4) are combined the result is

$$
\dot{q}=K_{2} \rho C_{p_{g}}\left(T_{g}-T_{\ell}\right) A_{p} \sqrt{a L}
$$

The characteristic wavelength $(L)$ of the initial disturbance is difficult to evaluate (see Appendix B). It can be expected that as the explosive becomes larger, the detonation becomes more violent. This should cause the characteristic wavelength to get smaller due to a greater Reynolds number of the flow imposed by the larger explosive. L is probably a function of the magnitude of the explosion for a given scale. As will be shown later it appears to be independent of the scale of the experiment, assuming that the magnitude of the explosion is properly scaled. To evaluate the heat transfer rate then the wavelength is assumed to be some proportion of the diameter of the piston $\left(\mathrm{L}=\mathrm{K}_{4} \mathrm{D}_{\mathrm{p}}\right)$. It should be understood though that $\mathrm{K}_{4}$ is not really a true constant because it is expected to be a function of the size of initial pressure disturbance at a fixed scale. So equation (3.3) becomes

$$
\dot{q}=C_{o} \rho_{g} C_{p}\left(T_{g}-T_{\ell}\right) A_{p} \sqrt{a D_{p}}
$$

Where $\mathrm{C}_{\mathrm{o}}=\mathrm{K}_{2} \sqrt{\mathrm{K}_{4}}$ can be varied as an empirical coefficient. 
Incidentally, the time of formation $\tau_{f}$ of one globule can be found by the equation

$$
\tau_{f}=K_{3} \frac{L}{\sqrt{a L}} \quad \therefore \tau_{f}=K_{3} \sqrt{\frac{L}{a}}
$$

where $K_{3} L$ is the distance traveled during formation and $\sqrt{\mathrm{aL}}$ is the relative amplitude velocity. It should be noted that implicit in the model above is the assumption that heat transfer occurs duxing the time of globule formation so that effectively $\tau_{f} \sim \tau_{h t}$ as figure 3.2 indicates.

Before examining the experimental SRI results it would be instructive to estimate the magnitude of the constant $\mathrm{C}_{0}$. The constant $k_{2}$ reflects the fraction of volume at the distorted interface (Fig. 3.2) which is occupied by the gas. A Good estimate is near one. The constant $k_{4}$ reflects the fraction of the piston diameter that represents L. L must be greater than the critical wavelength $\left(\lambda_{c}\right)$ to grow (see Appendix B). Physically, though, it would be of the same order of magnitude as the piston diameter (between .I and 1). So the constant $c_{0}$ can be expected to be between .1 and 1 .

The heat transfer model utilizes the picture of a gas globule coming to thermal equilibrium with the surrounding liquid. Because the liquid has such a large heat capacity in comparison to the hot gas the entrainment of gas bubbles in an equal volume of water cools the gas to essentially the liquid temperature (in fact a very small amount of water still does not change the water temperature greatly--see Appendix C.1). Also the time to attain thermal equilibrium 
between gas and water $(\tau)$ is small as compared to the gas expansion ( $t_{\text {exp }}$ ) as illustrated in Appendix $D$. So the two key parameters within the model that must be investigated - are the acceleration of the interface (a) and the constant $C_{0}$ which incorporates the size of the initial disturbance. In the following section these last two parameters are studied in relation to the experimental stanford results. 


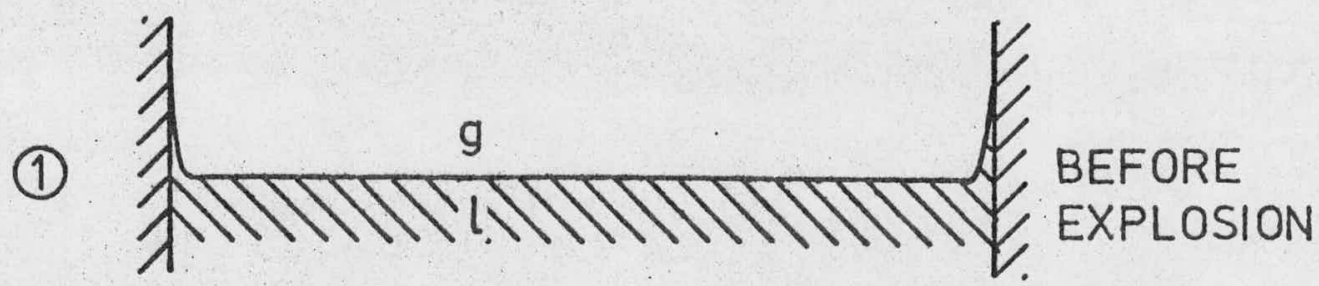

(2)

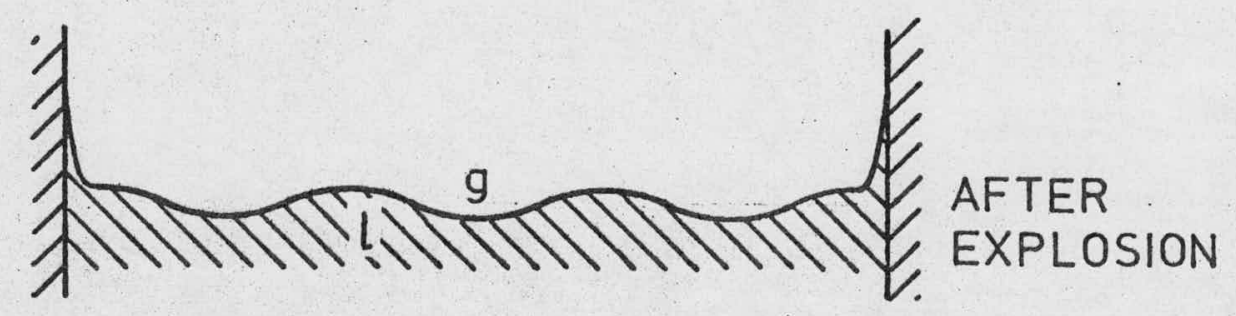

(3)

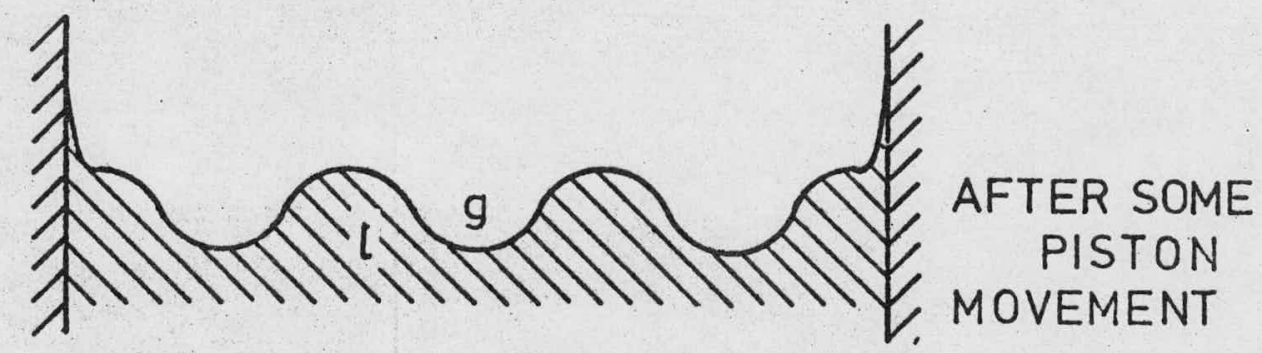

(4)

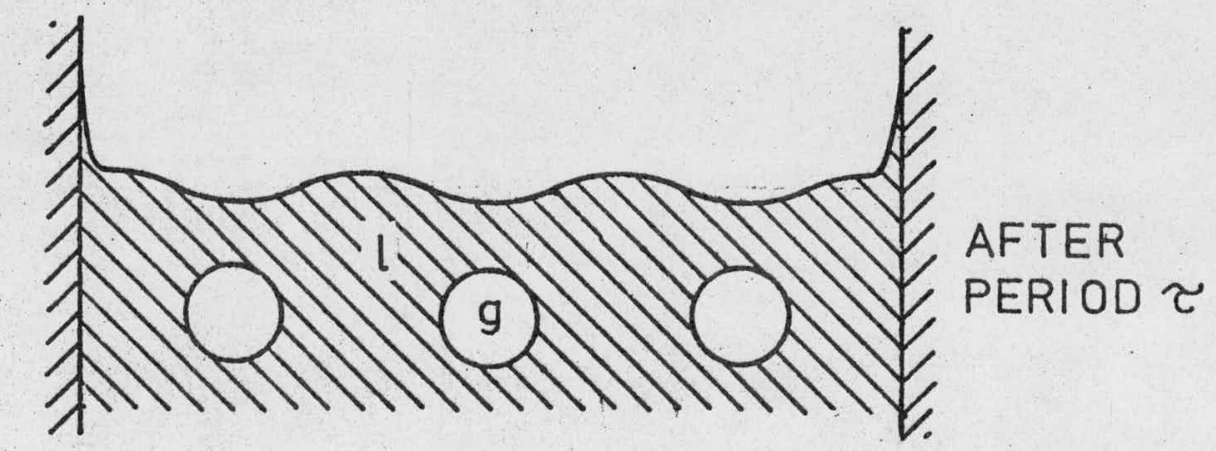

Figure 3.1 Physical Picture of Progression of Initial Disturbance 


$$
\dot{q}=c \rho_{g} c_{p g}\left(T_{g}-T_{i}\right) \sqrt{a D_{p}} A_{p}
$$

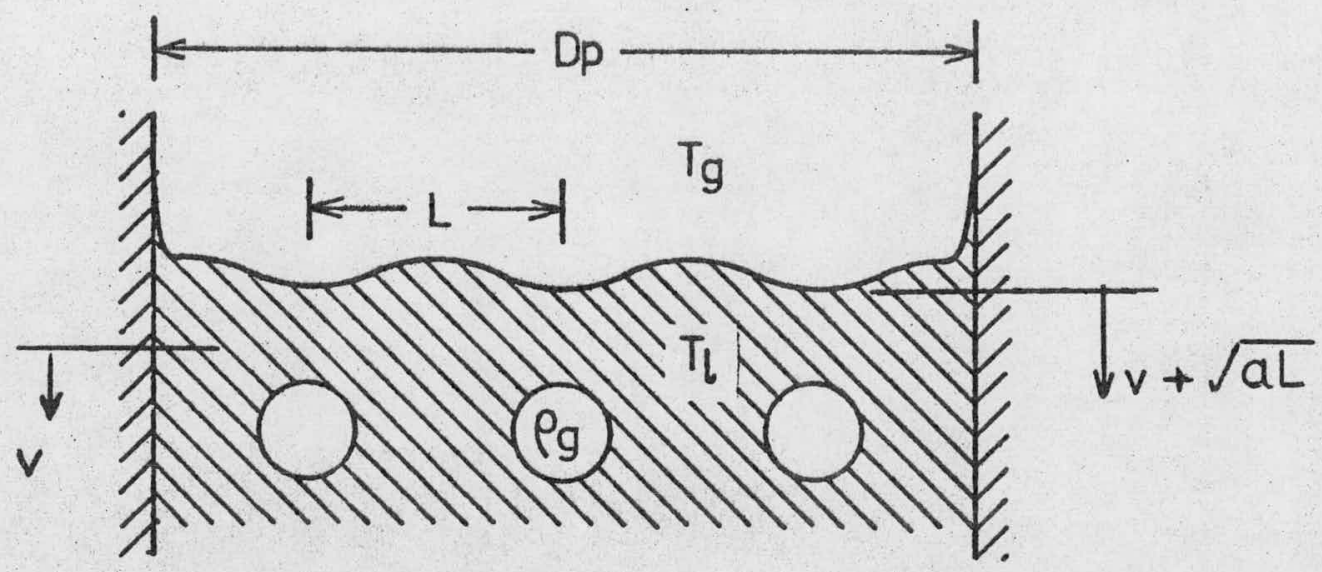

$$
v_{\text {REL }}=\sqrt{a L} \text { where } L=K_{4} D_{p}
$$

one globule: $\dot{q}=\frac{K_{1} \rho_{g} c_{p g}\left(T_{g}-T_{l}\right) L^{3}}{\tau}$

no. of globules: $N=\frac{K_{2}(\sqrt{a L}) A p \tau_{f}}{K}$

$$
\text { assume } \tau_{f} \doteq \tau
$$

Figure 3.2 Model of Interface Condition 
4.

COMPARISON TO SRI TEST RESULTS

To compare the proposed model to the Stanford test results, an approach suggested by Holten [14] was followed for evaluation of the change in internal energy of the gas, and the heat transfer to the cold cylinder structure. Appendix C.l discusses the calculational procedure in detail. The basic equation for describing the expansion is the first law of thermodynamics for the closed system of the expanding gas:

$$
\dot{\mathrm{U}}=\dot{\mathrm{Q}}-\dot{\mathrm{W}}
$$

The two key parameters in the heat transfer model are the acceleration of the interface and the constant $\mathrm{C}_{0}$. Two different approaches are used to verify the functional dependence of the model on the acceleration and $\mathrm{C}_{0}$.

First based upon reduction of the stanford data the instantaneous heat transfer rate $(\dot{q})$ to the liquid is determined at different interface accelerations. With the other properties in the model held constant, the dependence of the heat transfer rate $(\dot{q})$ on the acceleration (a) is verified and the constant is determined. The second approach is based upon an integral evaluation of the model. The total heat transferred to the liquid during the expansion is found by two methods; by a simple energy balance using the test results and by the proposed model. 
A comparison of the results is then made.

\subsection{Functional Dependence of Acceleration}

The proposed model suggests that the functional dependence of the heat transfer rate to the interface acceleration is $\dot{q} \alpha$ (a) ${ }^{5}$. A comparison is made to the SRI data based on three tests, (Al19, Al20, Al24). In each test the scale is $1 / 30$ and the eight-gram of PETN-microballoon explosive was used. The difference between these is that different amounts of water are in the cylinder resulting in different accelerations. Appendix C.2 describes the calculational method in detail. The object is to hold constant all the parameters in the model while varying the acceleration (a) to see its effect upon the heat transfer rate. To keep each parameter approximately constantexcept the acceleration, the piston displacement is fixed for all three tests. At this common point the heat transfer rate $(\dot{q})$ is found as well as the acceleration. The model is then written in the linear. slope-intercept form as

$$
\ln \dot{q}=\ln k_{0}+(\ln a) m
$$

where $k_{o}=C_{O} q^{C} p_{g} \Delta T A_{p} L^{m}$. The parameter $m$ is determined by evaluating the slope of the line defined by (4.2). Table 4.1 gives thenumerical results for the three tests at two piston displacements, while Fig. 4.1 shows a linear fit to the results. As shown, the slope of the line is approximately .5 as the model proposes. In evaluating the constant $C_{0}$, the data at each point is substituted into the model. 
A representative result is given in Table 4.2. The average of all the experimental points is .78. This result falls within the range of the original estimation of the constant. 4.2 Integral Comparison of SRI Data to Model

Appendix C.I details how the heat transfer to the 1 iquid is determined from an energy balance on the expanding gas volume. The heat transferred to the liquid is found by subtracting from the internal energy change of the gas the experimental work output and an estimation of the heat transferred to the wall: The heat transfer model is then compared to these results by numerically integrating equation (3.3) to obtain the total heat transfer to the liquid as

$$
\begin{aligned}
& \Delta Q_{L}=\int_{t_{0}}^{t_{f}} \dot{q} d t= \\
& \sum_{i} \frac{\dot{q}\left(t_{i}\right)+\dot{q}\left(t_{i-1}\right)}{2}\left(t_{i}-t_{i-1}\right)
\end{aligned}
$$

This method of comparison is made for four tests and Appendix C. 3 contains a detailed account of the calculations. The results are presented in this section to observe the behavior of the model in three specific areas: reproducibility of results, scaling, and the effect of the pressure source on the characteristic wavelength (L).

The first test to be examined in AVG 2. It is scaled to represent the 150 MW-sec TOP accident for the Fast Flux Test Facility in $1 / 30$ scale. The work output. due to the gas 
expansion is shown in Fig. 4.2. Although" the rigid cylinder tests without water had approximately double the gas work the difference between the work output of these two tests is not necessarily the heat transferred to the liquid. The work output only accounts for about 108 of the internal energy changes as Appendix C. 3 shows and Fig. 4.3 illustrates. Fig. 4.3 is the comparison of $\mathrm{Q}_{\mathrm{L}}$ obtained by the overall energy balance on the experimental results and the integrated heat transfer model. As the graph shows the agreement with the experimental results is quite good with the constant $c_{0}$ equal to .8. What is equally important to note is the partitioning of internal energy change in this small-scale test. Heat transfer to the liquid and the wall account for $90 \%$ of the internal energy change while only $10 \%$ is transformed to mechanical work output. The importance of this energy partitioning will be stressed in the following section but it suffices to say that ignoring the heat transfer effects in this phenomenon is too conservative a position.

Another factor to consider is the variability of the constant $C_{O}$ in the model due to the reproducibility of the experimental results. To examine this variability the results of test AVG 2 were compared with three other similar tests at $1 / 30$ scale, three inch water depth and eight gram explosive charges (tests Al22, Al24, Al25). Two of these tests agreed very well with the previous results of AVG 2 (see Fig. 4,4). For only one test (A122) did the expansion data vary slightly from the previous analysis. As Fig. 4.5 
illustrates the integrated model corresponds well with the overall energy balance but the constant is .72. A conclusion that can be drawn is that a small band of constant values $\left(C_{0}\right)$ is needed to fit the model at any one set of conditions due to experimental reproducibility.

The third factor to consider is the effect of the size of the pressure source on the characteristic wavelength of the initial disturbance. Test Al34 is used as an illustration of this effect (scale 1/30, water depth 3 inches, explisive charge $14 \mathrm{gm}$ ). The pressure almost doubles (Fig. 4.6) due to the increase in explosive power although the temperatures within the cylinder are approximately the same. The correlation between the energy balance method and the model again is very good (see Fig. 4.3). The major difference though is the size of the constant $\left(c_{0}=.3\right)$. Because the constant decreases a possible explanation is that the size of the characteristic wavelength (L) has decreased by almost a factor of 7 . With an explosive increase, more violence is done to the gas-liquid interface causing the disturbances to become more numerous and smaller. This should be physically expected and the model accounts for it. The constant $\mathrm{K}_{4}$ was originally postulated to be dependent on the size of the explosive charge and by this example it is seen that the dependence is rather strong. Scaling is the final effect on the proposed heat transfer model which is important to investigate. A test example to illustrate the effect is B102. This is a $1 / 10$ 
scale rigid piston cylinder experiment. The explosive mass scales as the volume so the equivalent charge increases by a factor of 27 to $216 \mathrm{gm}$. Again the integral analysis is applied to this test and as Fig. 4.8 illustrates the model agreed reasonably well. with the data when the constant $\left(C_{0}\right)$ is now .71. This is a very small change in the model with a factor of three change in scale. In fact as the reproducibility analysis illustrated the constant varied in value for identical test runs from .72 to .8. Based upon these results it seems reasonable to conclude that the constant does not change with a change in scale. The only dependence it has is the size of the original pressure source for a given scale. The second observation to make is that the fraction of internal energy change which leaves by heat transfer and work output remains almost the same. In the $1 / 30^{\circ}$ scale tests the work accounted for 10.38 of the internal energy change while in the $1 / 10$ scale test the percentage is 11.5\%. Because of the experimental error inherent in the tests this.could be considered essentially no change. This result is expected if a scaling analysis of the overall energy balance is done. The first law states

$$
\Delta U=\Delta Q-\Delta W
$$

If the heat transfer model to the liquid is inserted into $\Delta Q$ and integrated and the appropriate terms for $\Delta U$ and $\Delta W$ employed, the result is 


$$
\int_{T_{0}}^{T} n c_{V} d T=\int_{t_{0}}^{t} C_{0} \rho_{g} c_{p g}\left(T_{g}-T_{L}\right) A_{p} \sqrt{a D} d t-\int_{V_{0}}^{V} p d V
$$

To scale up the work output, the pressure scales as unity and the volume as the length scale cubed $\left(I^{3}\right)$.. The work at $1 / 10$ versus $1 / 30$ scale should be 27 times as large.

$$
\begin{aligned}
& \Delta \underset{\text { Energy }}{\text { Work }}=\int_{1 / 10} \text { pdv } \\
& =(3)^{3} \int p d v \\
& 1 / 30
\end{aligned}
$$

For the internal energy, the specific heat $\left(\mathrm{C}_{\mathrm{v}} \mathrm{cal} / \mathrm{gmole}^{\circ} \mathrm{K}\right)$ remains the same and $n$, the number of moles in the enclosure increases by the length scale cubed (27 times as large). The temperature, if the ideal gas relation is inserted, is shown to scale as unity.

$$
\begin{aligned}
& \Delta \underset{\text { Energy }}{\text { Internal }}=\int_{T_{0}}^{T} n c_{v} d T \underbrace{T}_{1 / 10}=\left(\frac{\frac{\text { mass }}{\text { molec }}}{\text { weight }}\right)_{1 / 10} \int_{T_{0}}^{T} c_{v} d T
\end{aligned}
$$

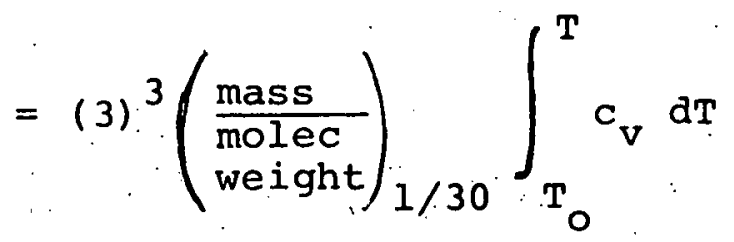


For the heat transfer model, the quantity $\mathrm{C}_{\mathrm{O}}{ }^{\rho} \mathrm{g}^{\mathrm{C}} \mathrm{pg}^{\Delta \mathrm{T}}$ scales as unity also. This can be seen from the substitution of the ideal gas law for temperature. The area $A_{p}$ increases by the length scale squared and the time increment (dt) decreases as the inverse of the length scale. For the interface relative velocity $(\sqrt{\mathrm{aD}})$ the acceleration decreases by the length scale while the converse is true of the diameter: The net result is that the heat transfer also increases by the length scale cubed.

$\begin{aligned} \underbrace{\Delta \text { Heat }}_{\text {Transfer }} & =\int_{t_{0}}^{t} C_{0} \rho_{g} C_{p g}\left(T_{g}-T_{L}\right)\left(A_{p} \sqrt{a D} d t\right)_{1 / 10} \\ \therefore \quad & =(3)^{3} \int_{t_{0}}^{t} C_{o} \rho_{g} C_{p g}\left(T_{g}-T_{\rho}\right) \cdot\left(A_{p} \sqrt{a D} d t\right)_{1 / 30}\end{aligned}$

Thus the proportion of internal energy allocated to work output and heat transfer does not change with scale. Rearranging equation (4.4) gives

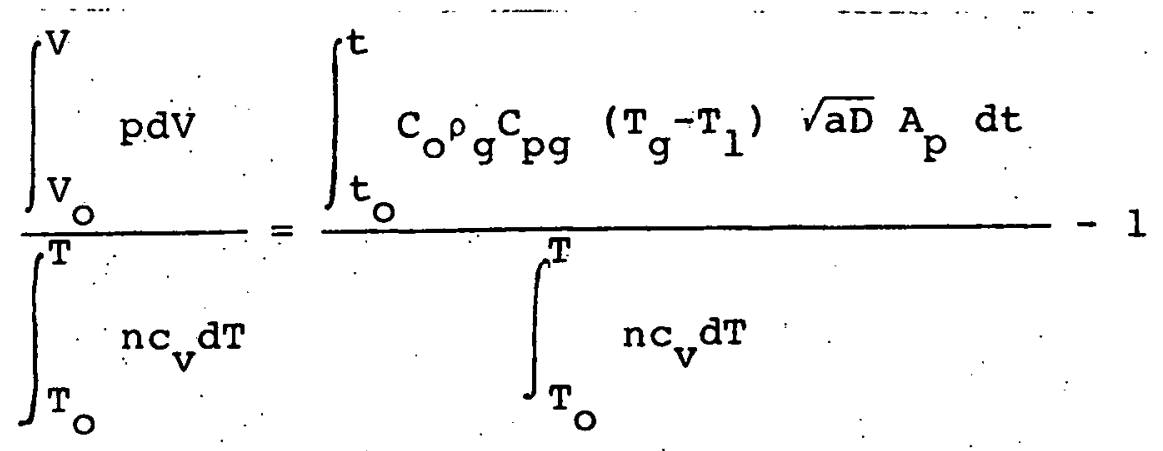


With a change of scale one obtains,

$$
\frac{L^{3} \int_{V_{0}}^{V} p d v}{L^{3} \int_{T_{0}}^{T} n c_{v} d T}=\frac{L^{3} \int_{t_{0}}^{t} c_{0}{ }^{\rho} g^{C} p g\left(T g^{-T}\right) A_{p} \sqrt{a D d t}}{L^{3} \int_{T_{0}}^{T} n c_{v} d T}-1
$$

Thus the ratios remain the same.

The results of both types of comparisons of the proposed heat transfer model to the experimental results indicate that it can describe the phenomenon of heat transport at the liquid interface reasonably well. The constant $\left(C_{0}\right)$ lies within the expected range of values, remains constant with a change of scale and is functionally dependent only on the size of the pressure source. Finally the proportion of the energy output from the gas expansion largely favors heat transfer to work output, with 908 . going to heat transfer and $10 \%$ to the work output, and this partitioning is independent of the scale of the experiment. 


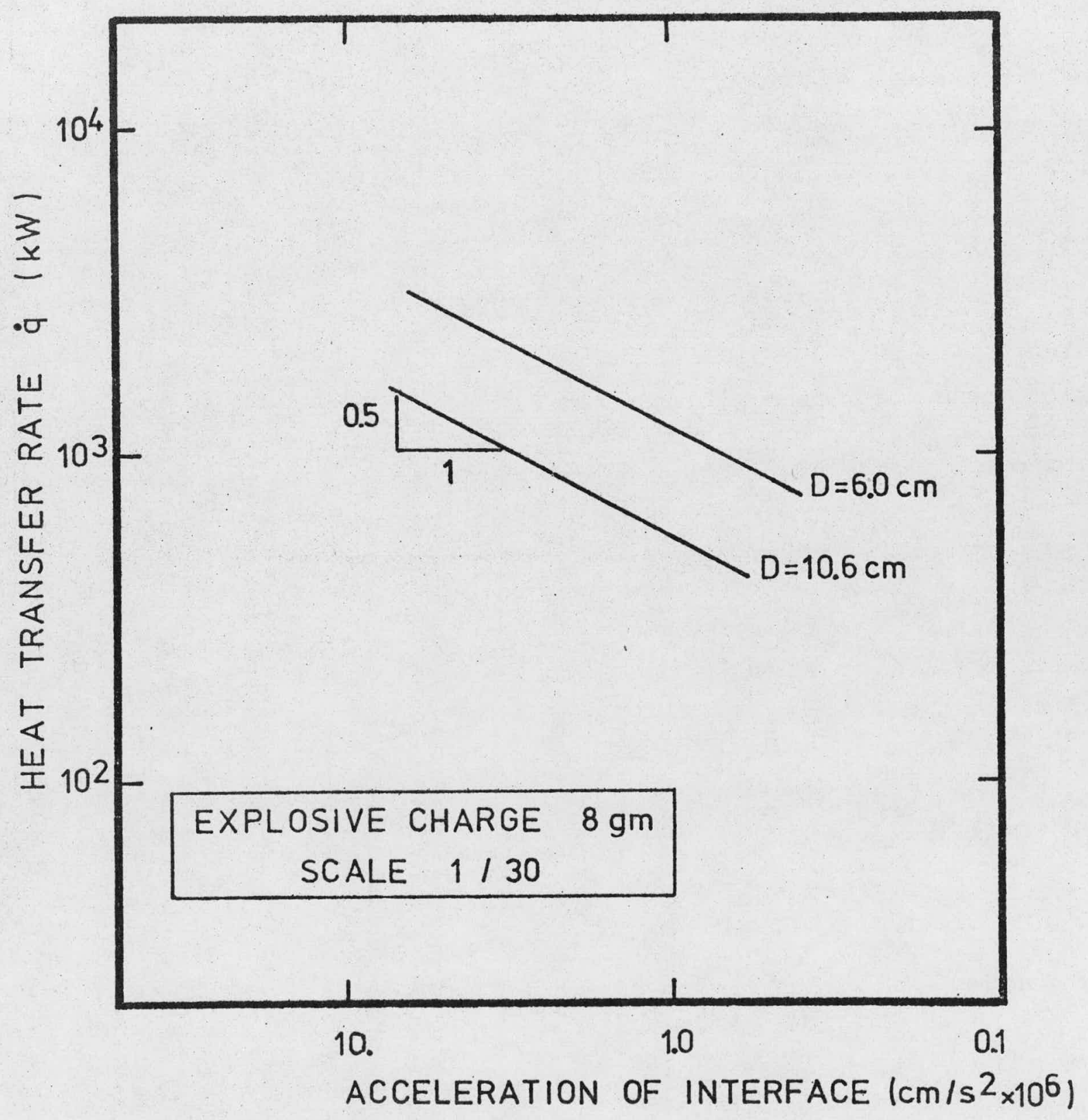

Figure 4.1 Heat Transfer Rate as a Function of Acceleration of the Gas-Liquid Interface 


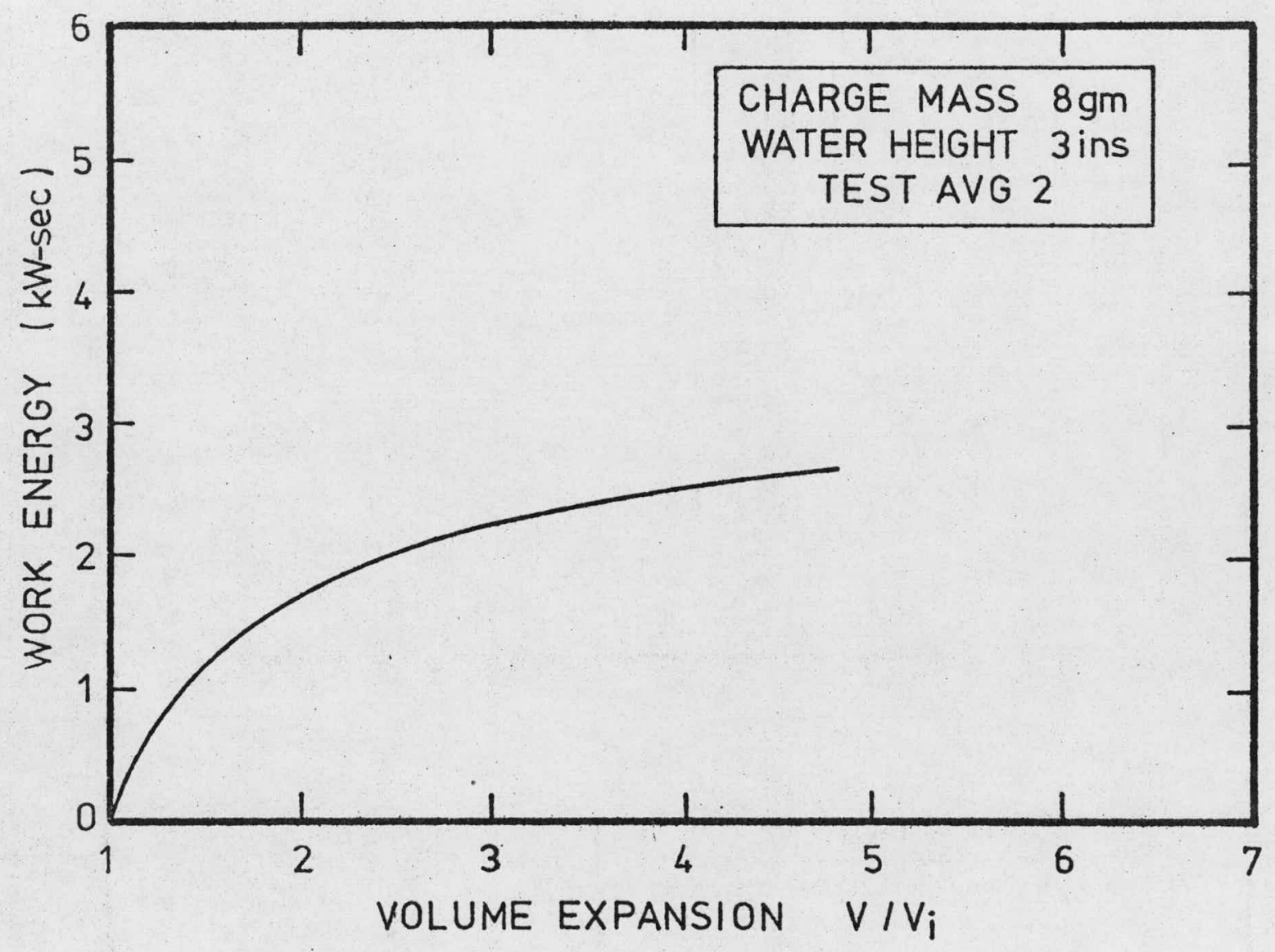

Figure 4.2 Gas Work Energy as a Function Volume Ratio for Test AVG2 


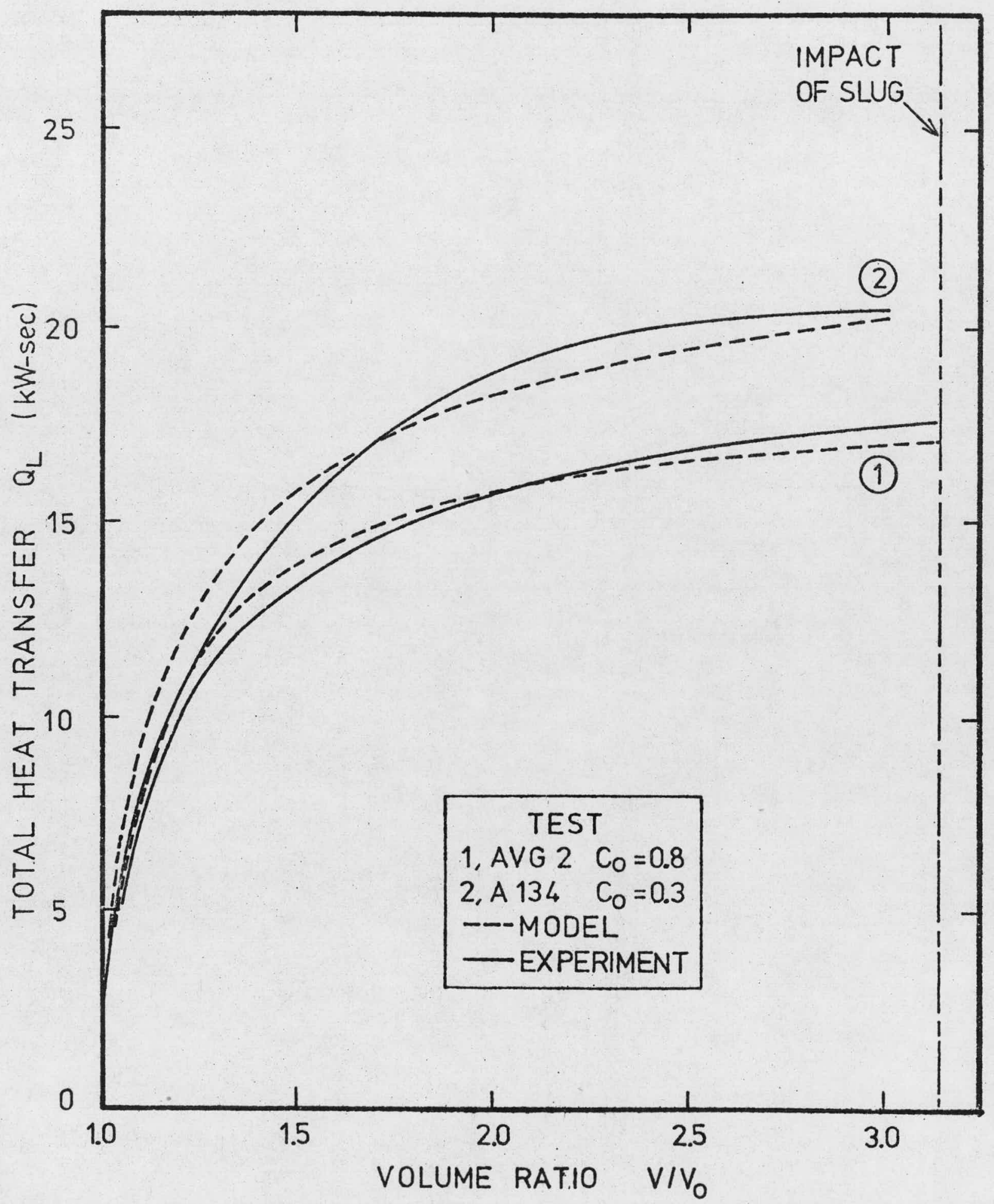

Figure 4.3 Comparison of Total Heat Transfer as a Function of the Volume Ratio for Model and Experimental Results 


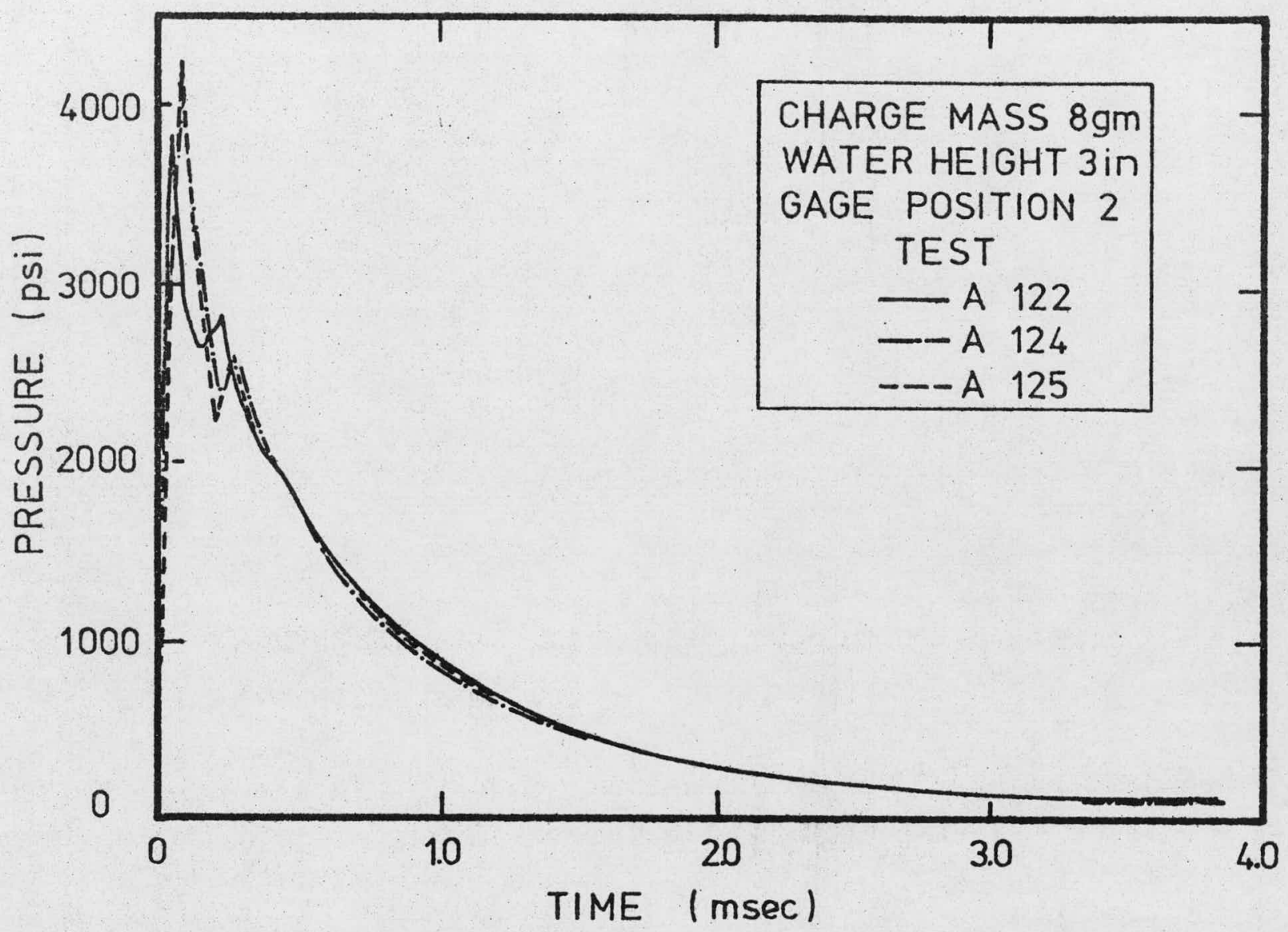

Figure 4.4 Reproducibility Comparison for Pressure vs. Time Results for $1 / 30$ Scale Tests 


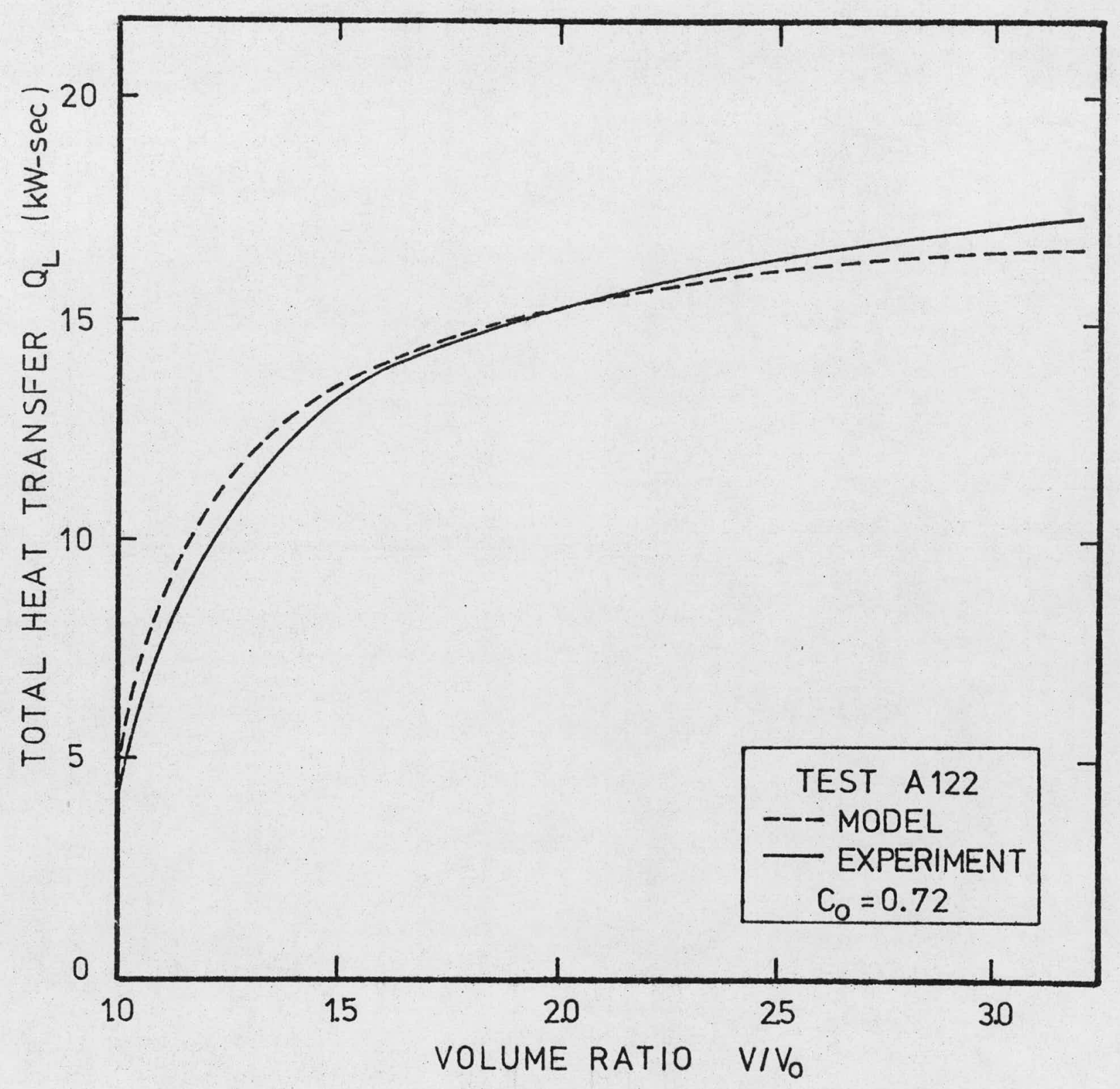

Figure 4.5 Comparison of Total Heat Transfer as a Function of the Volume Ratio for Model and Experimental Results 


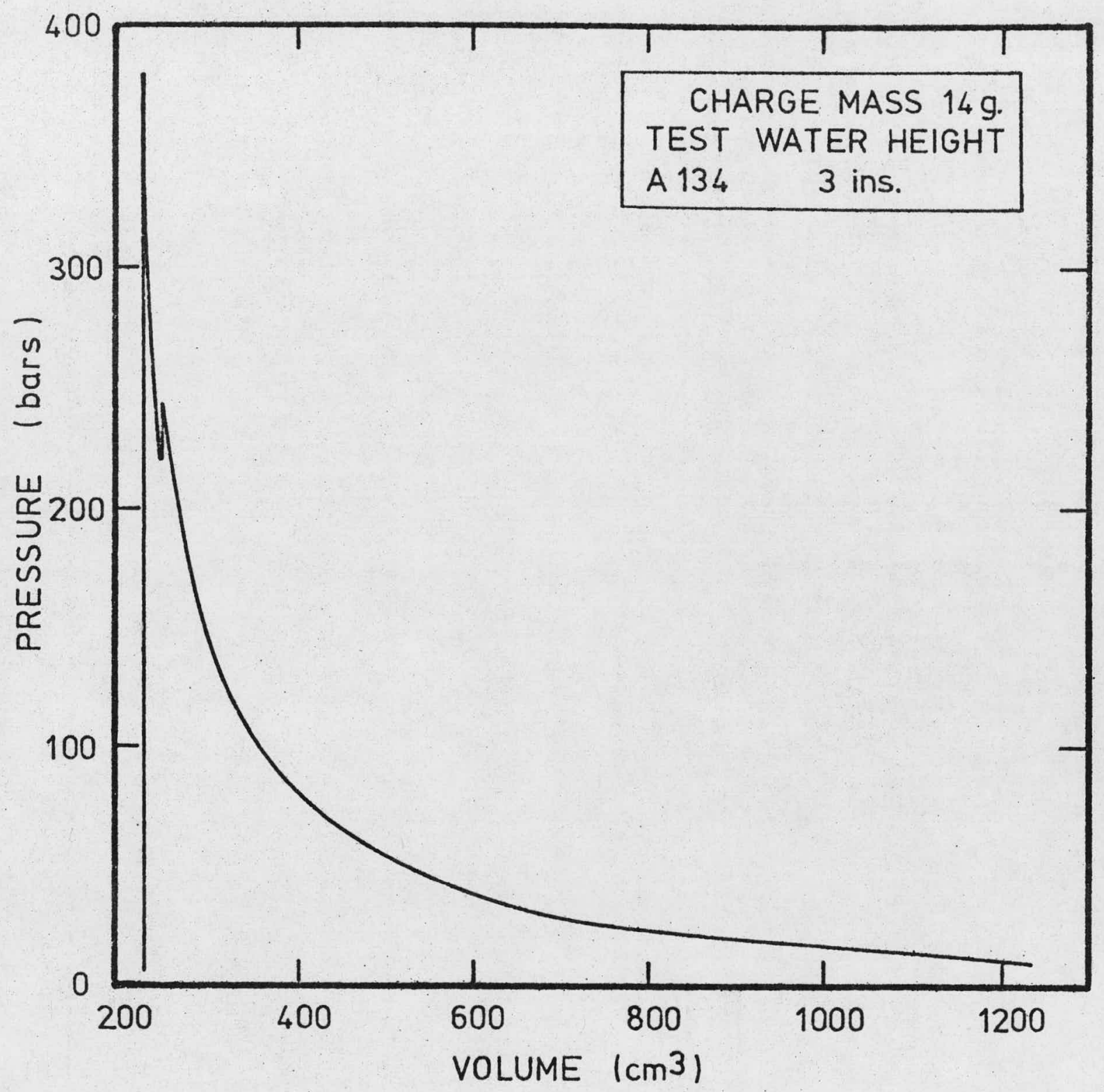

Figure 4.6 Pressure-Volume Relationship for Test Al34 


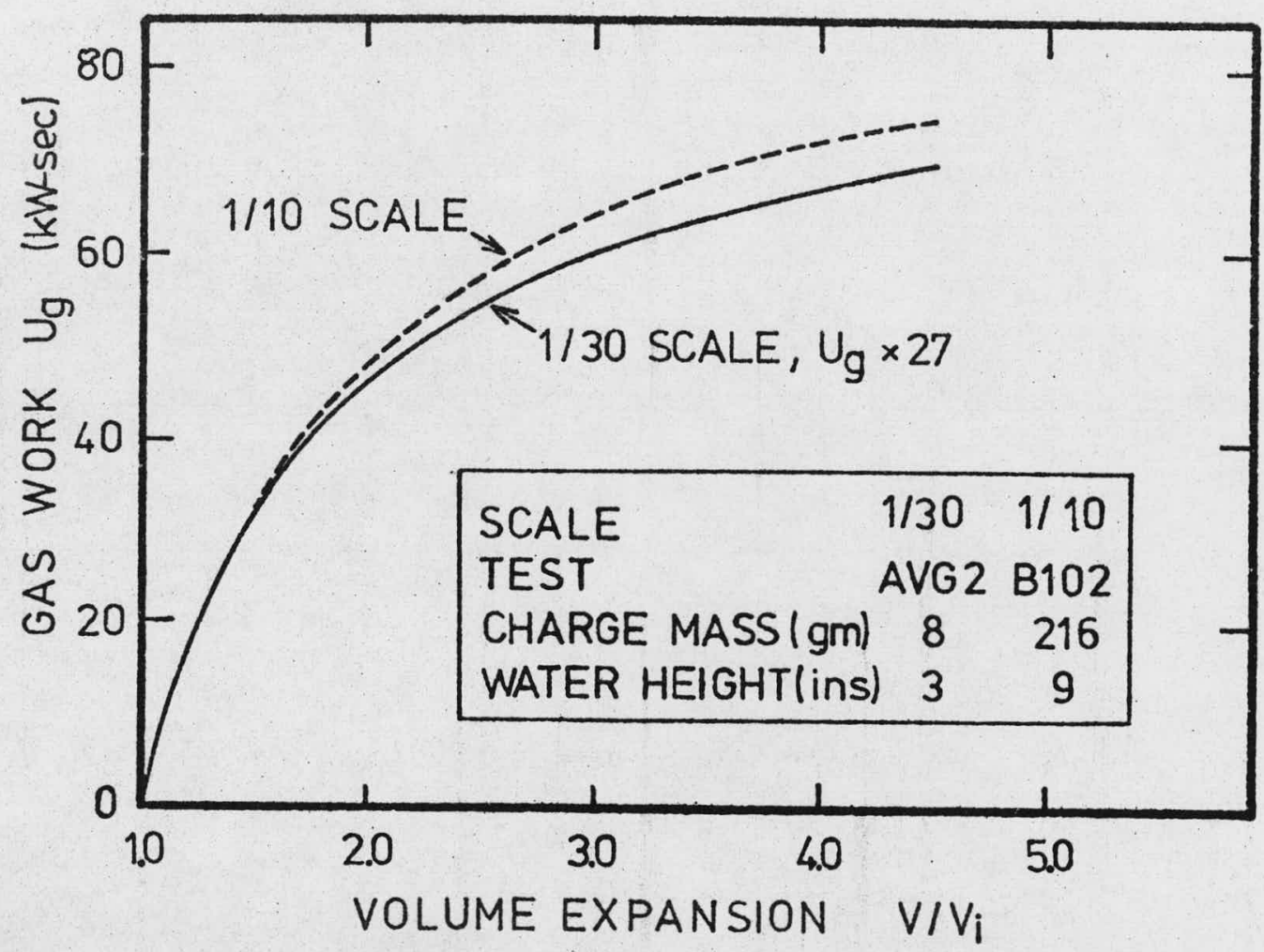

Figure 4.7 Comparison of Gas Work Energy as a Function of the Volume Ratio for Test AVG2 and $\mathrm{Bl} 02$ 


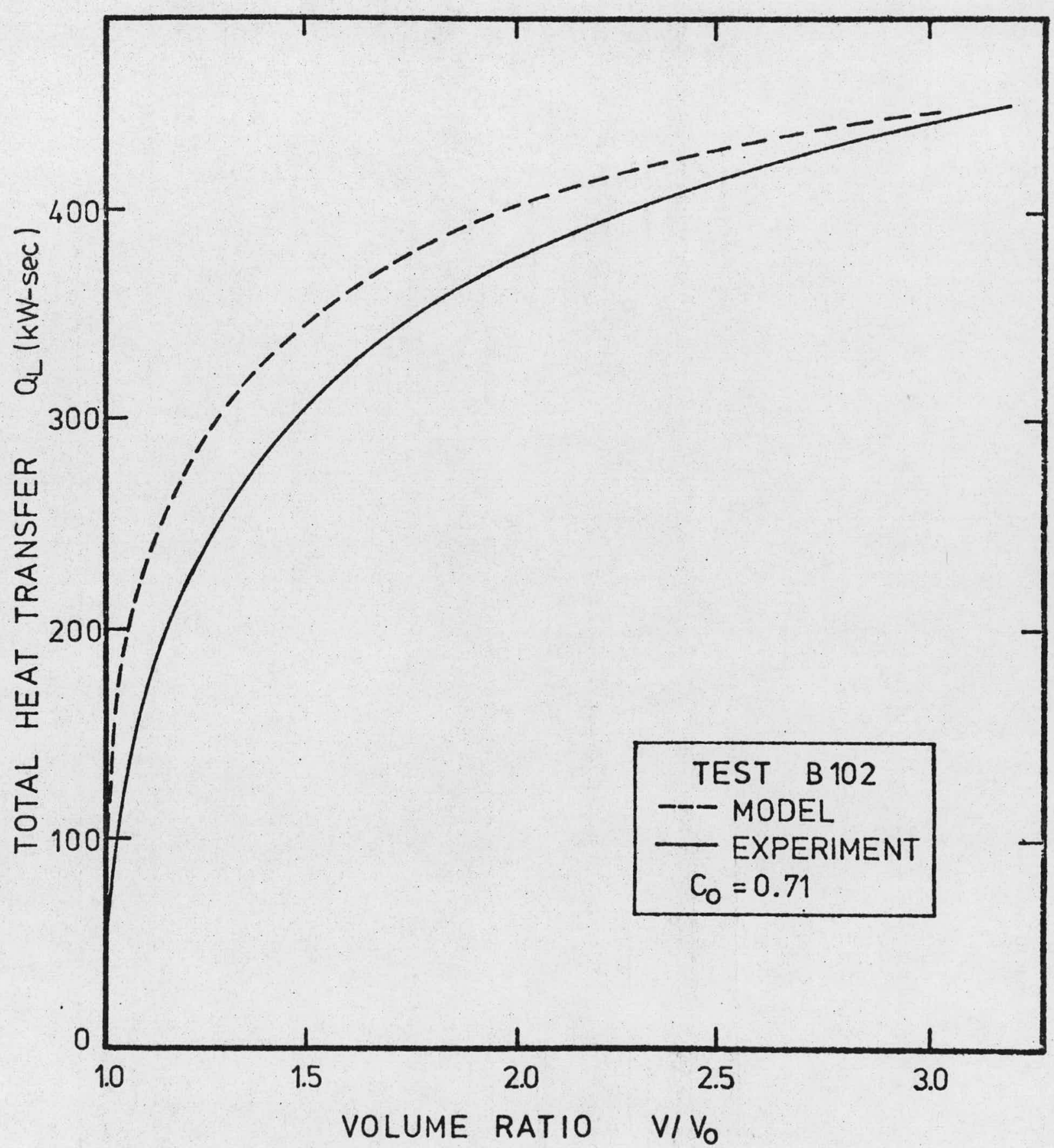

Figure 4.8 Comparison of Total Heat Transfer as a Function of the Volume Ratio for Model and Experimental Results 


\section{Table 4.1}

Piston

Distance

Test
$\vdots$
Al2 24
Al19.
A120 $\therefore 6 \mathrm{~cm}$

\section{Water}

Depth

(inches)

3
4
6 $\begin{aligned} & 1.65 \\ & 1.83 \\ & \end{aligned}$

Time
$\mathrm{V} / \mathrm{v}_{\mathrm{o}}=2.22$

Acceleration Heat Transfer

(msec)

$\left(10^{6} \mathrm{~cm} / \mathrm{s}^{2}\right)$

Rate

(kw-sec)

2633

2500

1428

Piston

Distance

$-10.6 \mathrm{~cm}$

$\mathrm{v} / \mathrm{v}_{\mathrm{o}}=3.14$

Water

Depth Time

Acceleration Heat Transfer

Test No.

(inches) (msec)

$\left(10^{6} \mathrm{~cm} / \mathrm{s}^{2}\right)$

Rate

(kw-sec)

A124

A119

A120

$\begin{array}{ll}3 & 2.25 \\ 4 & 2.15 \\ 6 & 3.4\end{array}$

5.72

4.0

1.0

1294

1000

600 
39

Table 4.2

Determination of Constant

$$
\dot{q}=C_{o} \rho C_{p g}\left(T_{g}-T_{\ell}\right) A_{p} \sqrt{a D_{p}}
$$

Test Al 19

Water Depth - 4 inches

Distance Fixed - $10.6 \mathrm{~cm}$

$$
\begin{aligned}
& \dot{q}=900 \mathrm{kw} \\
& D_{p}=7.62 \mathrm{~cm} \\
& A_{p}=45.6 \mathrm{~cm} \\
& a^{P}=4\left(10^{6}\right) \mathrm{cm} / \mathrm{s}^{2}
\end{aligned}
$$

$$
\dot{\rho}_{\mathrm{g}}=\frac{\text { Mass }}{\mathrm{Vol}}=\frac{5.5 \mathrm{gm}}{706.5 \mathrm{cc}}=.00778 \mathrm{~g} / \mathrm{cc}
$$$$
c_{\mathrm{pg}}=.38 \frac{\mathrm{cal}}{\mathrm{gm}^{\circ} \mathrm{K}}\left(\mathrm{e} 700^{\circ} \mathrm{K}\right)
$$

$$
\begin{aligned}
\mathrm{T}_{\mathrm{p}} & =300^{\circ} \mathrm{K} \\
\mathrm{P} & =14 \text { bars } \\
\mathrm{V} & =706 \mathrm{cc} \\
\mathrm{M} & =.191 \text { gmole } \\
\mathrm{M}_{\mathrm{O}} & =.01005 \text { gmole } \\
\mathrm{T}_{\mathrm{g}} & =\frac{\mathrm{P} \mathrm{V}_{\mathrm{O}}}{\mathrm{P}_{\mathrm{O}} \mathrm{V}_{\mathrm{O}}}=719^{\circ} \mathrm{K}
\end{aligned}
$$

$$
\therefore \quad c_{0}=.76
$$


5 . CONCLUSION AND RECOMMENDATIONS

This study has proposed a simple heat transfer model to analyze quantitatively the heat transfer phenomena from the hot gas mixture to the liquid. The mechanism suggested as the key to the heat transfer process, is area enhancement at the interface due to Taylor instabilities. This equilibrium model agrees with the SRI data reasonably well. The importance though of this model and the overall result extends beyond these scaled experiments.

The primary purpose of the Stanford experiments was to develop a pressure source which modeled the dynamic loading of the reactor vessel of the FFTF. These experiments were compared to the code results of SOCOOL for a FCI during a transient overpower accident." What the analysis of the experiments and the model illustrates is that the proportion of gas work energy to heat transfer from the expanding gas bubble is a ratio of $1: 9$. Thus if the experiments do model the expansion phenomenon as intended, the mechanistic work output due to the expanding gas bubble of TOP accident is almost a factor of ten less than that predicted by present computer models. The results of the heat transfer model development illustrate this conclusion. The partitioning, of internal energy between work and heat transfer does not change with the scale. The proposed model has been shown to scale up with the same proportion as the experimental work output of the tests. 
Since 1971 the question of fuel coolant interaction as a possible source of energetic mechanical damage to the reactor vessel has been questioned. For example, Fauske has argued for oxide fuels, based on the spontaneous nucleation theory, that FCI will not be energetic enough to offer any safety concerns. The HCDA which is being considered as the more limiting accident is the loss of flow accident. As previously described the working fluid for this accident is the fuel. It is envisioned that a two-phase bubble of fuel will expand out of the core to cause the possible mechanical damage to the vessel. In conjunction with this, Stanford Research Institute is continuing its testing of scaled explosions, but with the purpose now of modeling the expansion of fuel vapor.

The important observation to make is that even though the working fluid has changed, the possibility of heat transfer to the cold slug due to area enhancement by Taylor instabilities is still operative. Mechanistically there still is a less dense fluid accelerating against a more dense fluid, and some area enhancement at the interface will occur. The proportion of heat transfer to work output in the internal energy change may be different, but the proposed model would still be a useful tool in predicting the heat transfer behavior. At this time stanford is in the process of developing a new flashing water source to simulate the expansion of fuel vapor and no data comparisons are possible. 
This work then does indicate that there should be a further investigation into the phenomena of large scale energy dissipation due to heat transfer effects in the scaled experiments and possibly in the hupothetical core disruptive accidents. This model which has been shown to predict the SRI experimental results is only a simple first step in the direction of trying to model the heat transfer phenomena between the liquid and the expanding hot vapor. A more in depth investigation should be made into the experimental results of SRI and similar tests and into a more comprehensive model of the heat transfer effects. Some specific areas should be:

Analysis of the transient heat transfer to the cold wall is needed to understand more accurately how energy is partitioned in its transfer from the expanding bubble. This effect is also applicable to the full scale LMFBR.

- Investigation of the characteristic wavelength (L) of the initial disturbance. Henry (13) has suggested that the initial wavelength should be the Taylor unstability wavelength for the initially fastest growing disturbance (see Appendix B).

Some simple experiments similar to Lewis' original ones could be useful in determining this possibility.

- Clarification of the proportion of time during expansion that globule formation occurs in relation to different regimes of heat transfer. This could be attempted by both analytical and experimental means:

- Further analysis of the two phase bubble expansion characteristics in the new experiments, SRI is starting to conduct now in simulation of the Loss of FIOw HCDA. 
A more sophisticated analysis of the heat transfer to the liquid based upon examination of new experimental results and the effects of heat transfer to the cold wall.

- Inclusion of this more developed model into present day accident analys is codes to assess the realistic affects of energy dissipation due to heat transfer in the LMFBR hypothetical accidents. 


\section{APPENDIX A}

\section{SRI Test Results}

The Stanford tests covered a wide range of test conditions to investigate the effect of many of the variables on p-v curve results. The listing of all $1 / 30$ and $1 / 10$ scale tests are included to show the wide range of variables considered.

For the modeling of the SOCOOL results an explosive charge of 8 gms of PETN-microballoon mixture was used to depict the $150^{\circ} \mathrm{MW}-\mathrm{sec}$ expansion in $1 / 30$ scale. "Charge mass scales up like the volume $\left(L^{3}\right)$, thus the mass in $1 / 10$ scale is $216 \mathrm{gm}$ as shown in Table A.3. As a measure of the bounds on the piston kinetic energy, a lower and upper bound were calculated by SRI. The lower kinetic energy value is based on the mass of the piston alone with the measured velocity, whereas the upper limit is the mass of the piston and water in the cylinder. As shown in Table A. 3 the expansion time scales as the inverse of the length scale in the experiments.

Besides the primary purpose of the tests to simulate SOCOOL, two other small investigations were made. Stanford had constructed flexible scale model tests of the FFTF (Fig. A.1) and had to separate the explosive air chamber from the water by a Mylar sheet which upon detonation would break and allow expansion of the bubble. To determine if this method of separation affected the results, it was 
included in the rigid tests as a variable. As Fig. A.2 shows; it affects the work output by increasing it about 108. Physically this could be interpreted as inhibiting the mechanism of Taylor instabilities and the formation of less area for heat transfer. The second topic that was investigates is the effect of the upper fission gas plenum structure within the pressure vessel upon the heat transfer mechanism between the vapor and the liquid. To simulate this steel balls $(.1875 \mathrm{~cm})$ were put with the water in the cylinder and also inserted alone. As Fig. A.3 illustrates, there is less than 58 difference in gas work between the tests with water and the balls and water only. Also, for test with balls alone the gas work is 208 higher than that with water. A conclusion from these tests is that the balls don't appear to inhibit the liquid-gas heat transfer mechanism. Additionally the steel balls alone account for a large decrease (378) in gas work due to cold wall heat transfer in comparison to tests without water.

The final observation is that the scaled tests compare to the output of the socool code reasonably well. Fig. A.4 illustrates the results of the tests with socool results included. 


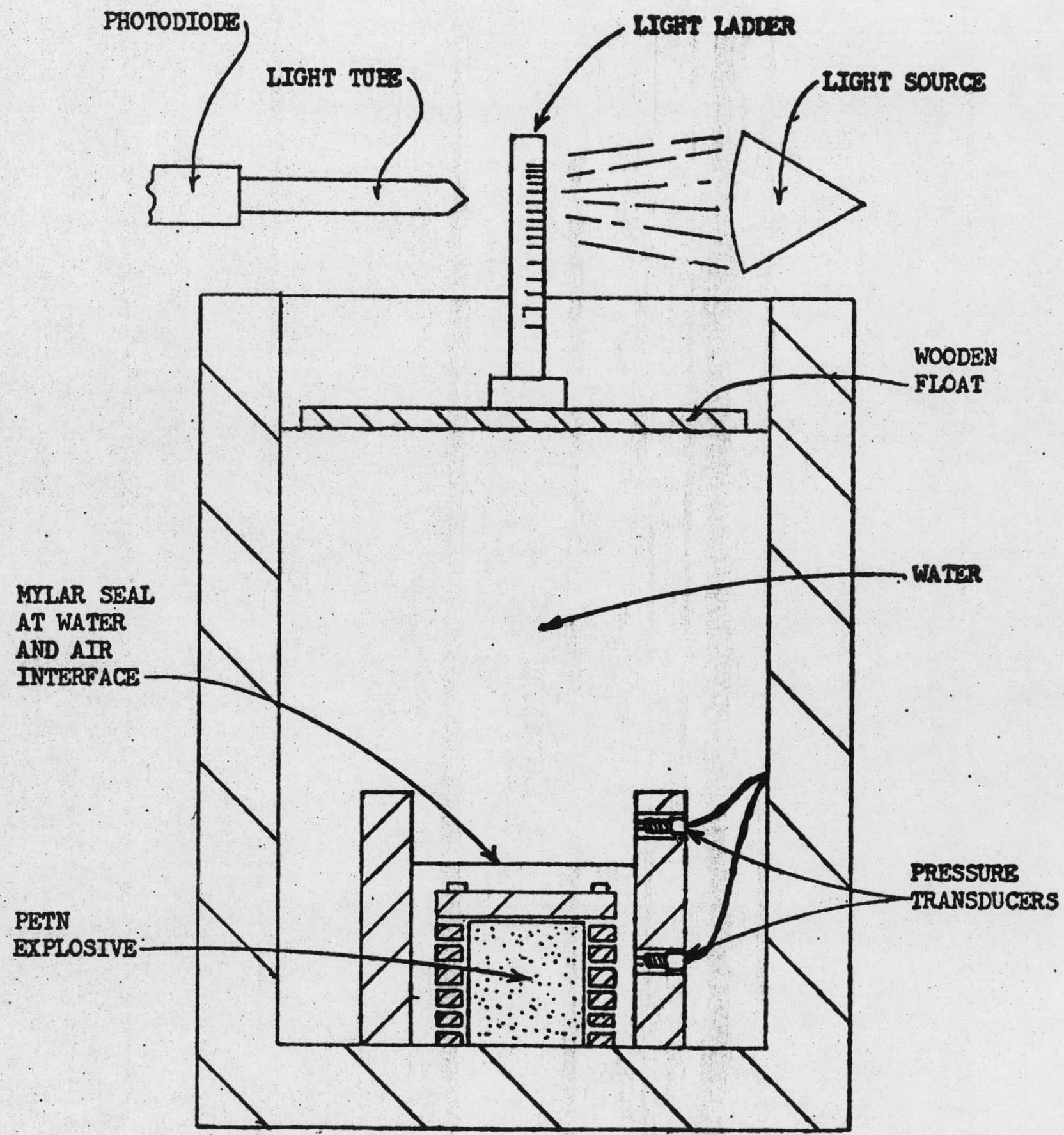

PIGUFE A.1

EXPLOSIVE ENERGI CALIBRATION APPARATUS

$-146$. 


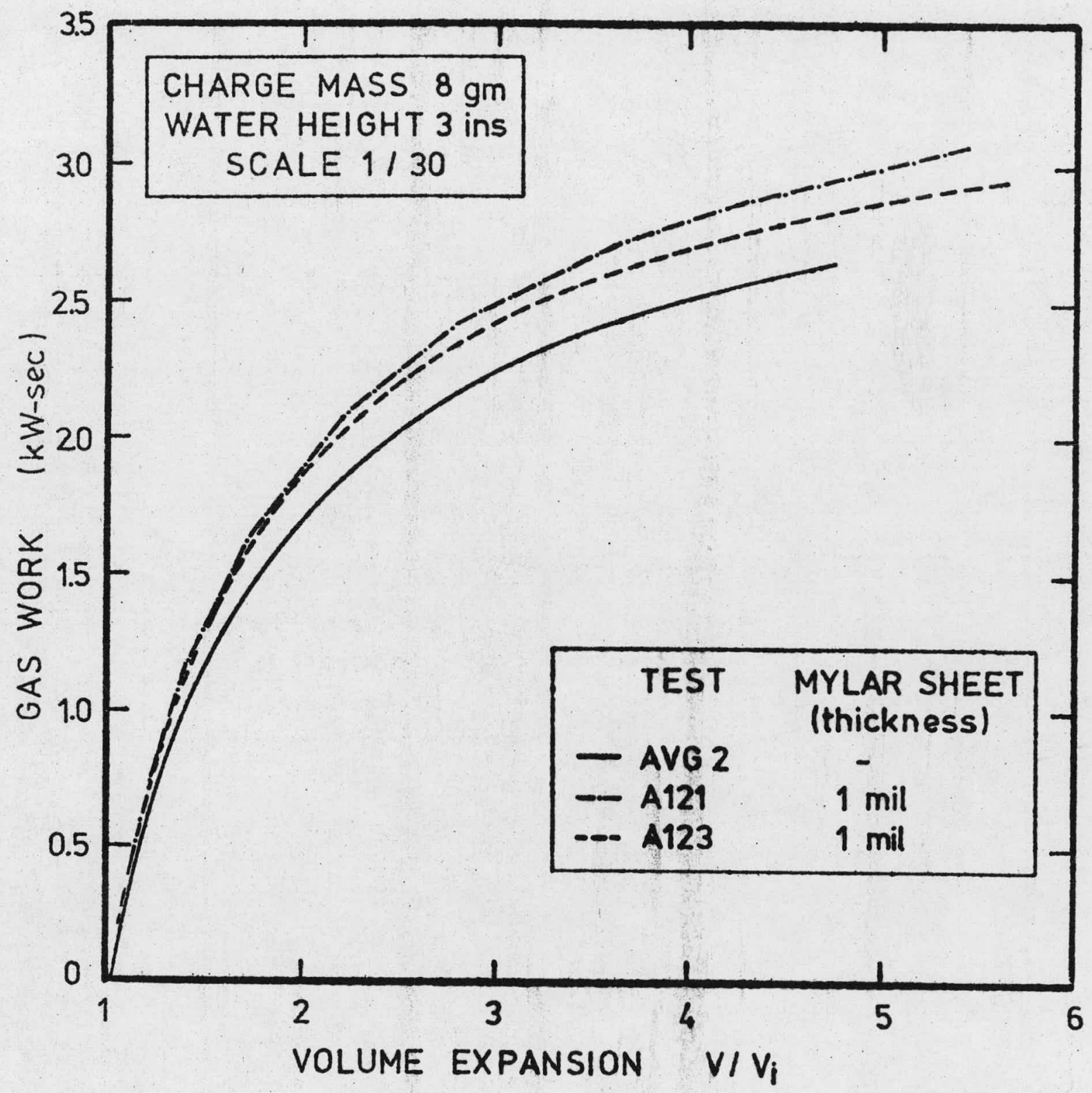

Figure A.2 Gas Work-Volume Ratio Relationship: Mylar Sheet on Water Surface 


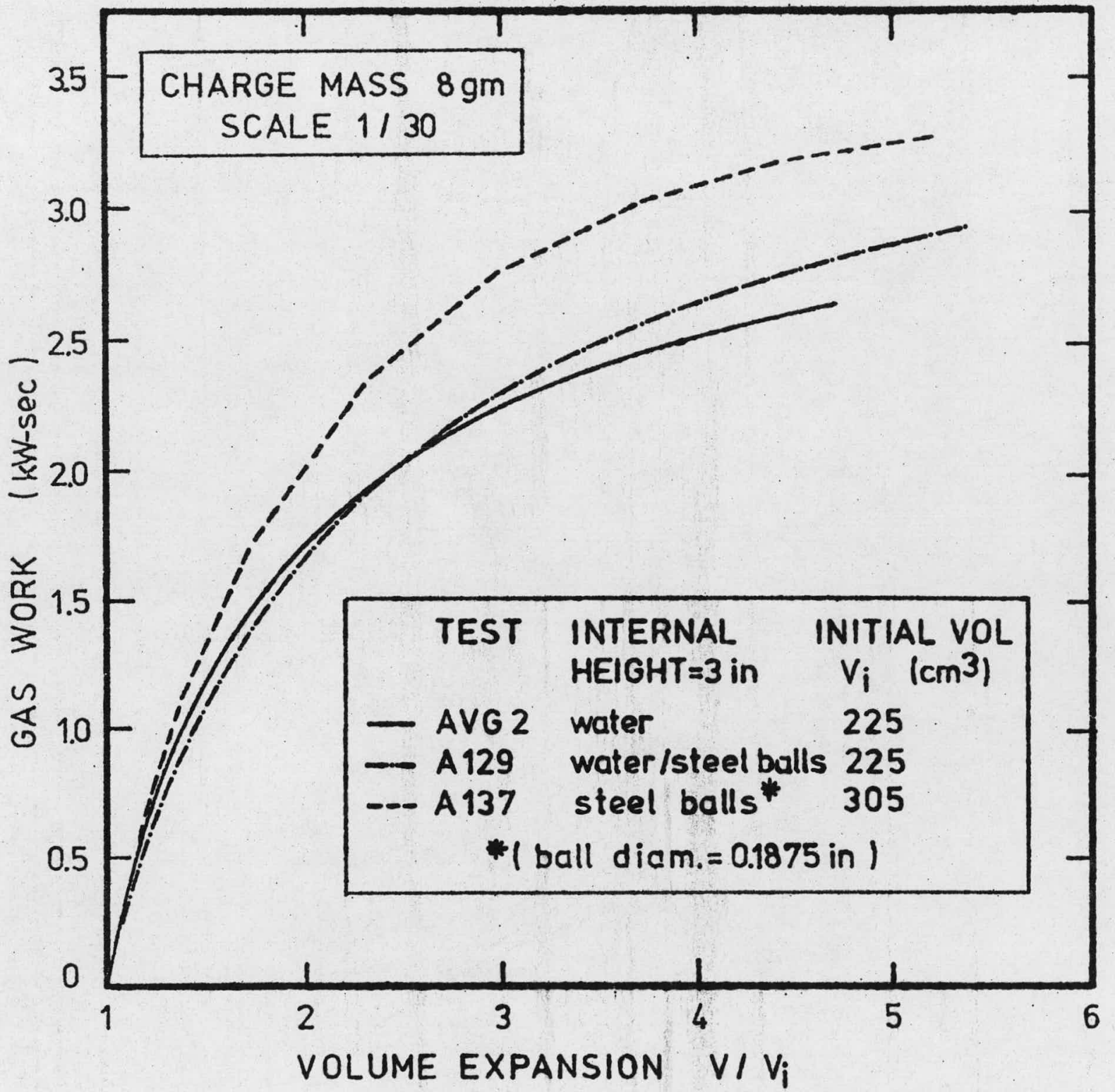

Figure A.3 Gas Work-Volume Ratio Relationship: Effect of Internals 


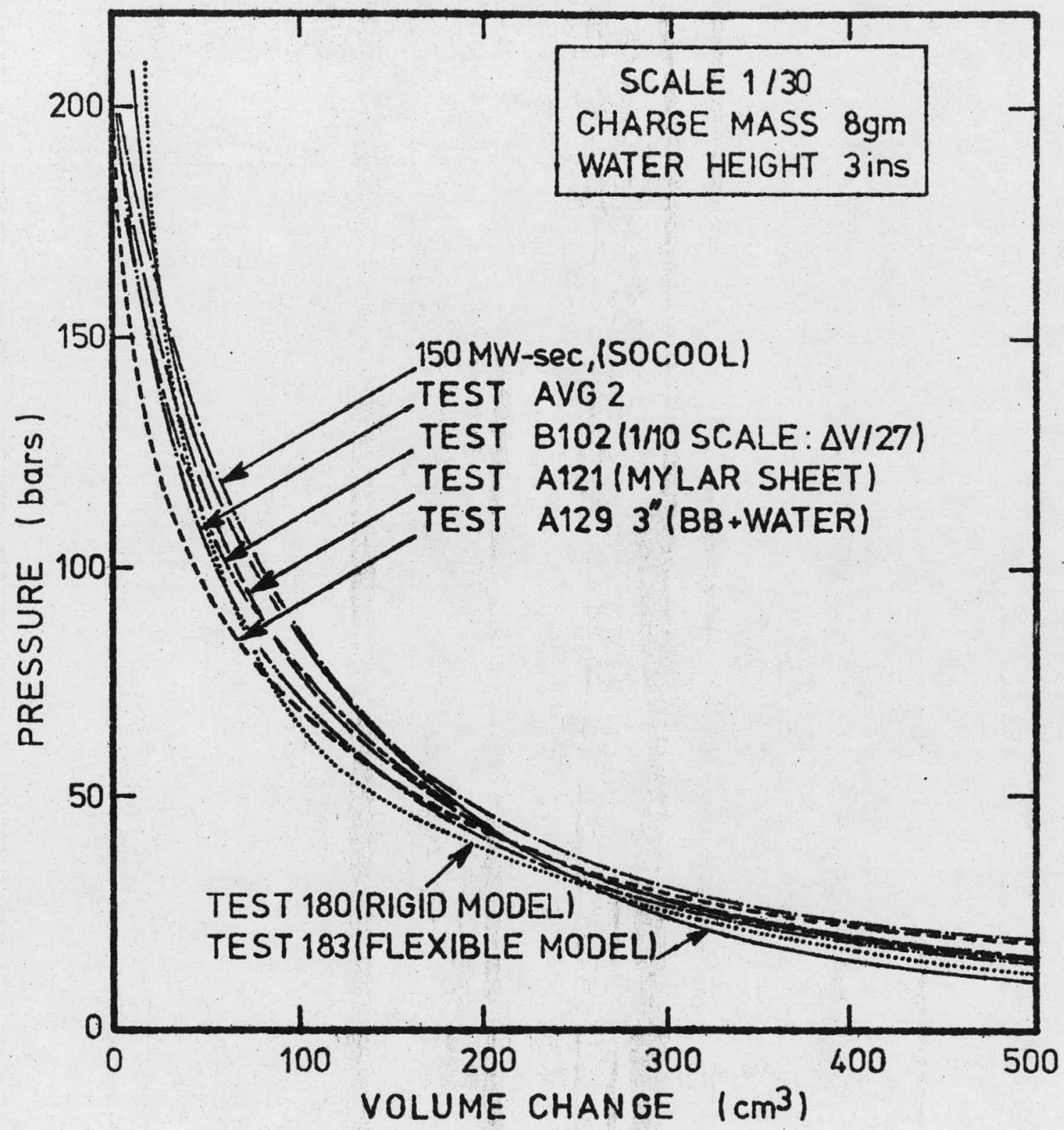

Figure A. 4 Comparison of Pressure-Volume Relationships to SOCOOL Results 
TABLE A.I

1/30-SCALE EXPERIMENTS

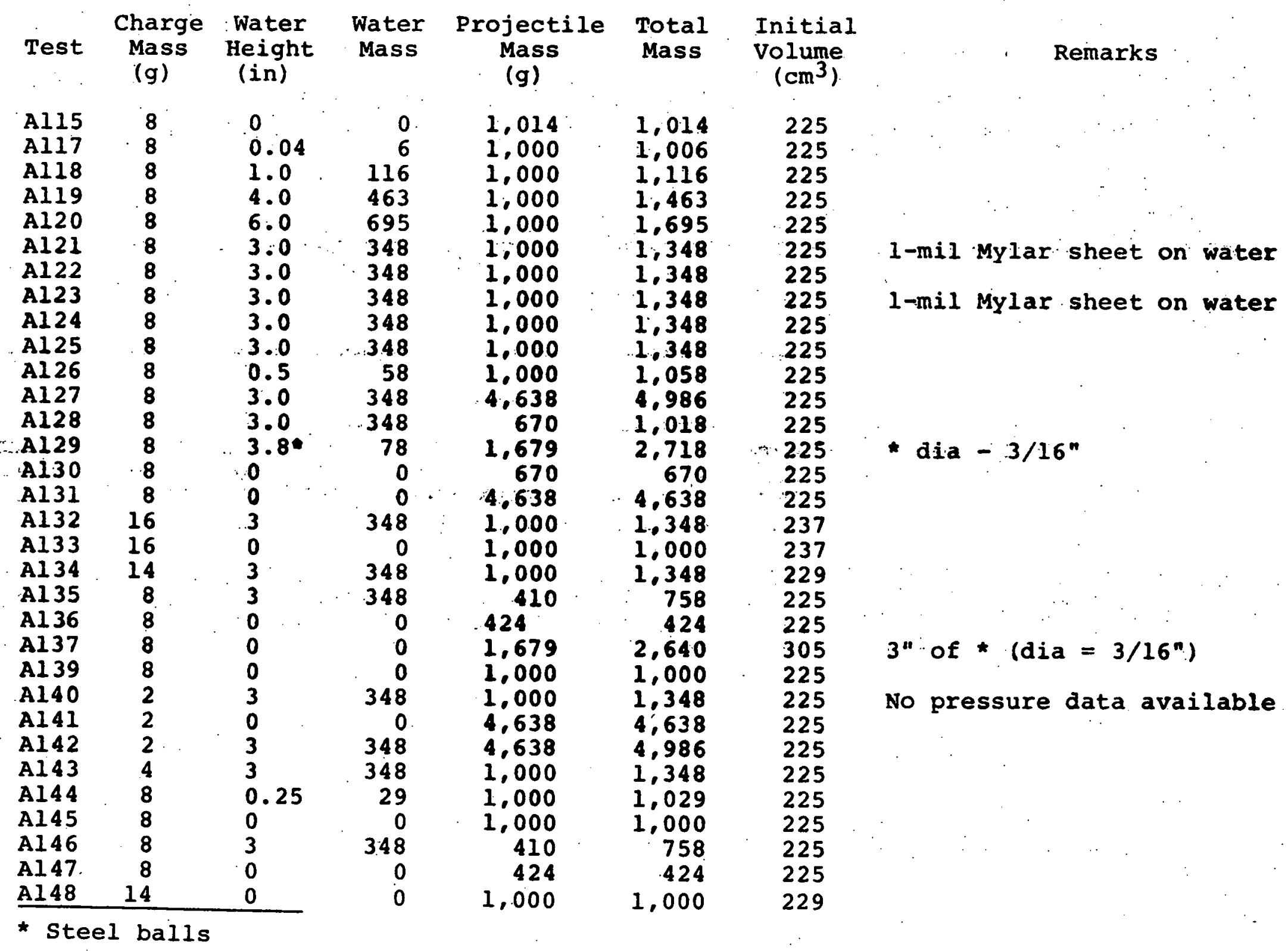


Table A.2

\section{1/10-Scale Experiments}

\begin{tabular}{|c|c|c|c|c|c|c|}
\hline Test & $\begin{array}{l}\text { Charge } \\
\text { Mass } \\
(g)\end{array}$ & $\begin{array}{c}\text { Water } \\
\text { Height } \\
\text { (in.) }\end{array}$ & $\begin{array}{l}\text { Water } \\
\text { Mass } \\
(g)\end{array}$ & $\begin{array}{c}\text { Projectile } \\
\text { Mass } \\
(\mathrm{g})\end{array}$ & $\begin{array}{l}\text { Total } \\
\text { Mass } \\
(g)\end{array}$ & $\begin{array}{l}\text { Initial } \\
\text { Volume } \\
(\mathrm{cm} 3)\end{array}$ \\
\hline 101 & 216 & 9 & 9,380 & $27: 480$ & 36,860 & 6.026 \\
\hline 102 & 216 & 9 & 9,380 & 27,480 & 36,860 & 6,026 \\
\hline 103 & 216 & 9 & 9,380 & 27,480 & 36.860 & $6,026^{+}$ \\
\hline 104 & $216^{\circ}$ & 12 & 12,510 & 27,480 & 39,990 & 6.026 \\
\hline 3105 & 216 & 1.5 & 1,560 & 27,620 & 29,180 & 6,026 \\
\hline 106 & 216 & 0 & 0 & 27,620 & 27,620 & 6.026 \\
\hline 107 & 216 & $9 *$ & 2,100 & 37,850 & 72.150 & $6,070^{8}$ \\
\hline B108 & 216 & 9 & 9,380 & 10,690 & 20,070 & 6,026 \\
\hline B109 & 216 & 0 & 0 & $10 ; 830$ & 10,830 & 6,026 \\
\hline 110 & 378 & 9 & 9,380 & 27,530 & 36,910 & 6,026 \\
\hline 111 & 378 & 0 & 0 & 27,690 & 27.690 & 6.026 \\
\hline 112 & 378 & 9 & 9,390 & 27530 & 36,910 & 6,026 \\
\hline
\end{tabular}

* Steel balls

${ }^{+} 3-\mathrm{mil}$ Mylar sheet on water

"Steel balls diameter - 9/16" 
Table A. 3

Work Energy - Scaling Results at $V / v_{i}=3.14$

Slub slug

Kinetic Kinetic

Charge water upper Energy

Test scale Mass : Height Bound Bound

(g)

(in.)

$(\mathrm{kW}-\mathrm{sec})$

$(\div 27)$

$(k w-s e c)$

$(\div 27)$

Gas Time Work Scale Remarks

(kW=sec) (msec)

$(\div 27)$

AVG $1 \quad 1 / 30$

8

0

4.88

4.88

(4. 45)

(4. 45)

$(4.66)$

(4.45).

3.07

2.90

(2.85)

(2.70)

2.82

2.10

(2.72)

(2.06)

2.85

(2.73)

1.94

(1.86)

3.11

2. 31

2.73

(2.58)

2.32

(2.44)

2. 51

(2.41)

2.60

3.00

1.85

2.38

(1. 71)

(2. 30)

B107 1/10

216

$9 *$

(3.28)

0

5.06

5.06

5.06

B109 $1 / 10$

21.6

0

(4.74)

$(4.74)$

(4.74)

3.55

(2.86)

$$
1.92
$$

2.41

(1.52)

(2.48)

8.47

8.47

8.47

(8.19)

$(8.19) \quad(8.19)$

BIII $1 / 10 \quad 378$

0

$(8.19)$

5.21

(5. 37) $x^{+}$from specific impulse

2.07

6.44

2.39

7.18

2.50

7.48

2.27

1-mil Mylar sheet on water

3.27 Steel ball dia $=3 / 16^{\prime \prime}$

10.2 Steel ball dia $=9 / 16^{\prime \prime}$

$x$ from specific impulse

3. $30 \times$ from specific impulse

1.71

5.33

$1.31 \times$ from specific impulse

$4.03 \times$ from specific impulse

\begin{tabular}{llr} 
A134 & $1 / 30$ & 14 \\
B112 & $1 / 10$ & 378 \\
\hline
\end{tabular}

$\begin{array}{cc}3.87 & 4.00 \\ (4.00) & (4.74)\end{array}$

$(4.00) \quad(4.74)$

${ }^{+} \mathbf{x}=$ projectile displacement 


\section{APPENDIX B \\ Brief Review of Taylor Instabilities}

In 1950 Sir Geoffrey Taylor advanced a mathematical description [9] of a commonplace phenomenon. When a less dense fluid is accelerated into a more dense fluid $\left(\rho_{2}>\rho_{1}\right)$ and the interface has some initial disturbance (see Fig. B.1), the amplitude of the disturbance will grow rapidly with time. If the acceleration occurs in the opposite direction (from more dense to less dense time) the disturbance will smooth out into a flat:surface. A good example of this is swinging a bucket of water in a vertical circle. In this case the centripetal acceleration is from the water to the air and the interface is flat. But if the bucket is help upside down the acceleration of gravity is from the air to the water and the interface breaks up allowing the water to fall to the ground.

Mathematically Taylor presented the phenomenon by looking at the linearized hydrodynamic equations:

$$
\begin{aligned}
& \text { continuity } \quad \frac{d u}{d x}+\frac{d v}{d y}=0 \\
& x-\text { mom } \\
& \frac{d u}{d t}+\frac{1}{p} \frac{d p}{d x}=0 \\
& y \text {-mom } \frac{d v}{d t}+\frac{1}{\rho} \cdot \frac{d p}{d y}+g+g_{1}=?
\end{aligned}
$$

where $u$ and $y$ are the velocities in the $x$ and $y$ directions respectively and $g_{1}$ is the external acceleration. Taylor 
obtained expressions for the pressure, velocity in both media and the amplitude of the disturbance as a function of space and time. References 9 and 10 give the mathematical details of his analysis. The important point in relation to this study is that Taylor identified the first stage of growth of the amplitude $(n)$ of the initial disturbance and it is of the form

$$
\eta=\frac{2 \pi}{\lambda} f(n t) \cos \frac{2 \pi x}{\lambda}
$$

At any $\mathbf{x}$ the amplitude $n$ is a function of the wavelength of the initial disturbance $(\lambda)$, the time $(t)$, and the parameter $n$. This parameter $(n)$ is a combination of the fluid properties and the directional acceleration of the interface such that

$$
n=\frac{2 \pi\left(g+g_{1}\right)\left(\rho_{1-} \rho_{2}\right)}{\lambda\left(\rho_{1}+\rho_{2}\right)}
$$

If $\rho_{2}>\rho_{1}$ (Fig. B. 1 ) then $n$ is a real number and $f(n t)$ grows exponentially and conversely for $\rho_{1}>\rho_{2}$ it dies away. Lewis. [11] in conjunction with Taylor's analysis ran a series of small experiments in a glass enclosure to verify. Taylor's results and to observe the whole phenomenon. His results verified the mathematical analysis of Taylor but also indicated that three distinct phases to the instability exist. Initially as Taylor described the amplitude of the disturbance increases exponentially. But this only occurs until $n \simeq .4 \lambda$. Secondly a transition phase exists between $.4 \lambda<\eta<\lambda$ where the growth in amplitude is decelerated to 
a constant velocity. Finally for $\eta>\lambda$ the amplitude's growth velocity is proportional to $\sqrt{\left(g_{1}-g\right) \lambda}$, with the constant of proportionality close to one: This final "stage of growth is what is used in the heat transfer model, because the amount of area enhancement is so large that it is the predominant stage of the amplitude growth during heat transfer.

What Taylor neglected in his analysis was the effect of the curved interface and viscosity. Bellman and Pennington [10] in 1953 reviewed Taylor's results and included these effects. Relevant to this study is their analysis of a minimum critical wavelength for a disturbance below which the amplitude will not grow. Given the same configuration as in Fig. B. 2 with the acceleration from the less dense to the more dense the pressure difference due to curved interface is

$$
\left(p_{1}-p_{2}\right) d s=\sigma \sin (d \theta) \simeq \sigma d \theta
$$

and from geometry

$$
\frac{d \theta}{d s}=\frac{1}{R} \quad \frac{d^{2} n}{d x^{2}}
$$

This gives

$$
p_{2}-p_{1}+\sigma \frac{d^{2} n}{d x^{2}}=0
$$

Using the same hydrodynamic analysis as Taylor, they obtained an expression for the parameter $n$ which is

$$
n^{2}=\frac{+\left(g+g_{1}\right)\left(\rho_{2}-\rho_{1}\right)^{2}}{\left(\rho_{1}+\rho_{2}\right) \lambda}-\frac{\sigma}{\rho_{1}+\rho_{2}} \cdot\left(\frac{2}{x}\right)^{3}
$$


For the amplitude to increase as Taylor illustrated $\mathrm{n}$ must be real $\left(\rho_{2}>\rho_{2}\right)$. This implies that the righthand side of (B.6) must be greater than zero. Solving for the critical wavelength $\left(\lambda_{c}\right)$, the result is

$$
\lambda_{c}=2 \pi\left[\frac{\sigma}{\left(g+g_{1}\right)\left(\rho_{2}-\rho_{1}\right)}\right]^{1 / 2}
$$

This is the lower bound on the initial disturbance caused by the explosive source which will be unstable. As Table. B.l illustrates this size is very small in comparison to the diameter of the piston. Therefore, it is very probable that the initial disturbance of the explosive pressure source is of a size (L) greater than $\lambda_{c}$ and any surface distortion wịll grow.

The velocity of the amplitude $(n)$ can be specified for both the initial $(n<\lambda)$ and final stage $(\lambda<n)$ of growth. In the first stage of growth Taylor [9] expresses the amplitude as a function of time as

$$
\frac{n}{n_{0}}=\cosh \left[\frac{2 \pi}{\lambda}\left(g+g_{1}\right)\left(\frac{\rho_{2}-\rho_{1}}{\rho_{2}+\rho_{1}}\right)\right]^{1 / 2} t
$$

where the initial disturbance is taken as

$$
n_{0}=A \cdot \cos \frac{2 \pi x}{\lambda}
$$

For the case where $\rho_{2}$ (water) $>\rho_{1}$ (air) this simplifies to

$$
\frac{n}{n_{0}}=\cosh \left[\frac{2 \pi}{\lambda}\left(g+g_{1}\right)\right]^{1 / 2} t
$$


Therefore the velocity is expressed as

$$
\begin{aligned}
\frac{d}{d t}\left(\frac{n}{n_{0}}\right) & =\left[\frac{2 \pi}{\lambda}\left(g-g_{1}\right)\right]^{1 / 2} \sinh \left[\frac{2 \pi}{\lambda}\left(g+g_{1}\right)\right]^{1 / 2} t \\
& \simeq \frac{2 \pi}{\lambda}\left(g+g_{1}\right) t \\
\frac{d n}{d t} & \simeq n_{0} \frac{2 \pi}{\lambda}\left(g+g_{1}\right) t
\end{aligned}
$$

This is the velocity of the disturbance when $n<.4 \lambda_{0}$. It should be noted again that Taylor assumed no surface tension effects here. So if $n_{0}$ is constant then the initial velocity increases as $\lambda$ decreases. If these surface tension effects are included as Bennington did [10] then it is found that a minimum wavelength for growth (equation B. 7 for $\lambda_{c}$ ) exists as well as a fastest growing wavelength $\left(\lambda_{m}=\sqrt{3} \lambda_{c}\right)$ for this stage of growth.

As the amplitude increases $(\eta \approx .4 \lambda)$ the nature of growth changes to one of constant velocity

$$
\frac{d \eta}{d t} \simeq \sqrt{\left(g+g_{1}\right) \lambda}
$$

In this stage of growth the velocity is proportional to the size of the initial disturbance, (L) so that as $L$ increases $(d n / d t)$ increases. This makes physical sense because it parallels the concept of the bubble rise velocity $(\sqrt{g D})$ used in two phase flow.

It has been suggested that by Epstein [5] and Henry 
[13] that this characteristic wavelength used in the model should be the wavelength at which the initial growth rate of the amplitude is a maximum. This occurs when $L=\sqrt{3} \lambda_{c}$, where $\lambda_{c}$ is the critical wavelength of a Tayior instability. This is based on the fact that some small scale experiments (where a differential pressure accelerated the liquid). show only these size disturbances growing in amplitude.. The situation in the SRI experiment appears to be different." The explosive charge creates the disturbance at the interface due to the violent release of the reactant gases. Because of this the first stage of amplitude growth of these disturbances seems to be caused by the impact of the pressure wave and not by the initial growth phase of the Taylor instability. This would then give disturbances of larger magnitudes the chance to grow with equal opportunity, thereby allowing the larger ones to grow with the greatest velocity. Since a spectrum of disturbance wavelengths is expected, the assumption that $\mathrm{L}=\mathrm{K}_{4} \mathrm{D}_{\mathrm{p}}$ is used in the analysis. 


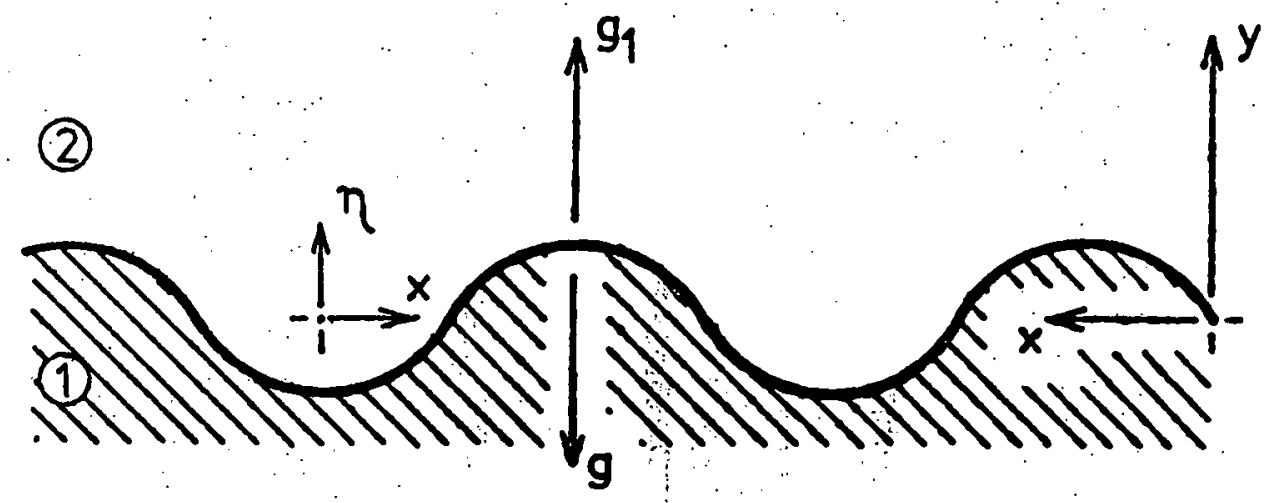

$\mathbf{g}_{\mathbf{p}}>\mathbf{9}$

Figure B.1 Taylor Instability Model for Interface between Two Fluids 


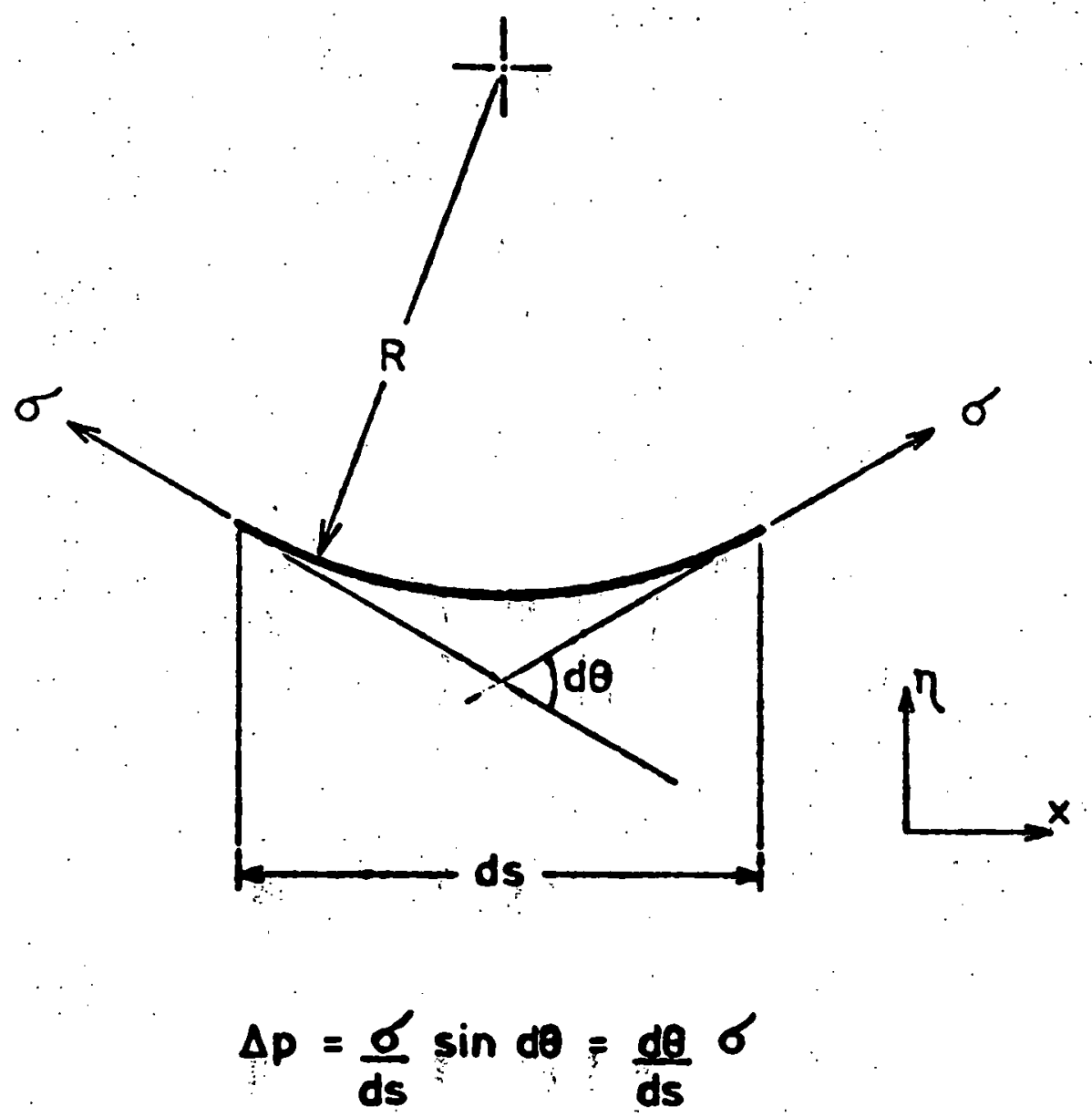

$\frac{d \theta}{d s}=\frac{1}{R}=\frac{d^{2} \eta}{d x^{2}}$

$$
\Delta p=\sigma \frac{d^{2} p}{d x^{2}}
$$

Figure B.2 Effect of Surface Tension on Taylor Instability Criterion: 


\section{Table B.1}

Critical size of Initial Disturbance for Taylor Instability

$$
\lambda_{c}>2 \pi \sqrt{\frac{\sigma}{a\left(\rho_{p}-\rho_{v}\right)}} \sim 2 \pi \sqrt{\frac{\sigma}{\rho_{p} a}} \quad \text { (eqn. B.7) }
$$

$\begin{array}{cccccc} & \begin{array}{c}\text { Temp } \\ (\rho \mathrm{C})\end{array} & \begin{array}{c}\rho \mathrm{p} \\ (\mathrm{g} / \mathrm{cc})\end{array} & \begin{array}{c}\sigma \\ (\text { dyne } / \mathrm{cm})\end{array} & \begin{array}{c}\mathrm{a} \\ \left(\mathrm{cm} / \mathrm{s}^{2}\right)\end{array} & \begin{array}{c}{ }_{\mathrm{c}} \mathrm{c} \\ (\mathrm{cm})\end{array} \\ \text { Water } & 27 & 1 & 70 & 6.4\left(10^{6}\right) & .02 \\ \text { Sodium } & 200^{\circ} \mathrm{C} & .90 & 188 & 6.4\left(10^{6}\right) & .036 \\ & 500^{\circ} \mathrm{C} & .83 & 156 & 6.4\left(10^{6}\right) & .034 \\ & 800^{\circ} \mathrm{C} & .76 & 126 & 6.4\left(10^{6}\right) & .032 \\ & 950^{\circ} \mathrm{C} & .72 & 111 & 6.4\left(10^{6}\right) & .0307\end{array}$


APPENDIX C

\section{1 Calculation of Heat Transfer to Liquid}

To calculate the heat transferred to the liquid from the experimental results, the governing equation for the system of the expanding gas is

$$
\Delta U=\Delta Q_{I}+\Delta Q_{W}-\Delta W
$$

where $\Delta W$ is the work output of the gas expansion in the form of kinetic energy of the piston and friction, $\Delta Q_{W}$ is the heat transferred to the cold cylinder wall, $\Delta Q_{I}$ is the total heat transferred to the liquid water, and $\Delta U$ is the change in internal energy of the gas.

The chemical reaction for the explosive PETN is

$$
\mathrm{C}_{5} \mathrm{H}_{8} \mathrm{O}_{12} \mathrm{~N}_{4}+3 \mathrm{CO}_{2}+2 \mathrm{CO}+4 \mathrm{H}_{2} \mathrm{O}+2 \mathrm{~N}_{2}
$$

The resulting gas mixture behaves nearly as a perfect gas $(T=p V / n R)$ as Table $C .6$ shows and the change in internal energy is then

$$
\Delta U=\int_{T_{0}}^{T}(t) c_{v} d T^{T}
$$

Also it is krown that

$$
c_{v}=c_{p}-R
$$

The specific heat $\left(c_{p}\right)$ is a function of temperature and can be expressed as

$$
c_{p}=c_{0}+c_{1} T+c_{2} T^{2}+\cdots
$$


Table C. 7 gives representative constants for equation (C.5) and for the range of temperatures gives examples of the calculation of $c_{p}$ and $c_{v}$. By evaluating the new $c_{p}$ and the equilibrium concentration of each constituent at a temperature the internal energy can be calculated at each stage of the gas expansion.

To evaluate the heat transfer to the cold wall, Holten [4] suggests a correlation which he formulated from the SRI test results. The major assumption that is made is that the area available for heat transfer to the cold wall is only the original surface area exposed to the air. The assumption is somewhat arbitrary in the sense that the partitioning of heat transferred between the wall and the water is difficult to distinguish. A lower bound of heat transfer to the wall is used in this analysis. After the detonation the water will most likely wet the cylinder walls as the piston moves downward, thus allowing heat transfer mainly to the water on the wall. The relation used is

$$
\ddot{q}_{W}=A_{s}\left|\frac{2912}{x(c m) t .573}-60.3\right| \frac{c a l}{s}
$$

To obtain the total heat transfer to the wall the equation is numerically integrated over time to get

$$
\left.\Delta \ddot{Q}_{W}=\sum_{t_{i}} \frac{\dot{q}_{W}\left(t_{i}\right)+q_{W}\left(t_{i}-1\right)}{2}\left(t_{i}-t_{i-1}\right) \quad \text { (c. } 7\right)
$$


The work output of the rigid piston-cylinder is directly measured by the test results for pressure and volume. To determine the heat transferred to the liquid, all the previous quantities are inserted into equation (c.l) and $\Delta Q_{L}$ is solved for. There is one tacit assumption in this calculational procedure: no liquid water is vaporized because of the heat transfer to it from the gas. The reason for this assumption can be seen by a simple energy balance. If the initial state of the gas is allowed to come to equilibrium with the water the equation relating this is

$$
{ }^{\rho}{ }_{g} C_{p_{g}}\left(T_{g}-T_{e}\right) V_{o}=\rho_{W} C_{p_{W}}\left(T_{e}-T_{W}\right) A_{p} d
$$

where $T_{e}$ is the final temperature of the two fluids, $d$ is the depth of water involved, and $v_{0}$ the initial volume of gas. For representative values of

$$
\begin{aligned}
& \mathrm{T}_{\mathrm{g}} \quad=3000^{\circ} \mathrm{K} \\
& T \text { (for liquid) } \\
& =300^{\circ} \mathrm{K} \\
& \mathrm{A}_{\mathrm{p}} \quad=45.6 \mathrm{~cm}^{2} \\
& \mathrm{~d}=1 \mathrm{~cm} \text { (total depth of water is usually } 8 \mathrm{~cm} \text { ) } \\
& \mathrm{v}_{\mathrm{O}} \quad=225 \mathrm{~cm}^{3} \\
& \rho_{g} / \rho_{W}=.025 \\
& \mathrm{C}_{\mathrm{pg}} / \mathrm{C}_{\mathrm{pw}}=.24 \\
& \therefore \mathrm{T}_{\mathrm{e}}=370^{\circ} \mathrm{K} \text {. This illustrates that even for a very } \\
& \text { small depth of water all the energy of the gas will not }
\end{aligned}
$$


vaporize it. What the assumption does in the calculation is set the minimum amount of heat transfer to the liquid. The reason for this is that if water were vaporized during the expansion, the change in internal energy would increase by the same amount as the heat transfer to the liquid would increase. Therefore the limit on the maximum decrease in internal energy also rises with water vaporization. So the assumption appears to be a reasonable one and in any event a conservative one.

\section{2 Functional Dependence of Acceleration}

The first method used to compare the model proposed and SRI results is to obtain the heat transfer rate $(\dot{q})$ at different accelerations (a) and determine the functional dependence of $\dot{q}$ on a. Three tests (A119, A120, A124) are used to do this. All are at the $1 / 30$ scale and use $8 \mathrm{gm}$ of the PETN-microballoon explosive." The change in internal energy, work and heat transfer to the liquid for these three tests are illustrated in Figs. C.1 and C.2, using the methods described in. Section C.1. The difference between the three tests is the water depth in each which causes a change in the acceleration. To determine the heat transfer rate the approximation is made

$$
\frac{d q}{d t} \doteq \frac{Q(t+\Delta t)-Q(t-\Delta t)}{2 \Delta t}
$$

The object of this comparison is to $f i x$ the other parameters in the model and vary the acceleration to determine its functional relation to $\dot{q}$. This can be done by fixing the volume 
ratio at which each $\dot{q}$ is measured. At a fixed volume ratio the quantity ${ }^{\rho} \mathrm{g}^{\mathrm{C}} \mathrm{pg}^{\Delta T}$ is approximately equal for all three tests. Then the model can be written as

$$
\ln \dot{q}=\ln k+m \ln a
$$

where $K=C_{o} \rho_{g}^{c} c_{p g} \Delta T A_{p} I^{m}$. The parameter $m$ is the functional dependence that is to be found from the SRI data. The model proposes $m=.5$.: To determine the acceleration (a) the piston displacement versus time is plotted in Fig. c. 3 and a curve fit is made of the data $\left(a=d^{2} x / d t^{2}\right)$. The results of this analysis is presented in section 4 of the report.

C. 3 Integral Comparison of the Data to Model

The purpose of this section is to present the detailed calculations for the integral comparisons made between the proposed heat transfer model and the experimental results. There are four tests which are compared to the heat transfer model. A summary of the test conditions and results are shown in rables C.2 to C.5. Section C.I gives the method of calculating the heat transferred to the liquid $\left(\Delta Q_{L}\right)$ by an overall energy balance. The only other calculational technique used is a time smoothing of the pressure measurements, as a means of determining the initial average pressure in the cylinder after the explosion has occurred.

At the beginning of the experiment there are noticeable pressure oscillations within the cylinder. An averaging 
technique is used to determine the correct temperature in the cylinder. As Fig. C.5 shows the product $p-v$ is plotted versus time until a smooth curve results. Then this curve is extrapolated back in the oscillatory region to obtain an estimation of $\mathrm{pv}$ and subsequently the initial temperature by perfect gas relations.

- For calculation of the overall heat transfer to the liquid from the proposed model, the model is numerically integrated as

$$
\Delta Q_{L}=\int_{t_{0}}^{t} q d t=\sum_{t} \frac{\dot{q}\left(t_{i}\right)+\dot{q}\left(t_{i-1}\right)}{2}\left(t_{i}-t_{i-1}\right)
$$

where $\dot{q}=C_{0} \rho_{g} C_{p g}\left(T_{g}-T_{\ell}\right) A_{p} \sqrt{a D}$

To calculate the acceleration the same technique that has been previously mentioned is employed, The displacement versus time is plotted for all the tests on Fig. C.4. From this a curve fit is made of the data to obtain $x=f(t)$. The acceleration is obtained by differentiation. Tables C. 2 to C. 5 provide the tabular results for all the tests while the remaining Figs. C. 7 to C.10 give the Stanford data for each of the tests. 


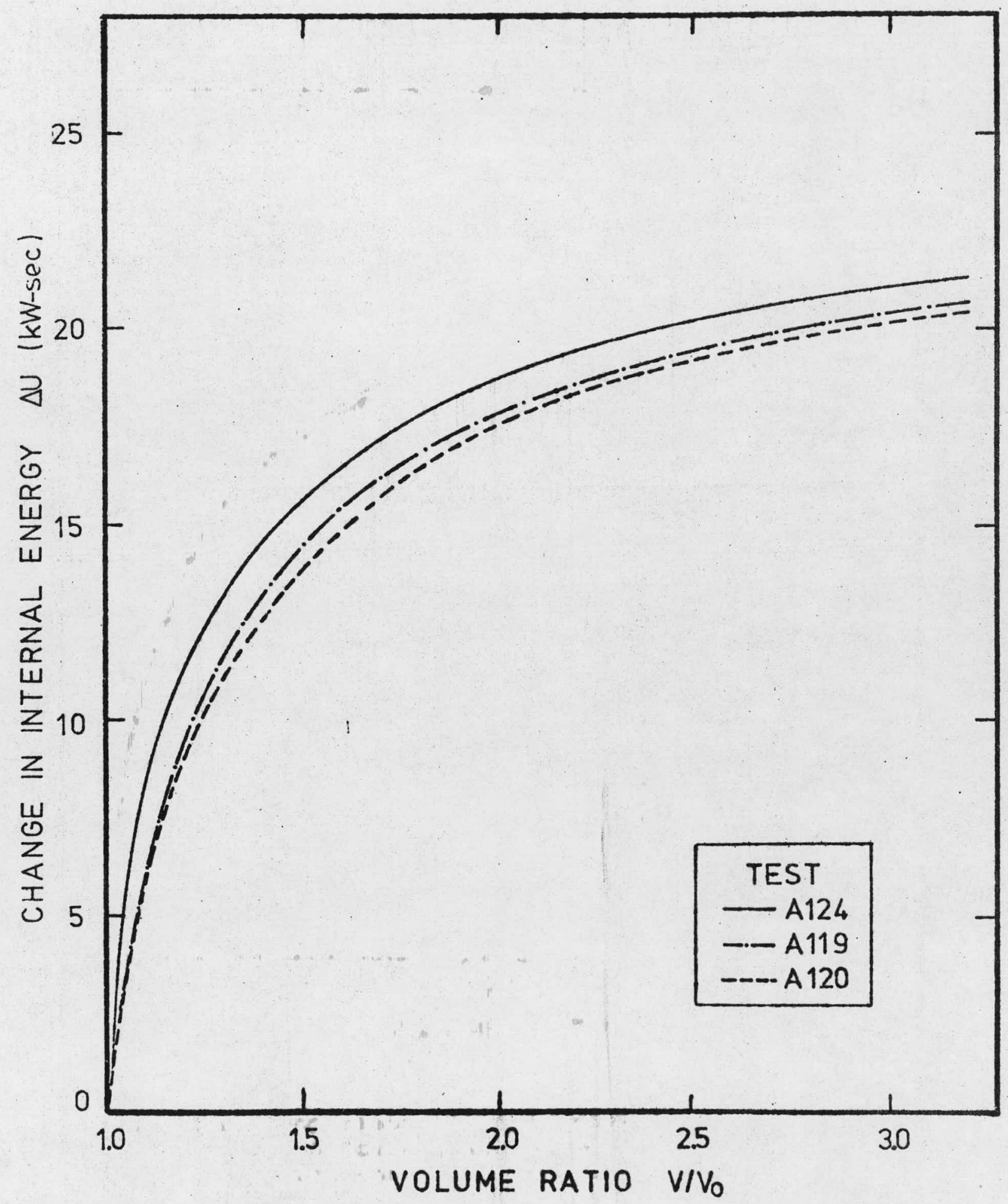

Figure C.l Comparison of Internal Energy Change for Three $1 / 30$ Scale Tests 


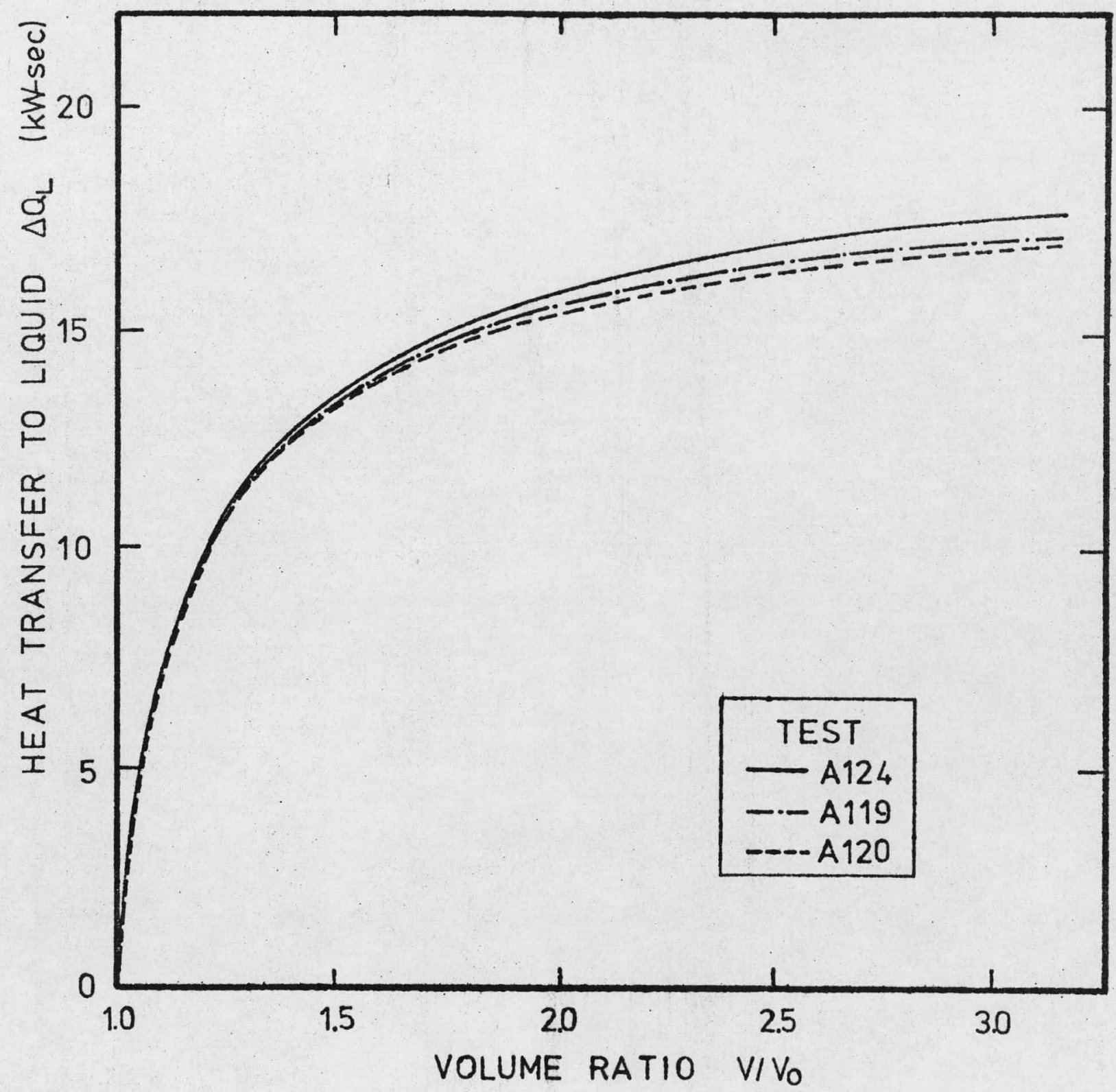

Figure C. 2 Comparison of Heat Transfer to Liquid for Three 1/30 Scale Tests to Determine Functional Dependence on Acceleration 


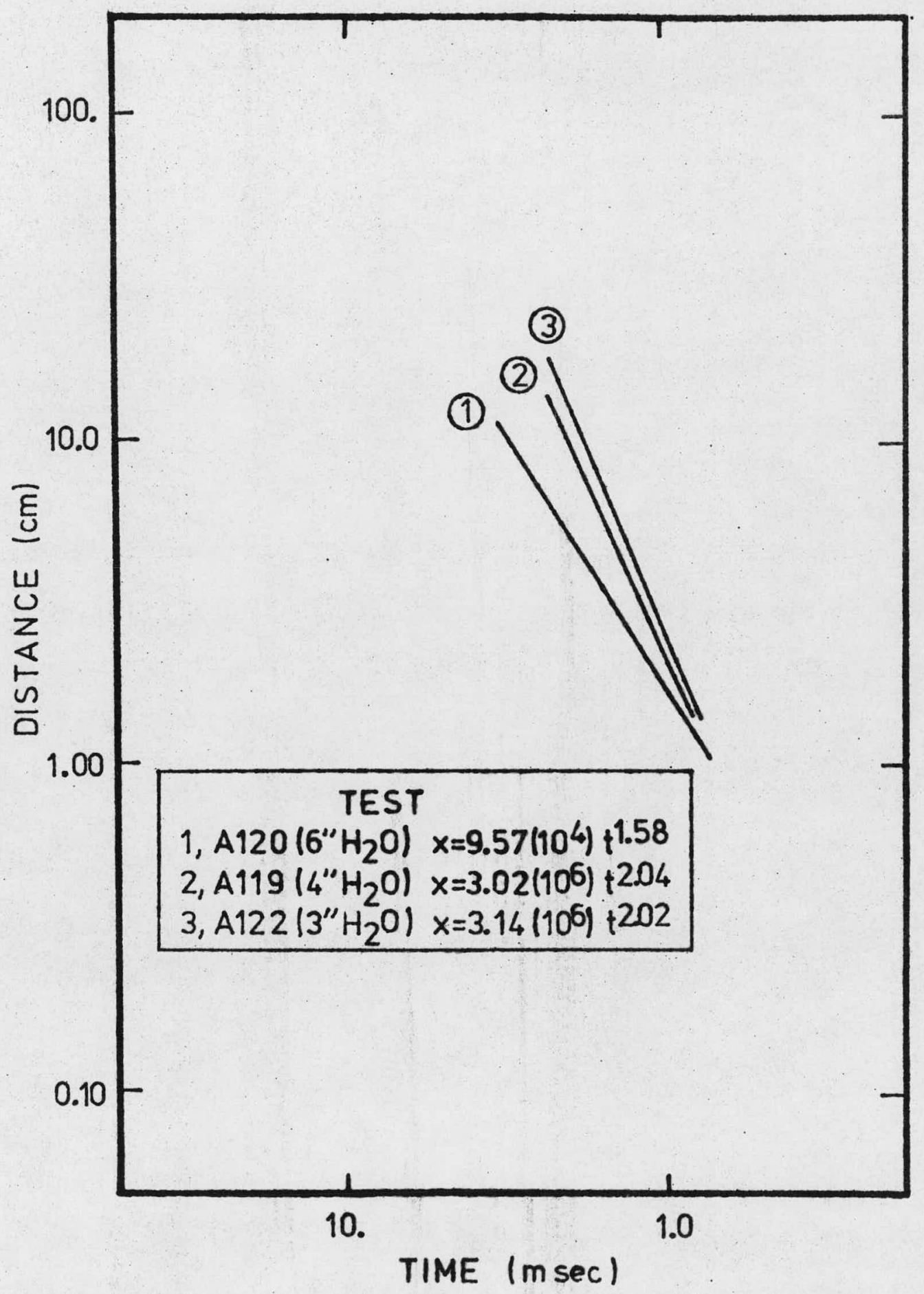

Figure C. 3 Graph of Displacement vs. Time for Determination of $Q_{L}$ Dependence on Acceleration 


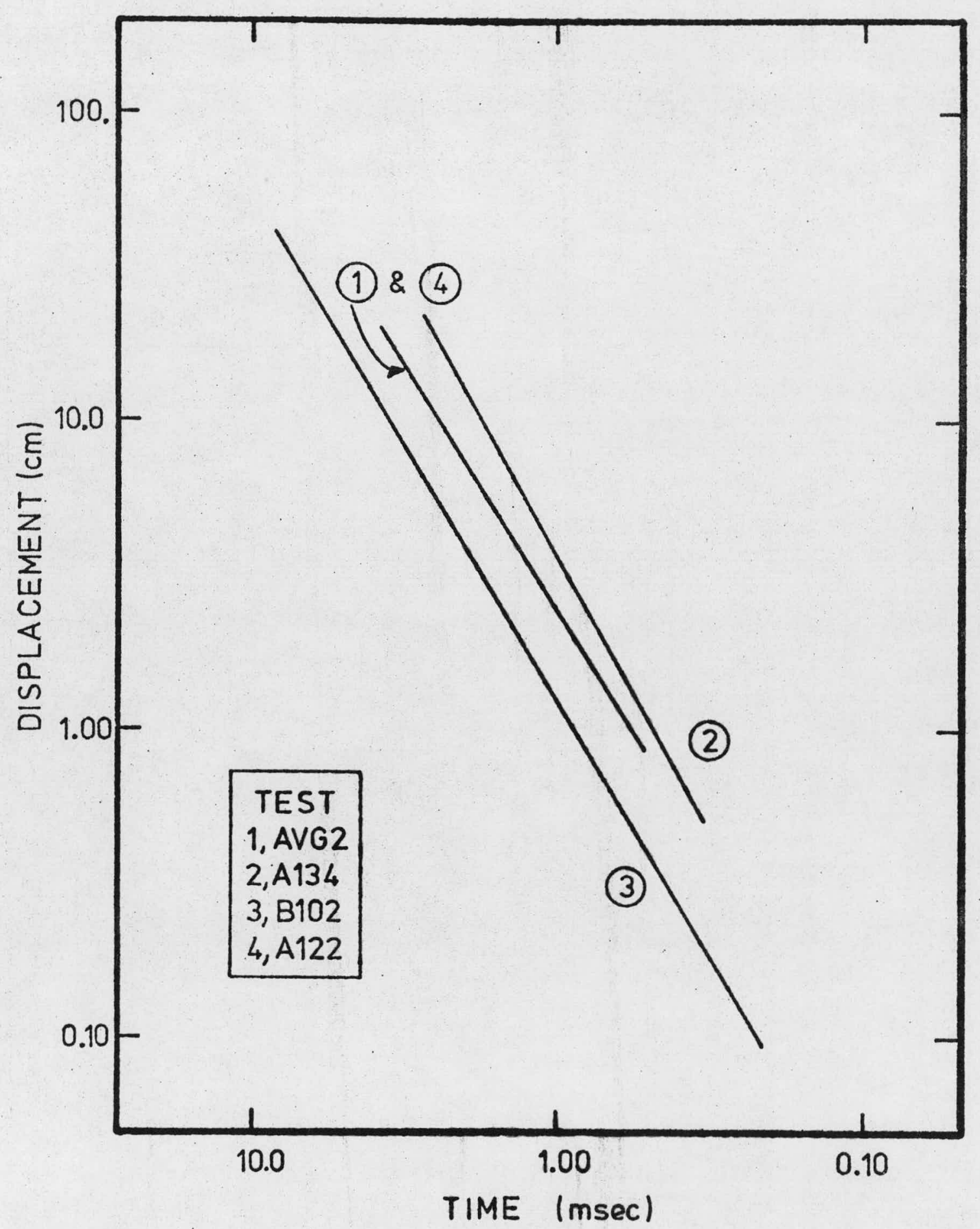

Figure C. 4 Graph of Displacement vs. Time for Integral Comparison of the Model and Experiment 


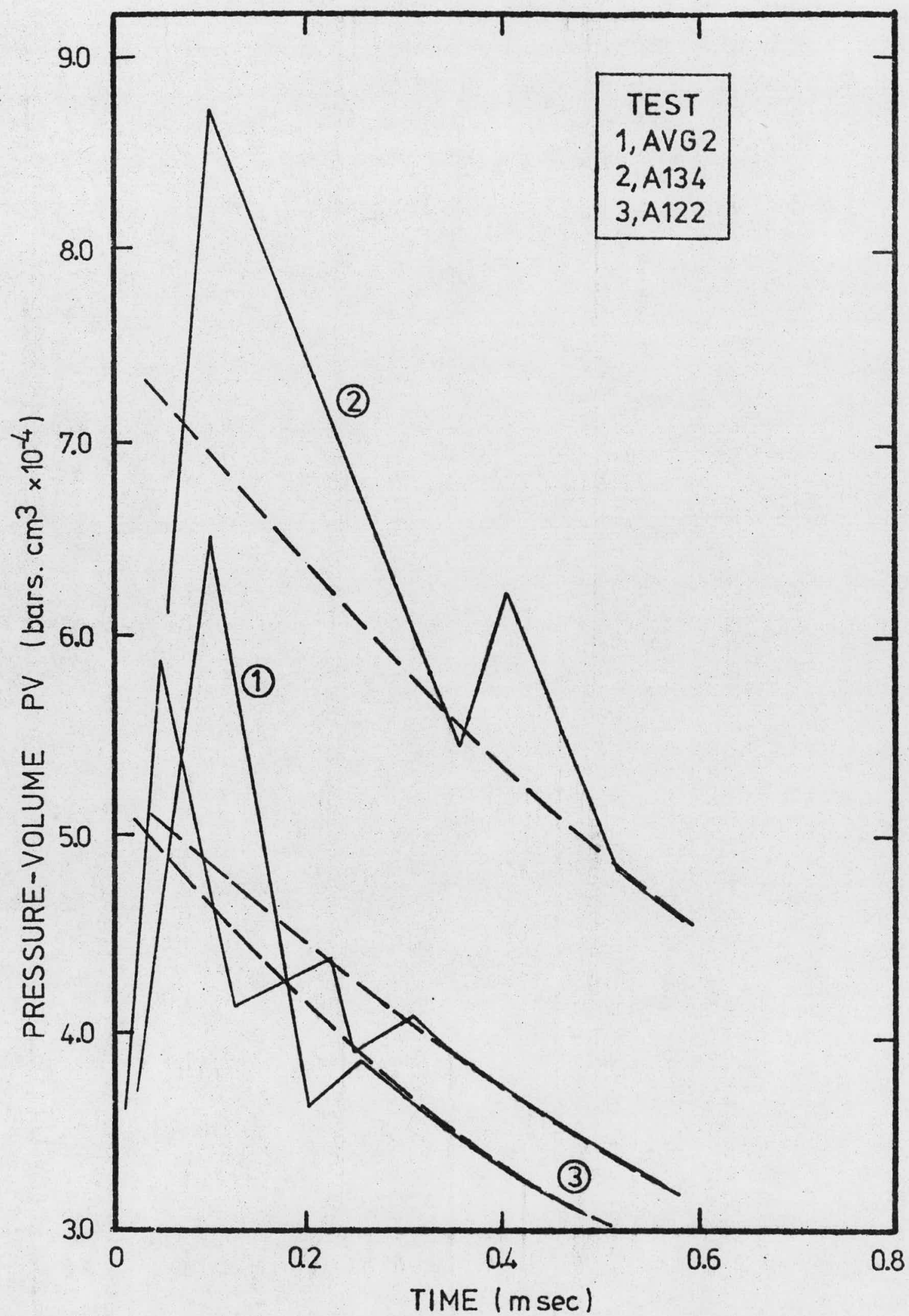

Figure C. 5 Time Smoothing of Pressure Pulses for 1/30 Scale Tests 


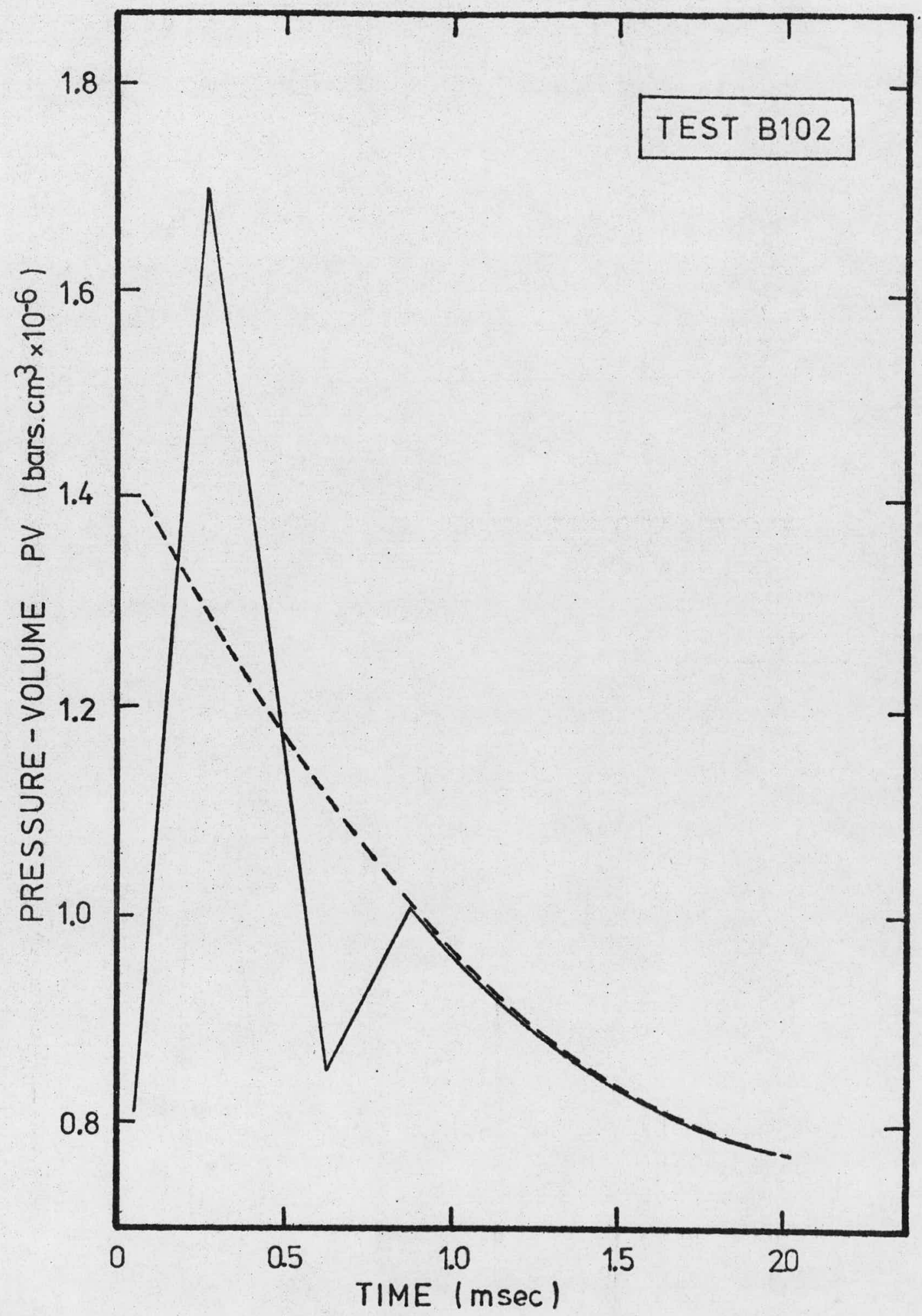

Figure C. 6 Time Smoothing of Pressure Pulse for 1/10 Scale Tests 


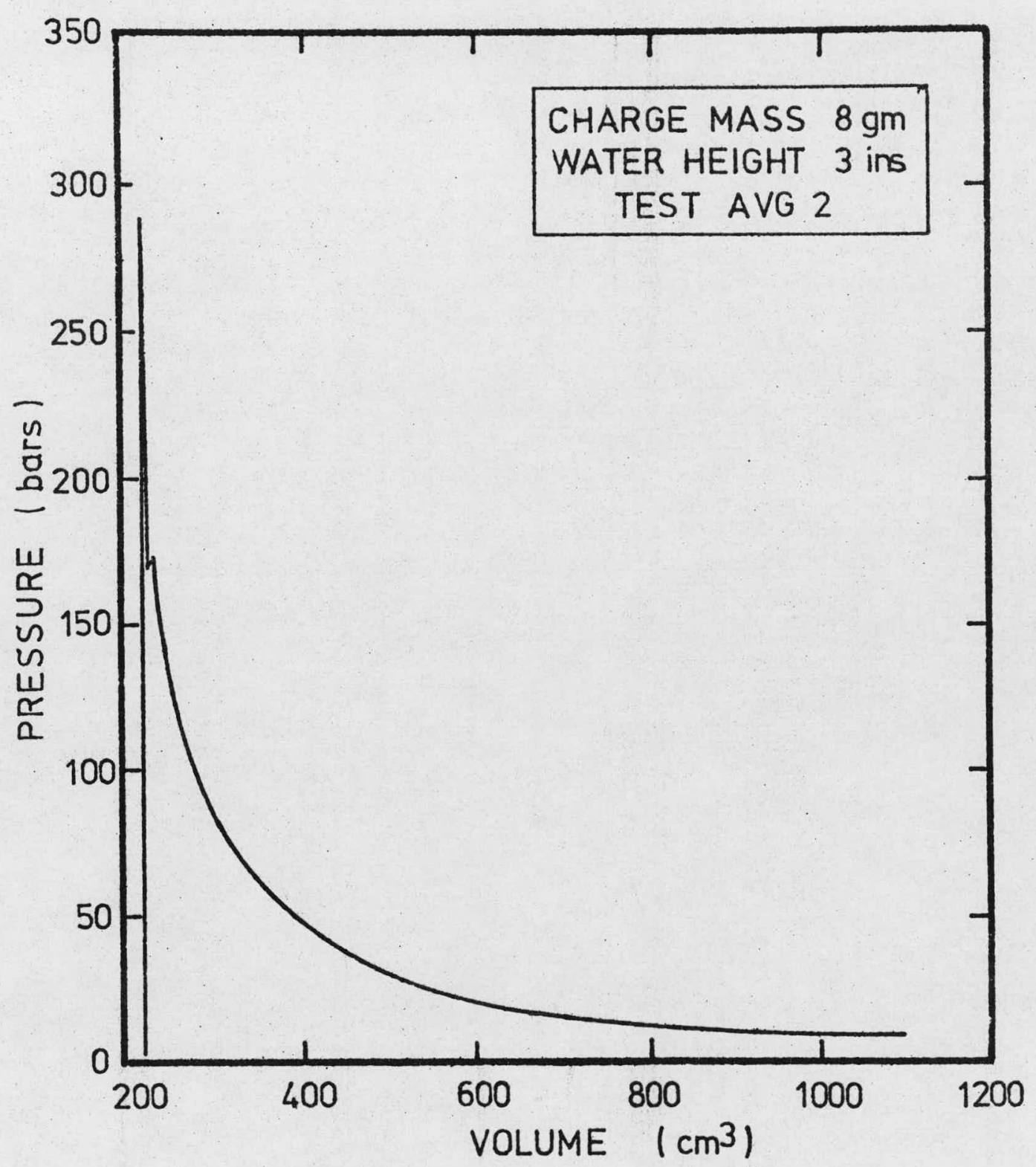

Figure C.7 Pressure-Volume Relationship for Test AVG2 


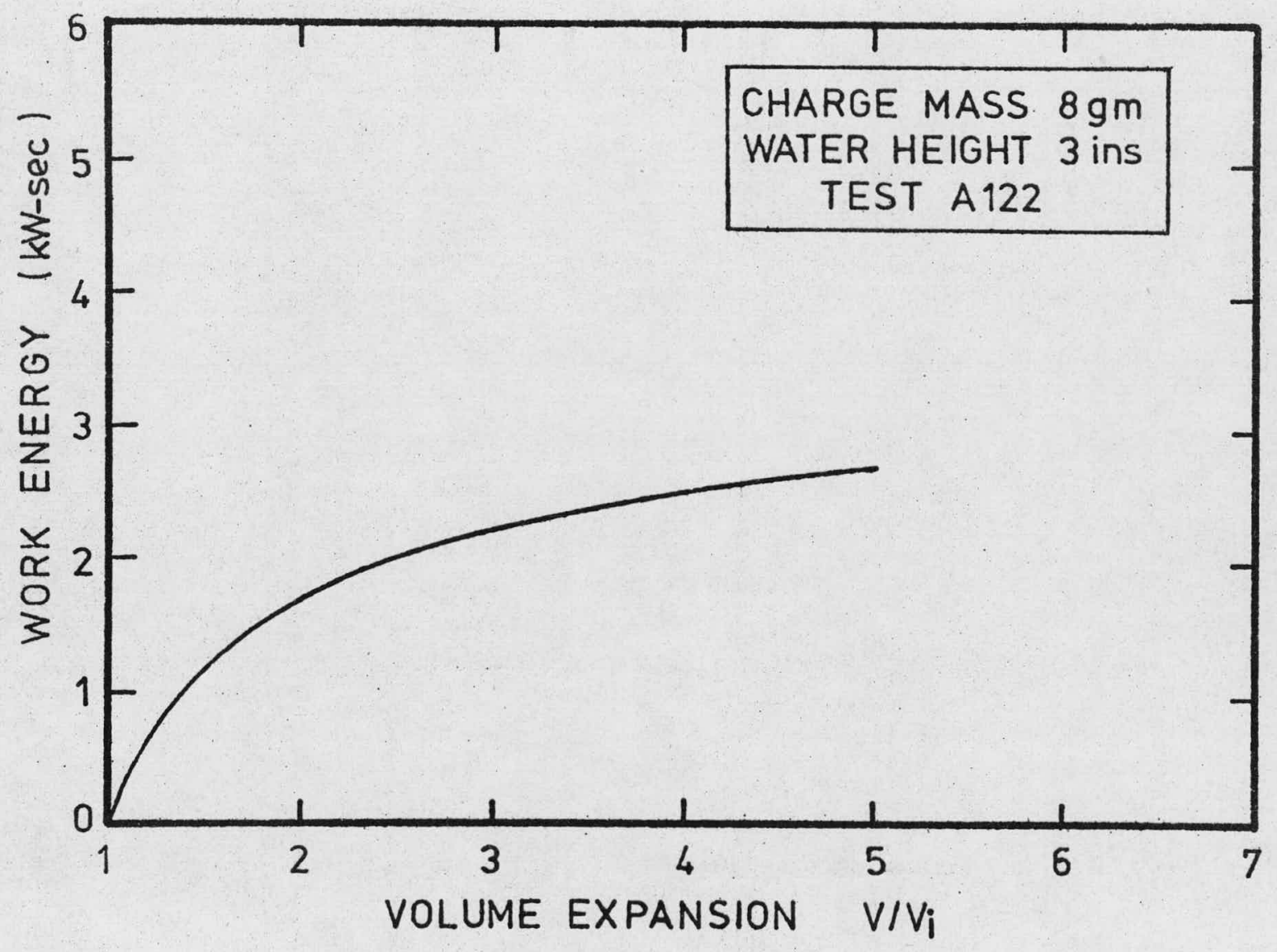

Figure C. 8 Gas Work vs. the Volume Ratio for Test Al22 


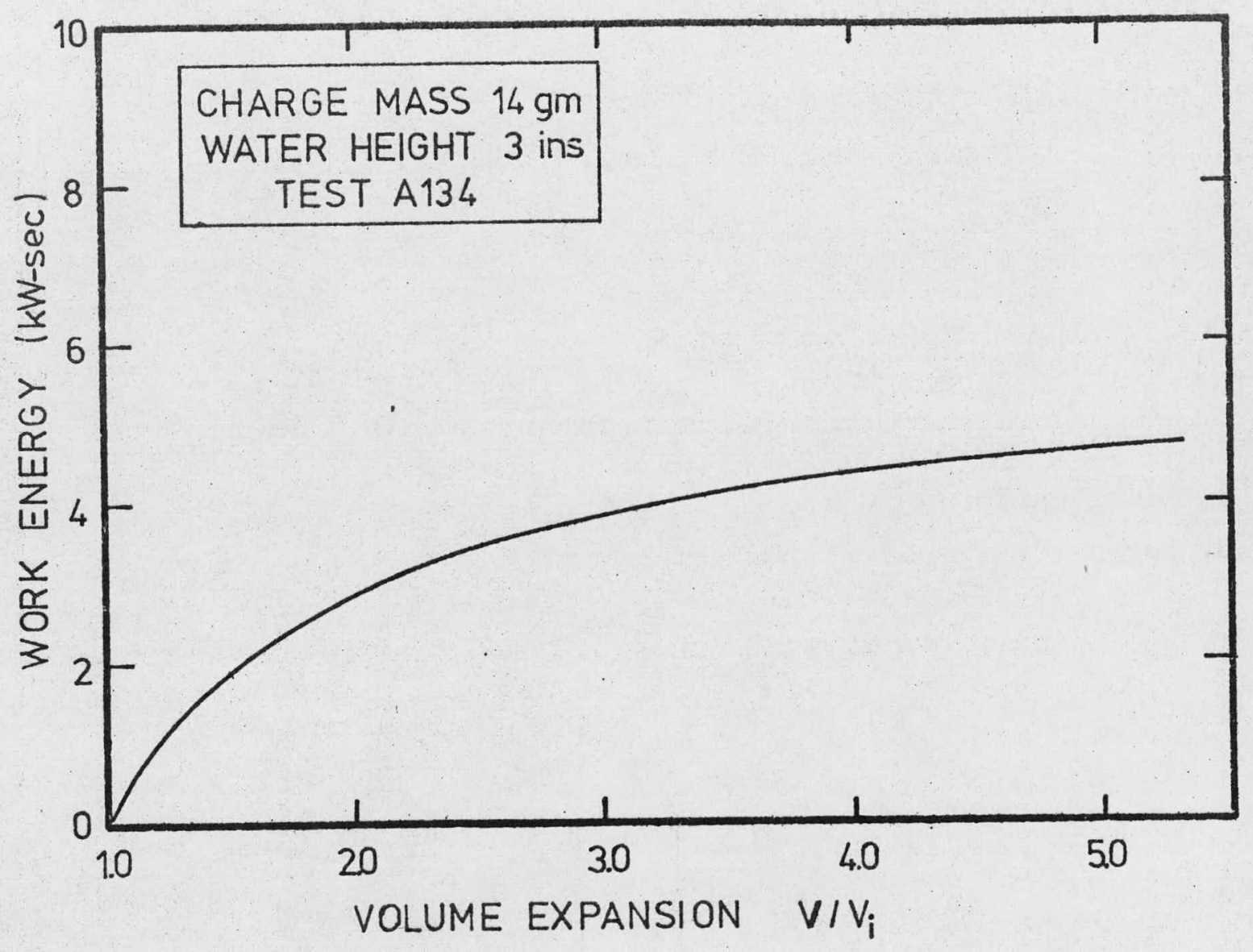

Figure C.9 Gas Work vs. the Volume Ratio for Test Al34 


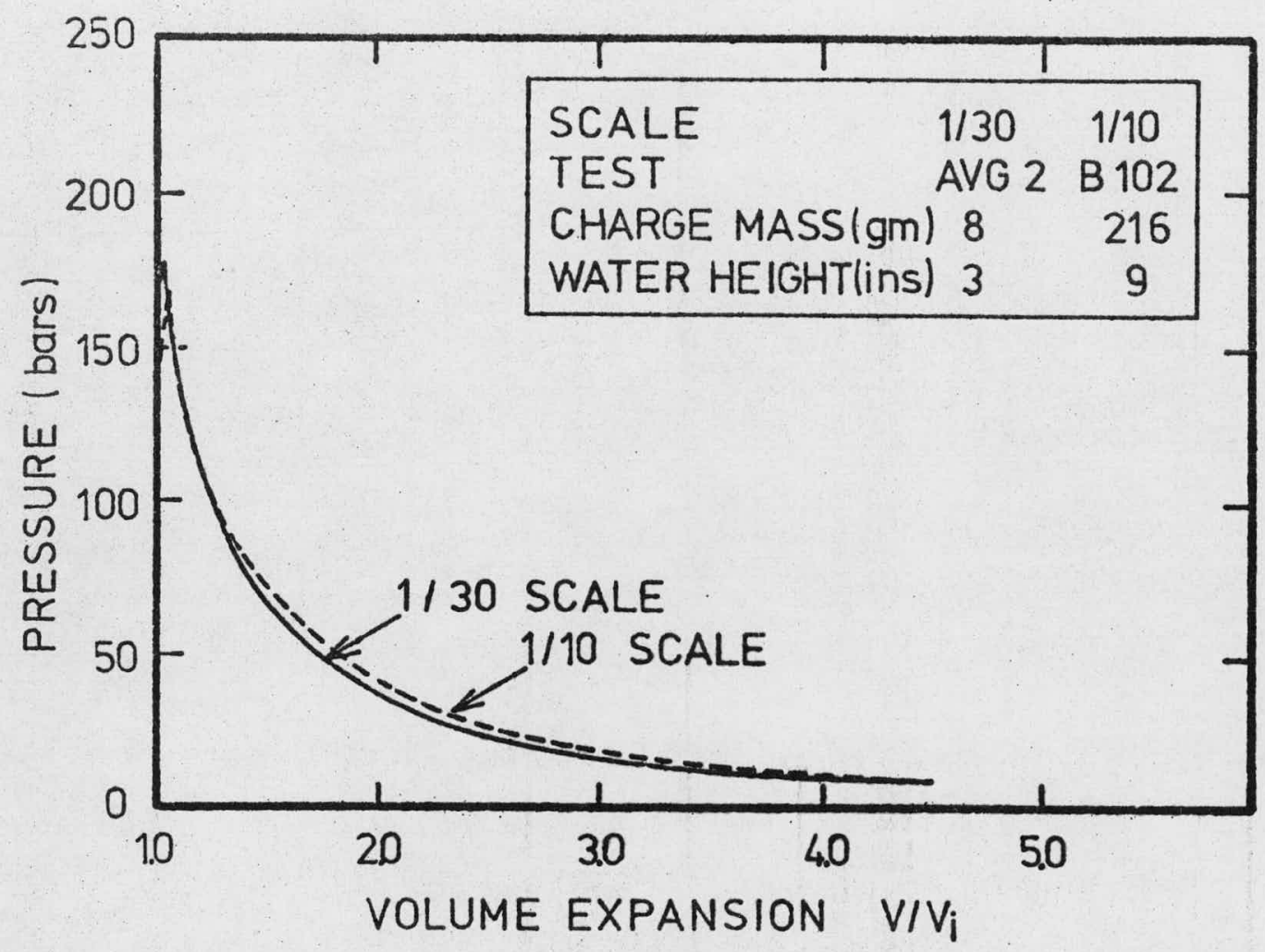

Figure C.10 Pressure-Volume Relationship for Test $\mathrm{B} 102$ 
TABLE C.I

\begin{tabular}{|c|c|c|c|c|c|c|c|}
\hline $\begin{array}{l}\text { Test } \\
\text { No. }\end{array}$ & $\begin{array}{c}\text { Travel } \\
\text { Distance } \\
\quad(\mathrm{cm})\end{array}$ & $\begin{array}{l}\text { Water } \\
\text { Depth } \\
\text { (in) }\end{array}$ & $\begin{array}{l}\text { Explosive } \\
\text { Charge } \\
\text { (gm) }\end{array}$ & $\begin{array}{l}\text { Piston } \\
\text { Mass } \\
\text { (gm) }\end{array}$ & $\begin{array}{l}\text { Gas Work } \\
\left(\mathrm{v} / \mathrm{V}_{\mathrm{o}}=3.14\right) \\
(\mathrm{kw}-\mathrm{sec})\end{array}$ & $\begin{array}{l}\text { Acceleration } \\
\left(10^{6} \mathrm{~cm} / \mathrm{s}^{2}\right)\end{array}$ & $\begin{array}{l}\text { Heat Transfer } \\
\text { Rate } \\
\text { (kw) }\end{array}$ \\
\hline Al24 & 6 & 3 & 8 & 1000 & 2.44 & 5.69 & 2633 \\
\hline A119 & 6 & 4 & 8 & 1000 & 2.51 & 4.95 & 2500 \\
\hline A 120 & 6 & 6 & 8 & 1000 & 2.50 & 1.17 & 1428 \\
\hline A124 & 10.6 & 3 & 8 & 1000 & 2.44 & 5.72 & 1294 \\
\hline A119 & 10.6 & 4 & 8 & 1000 & 2.51 & 4.0 & 1000 \\
\hline A 120 & 10.6 & 6 & 8 & 1000 & 2.50 & 1.0 & 600 \\
\hline
\end{tabular}


Table C. 2

Test AVG 2

Explosive Charge $8 \mathrm{gm}$

Water Depth 3 in.

Scale $1 / 30$

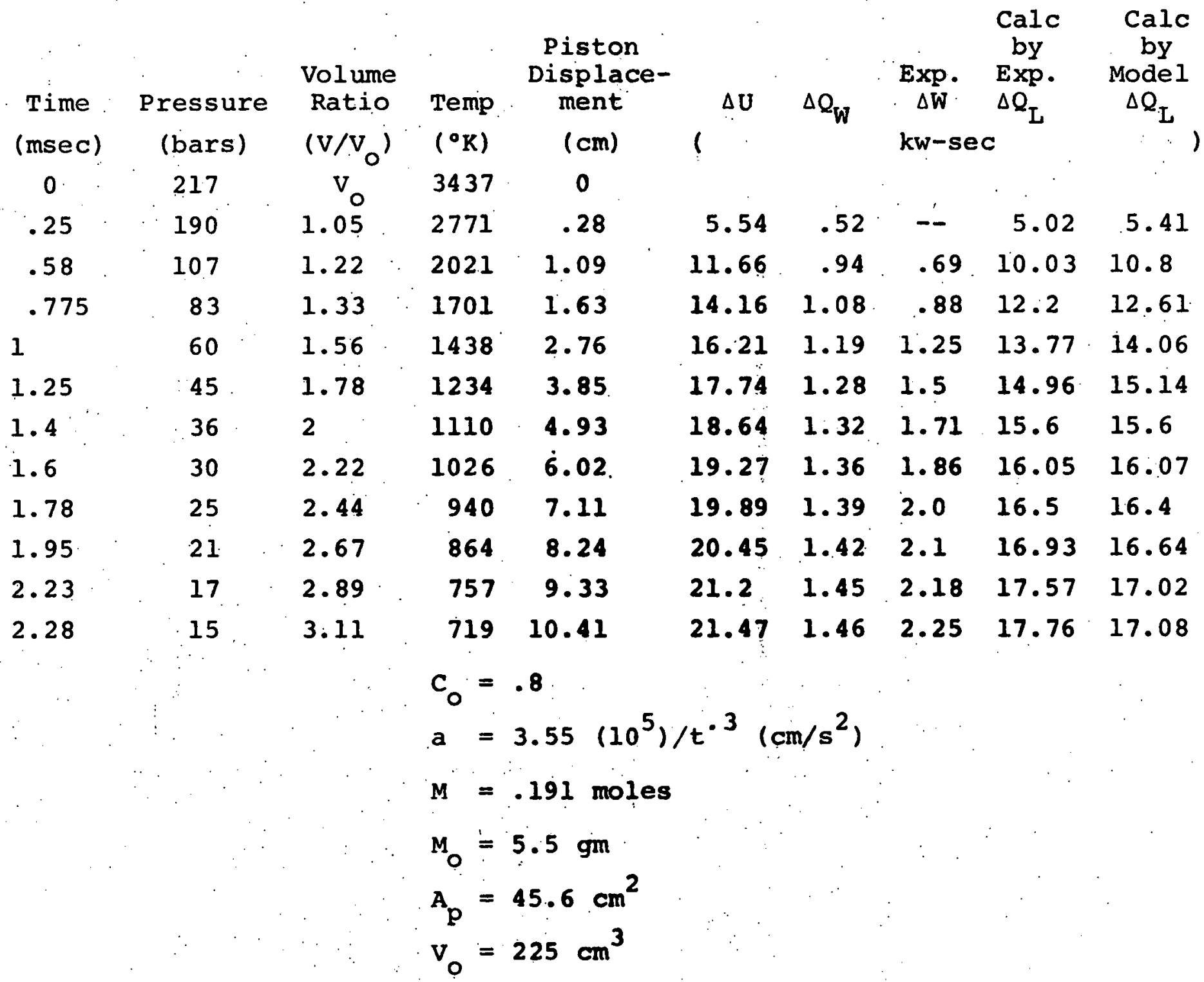


Table C. 3

Test Al34

Explosive Charge $14 \mathrm{gm}$

Water Depth 3 in

Scale $1 / 30$

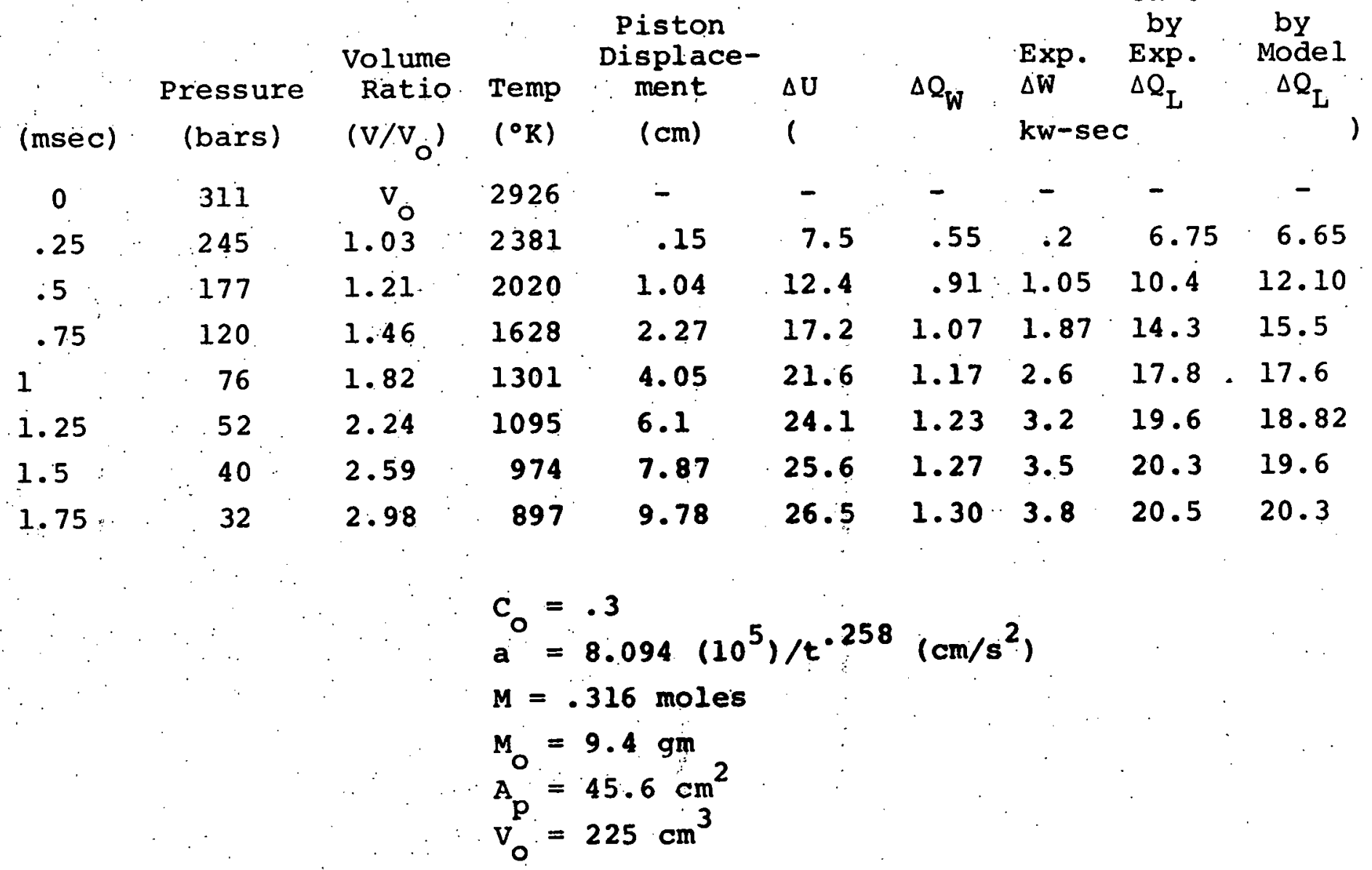


Table C. 4

Test B102

Explosive charge $216 \mathrm{gm}$

Water Depth 9 in

Scale $1 / 10$

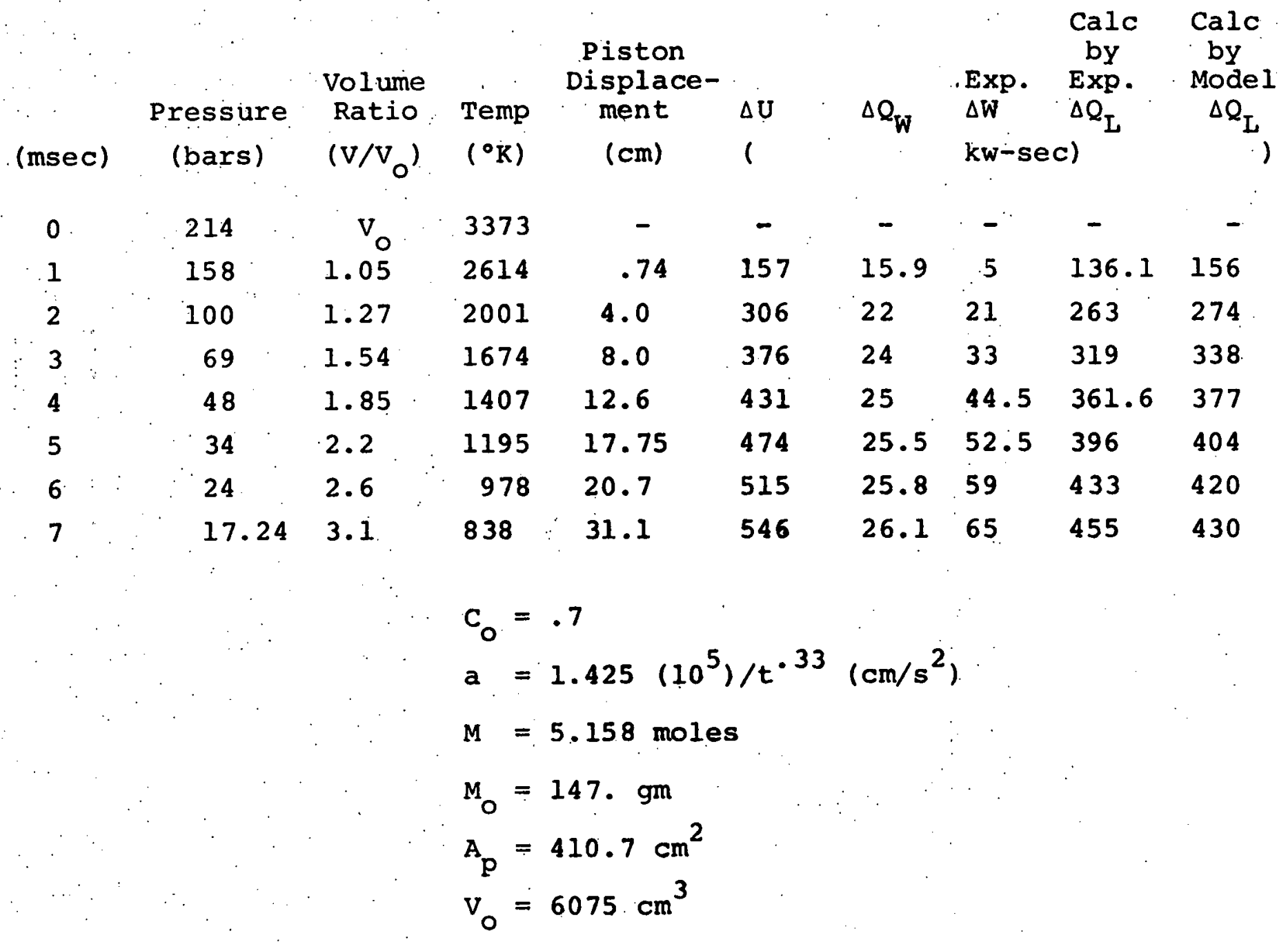


Table C. 5

Test A:122

Explosive Charge $8 \mathrm{gm}$ Water Depth 3 in

Scale $1 / 30$

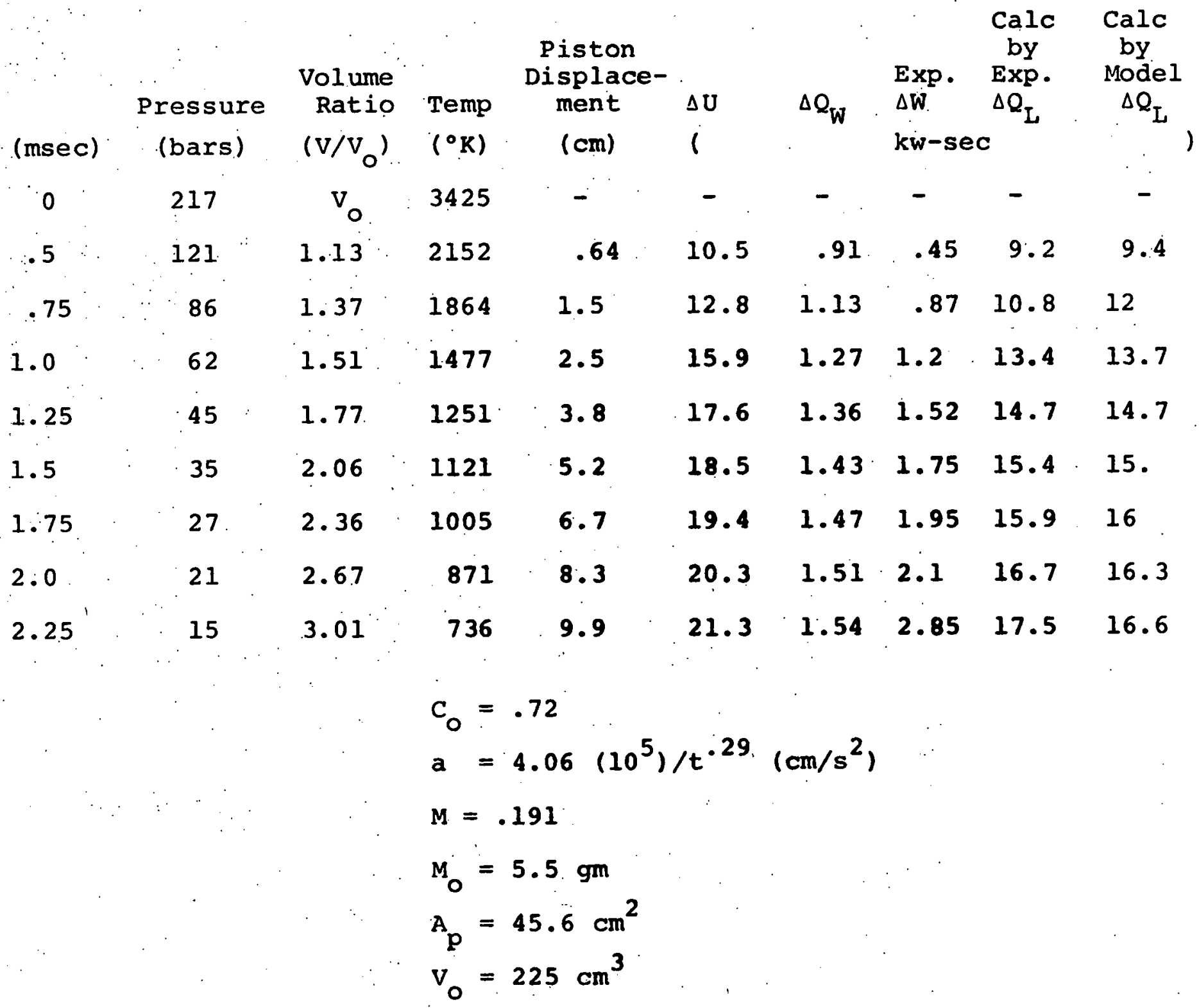




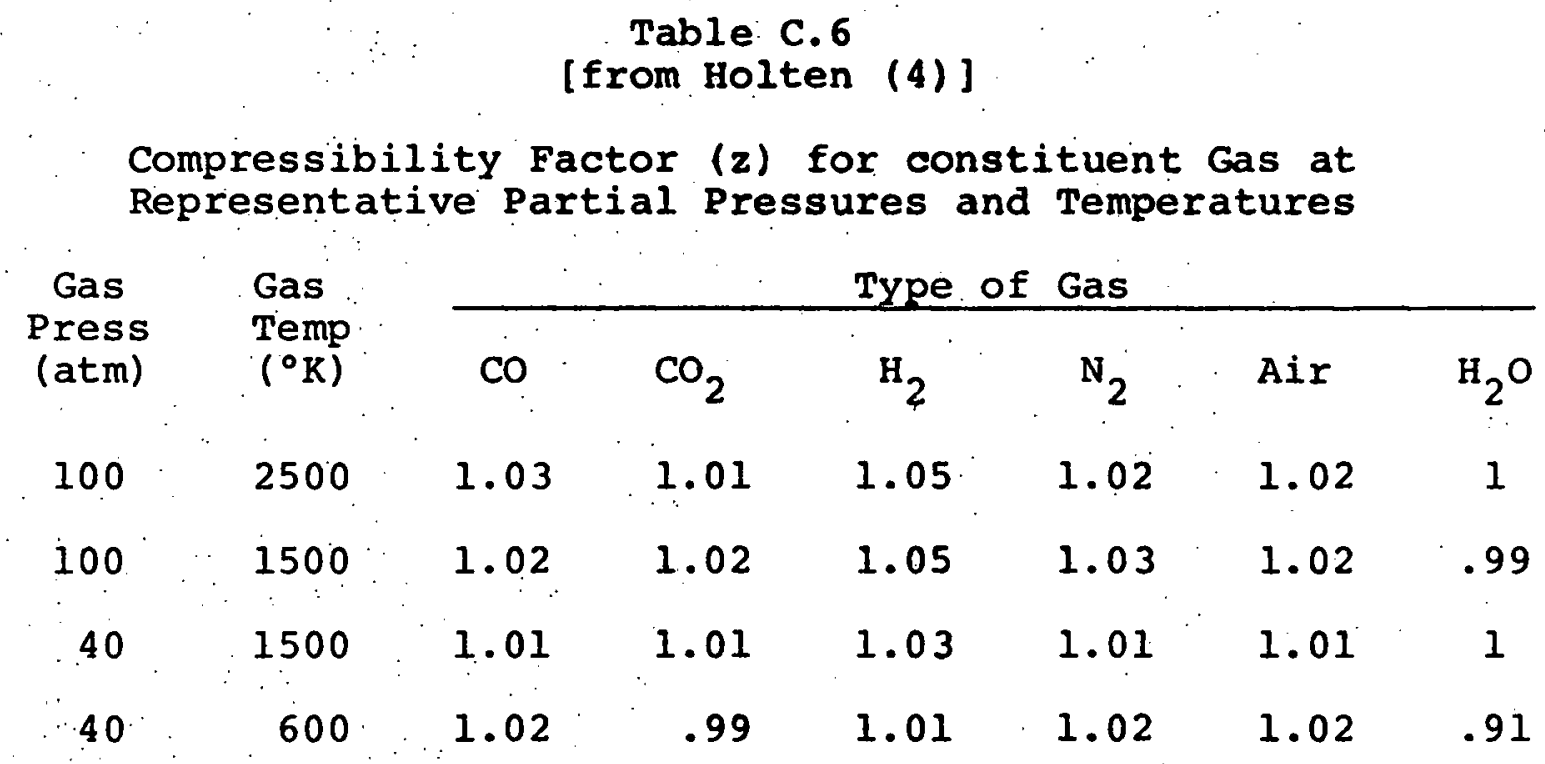

By the above comparison the compressibility factor is near one thus an ideal gas assumption is reasonable. 


$$
\begin{gathered}
\text { Table } c .7 \\
\text { [from Holten (4)] } \\
\text { Constants for } c_{p}=c_{0}+c_{1} T+c_{2} T^{2}
\end{gathered}
$$

\begin{tabular}{|c|c|c|c|}
\hline $\begin{array}{c}\text { Gas } \\
\ddots\end{array}$ & $\frac{c_{0}}{\left(\mathrm{cal} / \mathrm{gmol}^{\circ} \mathrm{K}\right)}$ & $\frac{c_{1}}{\left(\mathrm{cal} / \mathrm{gmol}^{\circ} \mathrm{K}^{2}\right)}$ & $\begin{array}{c}\mathrm{C}_{2} \\
\left(\mathrm{cal} / \mathrm{gmol}^{\circ} \mathrm{K}^{3}\right)\end{array}$ \\
\hline $\mathrm{CO}_{2}$ & 18.036 & -.045 & $-158 *$ \\
\hline co & 6.48 & 1.566 & $-.2387\left(10^{-6}\right)$ \\
\hline $\mathrm{H}_{2} \mathrm{O}$ & 6.97 & 3.464 & $-.4833\left(10^{-6}\right)$ \\
\hline $\mathrm{H}_{2}$ & 6.424 & 1.039 & -.078 \\
\hline $\mathrm{N}_{2}$ & 6.529 & 1.488 & $-.2271\left(10^{-6}\right)$ \\
\hline Air & 6.557 & 1.477 & $-.2148\left(10^{-6}\right.$ \\
\hline
\end{tabular}
Typical Values of $C_{v}$ as Function of Temperature for Compo-
site Gas

$\begin{array}{cc}\text { Temp } & \mathrm{C}_{\mathrm{V}} \\ \left(^{\circ} \mathrm{K}\right) & \left(\mathrm{cal} / \mathrm{gmol}^{\circ} \mathrm{K}\right) \\ 3400 & 10.7 \\ 3000 & 10.5 \\ 2600 & 10.3 \\ 2200 & 10.1 \\ 1800 & 9.8 \\ 1400 & 9.5 \\ 1000 & 9.2\end{array}$




\section{APPENDIX D \\ Estimation of cooling Time for Gas Bubble}

The proposed heat transfer model for the heat transfer rate between the hot gas and cold liquid is based on the notion that gas globules become trapped and come to thermal equilibrium with the water. For this to be a physically appealing concept the time for a gas bubble to give up its heat to the water should be less than the expansion time of the piston to go to $V / V_{0}=3.14$. The test expansion times vary as Table A.3 indicates from 2 to 3 msec.

To compare this to the equilibration time of gas bubble, a simply analysis was done. If the spherical gas bubble at temperature $\mathbf{T}_{\boldsymbol{g}}$ is considered to be within a liquid at $T_{\ell}$, the time for it to come to equilibrium with the water can be determined by use of standard transient conduction solutions (see Table D.1). The resistance to heat transfer is primarily due to the conductivity of the gas rather than the liquid thus the ratio of $\frac{\mathrm{hr} g}{\mathrm{~K}}$ is expected to be much less than one. The size of the ${ }^{\mathrm{K}}$ gas bubble is actually not known. Its volume is proportional to $L^{3}$ the initial characteristic wavelength. So to get a feeling for the time of equilibration the radius is parametrically varied.

The range of values is taken from the size of critical wavelength of a Taylor instability $(.02 \mathrm{~cm})$ to a size 
where the equilibration time is much greater than the expansion time of the experiment. As the table shows for gas bubble sizes which are of a realistic size range 1.2 $.05 \mathrm{~cm})$ the equilibration times are of the same order of magnitude as the expansion times. The physical picture presented is an equal volume of gas becoming entrapped within the liquid. As Appendix C.1 demonstrated the change in liquid temperature (even with a small volume) is small compared to the change in gas temperature. So the gas cooling down within to near the liquid temperature is not unrealistic. Thus the equilibrium approach seems viable. 
Table D.I

Estimation of Cooling Time for a Gas Bubble in Sea of Liquid

$$
\frac{T(0, t)-T_{\ell}}{T_{g}-T_{\rho}}=\frac{h r g}{K_{g}}, \frac{\alpha t}{r_{g}{ }^{2}}
$$

For $\frac{T(0, t) p T_{\ell}}{T_{g}-T_{\rho}}=.01$

$$
\begin{aligned}
& \frac{h r g}{k_{g}} \simeq 0 \\
& \frac{\alpha t}{r_{g}^{2}}=.52
\end{aligned}
$$

\begin{tabular}{lcccc}
\hline$r_{f}(\mathrm{~cm})$ & .02 & .05 & .1 & 1 \\
$t$ (msec) & .05 & .3 & 1.2 & 121 \\
\hline
\end{tabular}

$$
\begin{aligned}
& \text { where } \\
& \mathrm{T}_{\mathrm{g}} \quad=\text { initial temperature gas }-3000^{\circ} \mathrm{K} \\
& \mathrm{T}_{\rho} \quad=\text { initial temperature liquid }-300^{\circ} \mathrm{K} \\
& T(0, t)=\text { instantaneous tempurature of gas } \\
& \alpha=\text { thermal diffusivity }=3.6 \mathrm{~cm}^{2} / \mathrm{sec}
\end{aligned}
$$


REFERENCES

1. Final Safety and Analysis Report for Fast Flux Test Facility. U.S. ERDA, 1975.

2. Preliminary Safety and Analysis Report for Clinch River Breeder Reactor Plant. U.S. ERDA, 1975.

3. Padilla, Jr., A. "Analysis of Mechanical Work Energy for LMFBR Maximum Accidents," Nuclear Technology, 12:348-355, 1971 .

4. Holten, R. A., Heat Transfer Effects in the Fast Flux Test Facility, Scale Model Experiments, MIT Master's Thesis, August 1975 .

5. Epstein, M. Private communication, June 1976.

6. Padilla, Jr., A. "Mechanical Work Energy for SodiumFuel Thermal Interactions;" HEDL-TME-71-94, June 1971.

7. Cagliostro, D. J., and Florence, A. L., Characterization of an Energy Source for Modeling Hypothetical Core Disruptive Accidents in Nuclear Reactors. First Interim Report, Stanford Research Institute, october 1972 .

8. Florence, A. L. and Abrahamson, Simulation of a Hypothetical Core Disruptive Accident in a Fast Flux Test Facility. Second Interim Report, Stanford Research. Institute, $197 i$.

9. Taylor, G. I. "The Instability of Liquid Surfaces when Accelerated in the Direction Perpendicular to Their Planes, I," Proceedings of the Royal Society of London, A, 201 (92), 1950 .

10. Bellman, R., Pennington, R. H. "Effects of Surface Tension on Taylor Instability," Quarterly Journal of Applied Mathematics, 12:151, 1954 .

11. Lewis, D. J. "The Instability of Liquid Surfaces when Accelerated in the Direction Perpendicular to their Planes, II," Proceedings of the Royal Society of London, A, 202:81, 1950 .

12. Cagliostro, D. J., Florence, A. L., Abrahamson, G. R., Najumo, G. "Characterization of an Energy Source for Modeling Hypothetical Core Disruptive Accidents in Nuclear Reactors," Nuclear Eng. and Design, 27:94, 1974.

13. Henry, R.E., Private Communication, October 1976. 